\title{
FALLACIOUS BELIEFS: GAMBLING SPECIFIC AND BELIEF IN THE PARANORMAL
}

\section{CARRIE A. LEONARD}

Master of Science, University of Lethbridge, 2014

\author{
A Thesis/Project \\ Submitted to the School of Graduate Studies \\ of the University of Lethbridge \\ in Partial Fulfillment of the \\ Requirements for the Degree \\ DOCTOR OF PHILOSOPHY \\ Department of Psychology \\ University of Lethbridge \\ LETHBRIDGE, ALBERTA, CANADA
}

(C) Carrie A. Leonard, 2018 
FALLACIOUS BELIEFS: GAMBLING SPECIFIC AND BELIEF IN THE

PARANORMAL

CARRIE A. LEONARD

Date of Defence: April $16^{\text {th }}, 2018$

Dr. R. J. Williams

Professor

$\mathrm{PhD}$

Supervisor

Dr. J. Vokey

Professor

$\mathrm{PhD}$

Thesis Examination Committee Member

Associate Professor

$\mathrm{PhD}$

Thesis Examination Committee Member

Professor

$\mathrm{PhD}$

Internal External Examiner

Dr. P. Delfabbro

Professor

$\mathrm{PhD}$

External Examiner

University of Adelaide

Adelaide, South Australia

Dr. S. Allen

Associate Professor

$\mathrm{PhD}$

Chair, Thesis Examination Committee 


\section{Dedication}

Marcel, Rokelle, and Jaden - I dedicate this work to you. Marcel, this path started with your encouragement ("If that's what you want to do, what are you waiting for?"), and your continued support has helped make the realization of my goals possible. Marcel, you continue to be my pillar and my partner, and I am so grateful to you. Rokelle, my ultimate cheerleader, you exemplify the quote: "It is not how many times you get knocked down that counts, it is how many times you get back up". Your unwavering optimism as you continue to 'get back up' is an inspiration to me. Jaden, too many times to count you've said: "I got this mom", you do "have it" and I couldn't be more proud of you. You are calm in all types of storms and take on adventures that I would never have dreamed of. Both of these attributes I admire, and aspire to. All of these things and more, I thank each of you for. 


\begin{abstract}
This thesis presents a series of studies investigating two types of fallacious belief: gambling fallacies (GF) and paranormal beliefs (PB). The first study identifies the errors that constitute GF and critically evaluates instruments designed to measure them. The second study re-evaluates the etiological role of GF in problem gambling using an improved instrument in a longitudinal dataset with results indicating that GF do contribute to problematic gambling, but to a lesser extent than previously supposed and in a bidirectional manner. The third study examines factors associated with susceptibility to GF and compares them to those associated with PB. A very similar set were predictive of both, with most being inherently malleable. The final study, a systematic review, evaluates the efficacy of interventions designed to reduce PB with results indicating that direct examination of the evidentiary basis of PB appears to be effective, although the generalizability of this effect remains uncertain.
\end{abstract}

Keywords: gambling fallacies, paranormal belief, erroneous beliefs, individual differences, critical thinking, problem gambling, belief change 


\section{Acknowledgments}

I would like to thank my supervisor, Dr. Robert Williams. The experience and opportunities I have been afforded under your supervision have been invaluable. I would like to thank Dr. John Vokey for the continued support and advocacy during these thesis projects as well as during the development and delivery of Science and Pseudoscience. I would also like to thank Dr. Darren Christensen for the inestimable support and advice during my $\mathrm{PhD}$ program. It has been an honour and a privilege to have worked with, and learned from, each of you over the past years.

I would like to acknowledge the research assistance of Cassandra Jackson. Working with you was a pleasure, and the efforts put forth by you were greatly appreciated.

I would also like to acknowledge the support and encouragement received from family, friends, and colleagues. With special thanks to Dr. Stephanie Hancock: the page numbering whisperer.

This research was financially supported by both, the Alberta Gambling Research Institute (AGRI), and the Social Sciences and Humanities Research Council (SSHRC). The financial assistance contributed by both of these institutions was appreciated immensely. 


\section{Table of Contents}

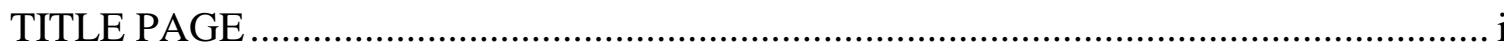

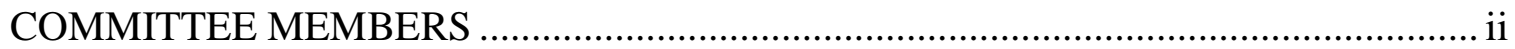

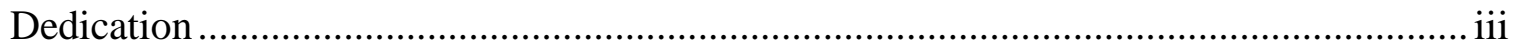

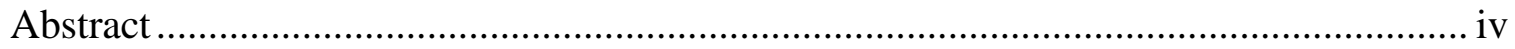

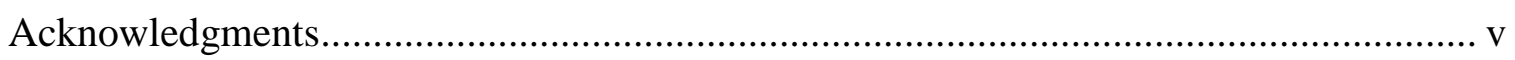

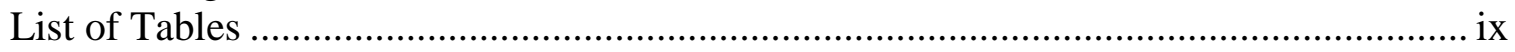

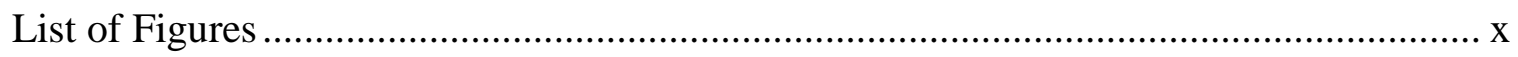

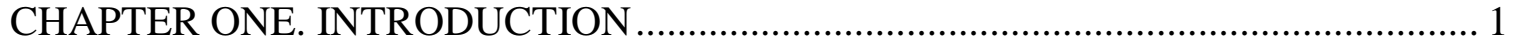

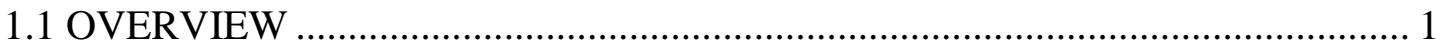

CHAPTER TWO. GAMBLING FALLACIES: WHAT ARE THEY AND HOW

ARE THEY BEST MEASURED ….............................................................. 4

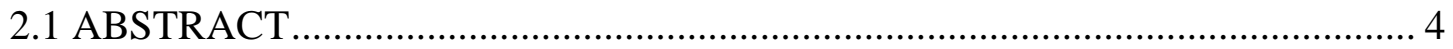

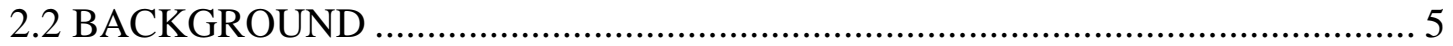

2.3 WHAT ARE THE SPECIFIC GAMBLING FALLACIES? ............................... 7

2.4 HOW ARE GAMBLING FALLACIES BEST MEASURED? .......................... 11

2.5 WHAT IS THE RELIABILITY AND VALIDITY OF EXISTING

GAMBLING FALLACY INSTRUMENTS? ........................................ 15

2.6 SUMMARY, CONCLUSION, AND FUTURE DIRECTIONS ......................... 27

CHAPTER THREE. THE RELATIONSHIP BETWEEN GAMBLING

FALLACIES AND PROBLEM GAMBLING ............................................. 31

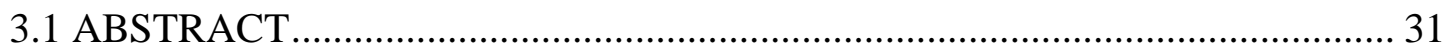

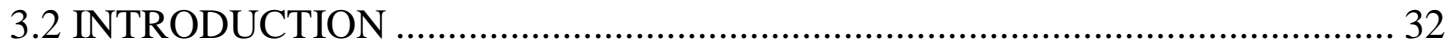

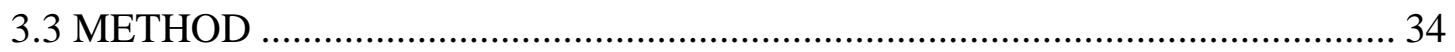

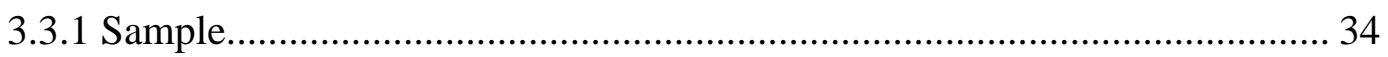

3.3.2 Measures ......................................................................................... 35

3.3.2.1 Gambling Fallacies Measure (Leonard, Williams, et al., 2015; Williams, 2003)......................................................................... 35

3.3.2.2 Problem and Pathological Gambling Measure (PPGM;

Williams \& Volberg, 2010, 2014) ................................................ 36

3.3.2.3 Number of Gambling Formats Engaged in Within Past Year ........... 37

3.3.2.4 Frequency of Gambling in Past Year.............................................. 37

3.3.2.5 Net Aggregate Gambling Expenditure in Past Year ........................ 37

3.3.2.6 Biggest Gambling Win in Past Year............................................... 38

3.3.2.7 One or More Family Members being Problem Gamblers while Growing up ......................................................................... 38

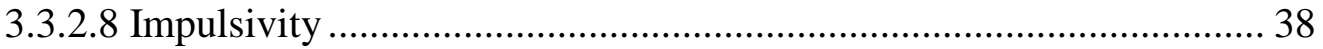

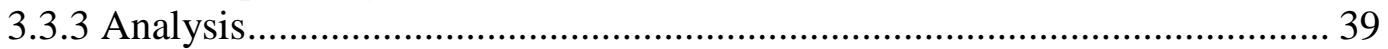

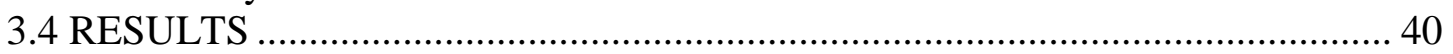

3.4.1 Cross-Sectional Results ................................................................... 40

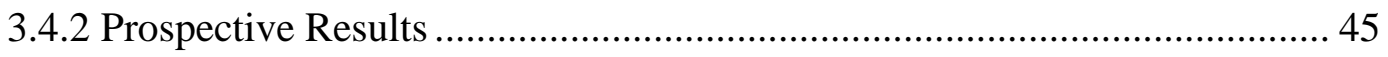

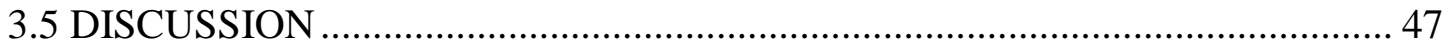




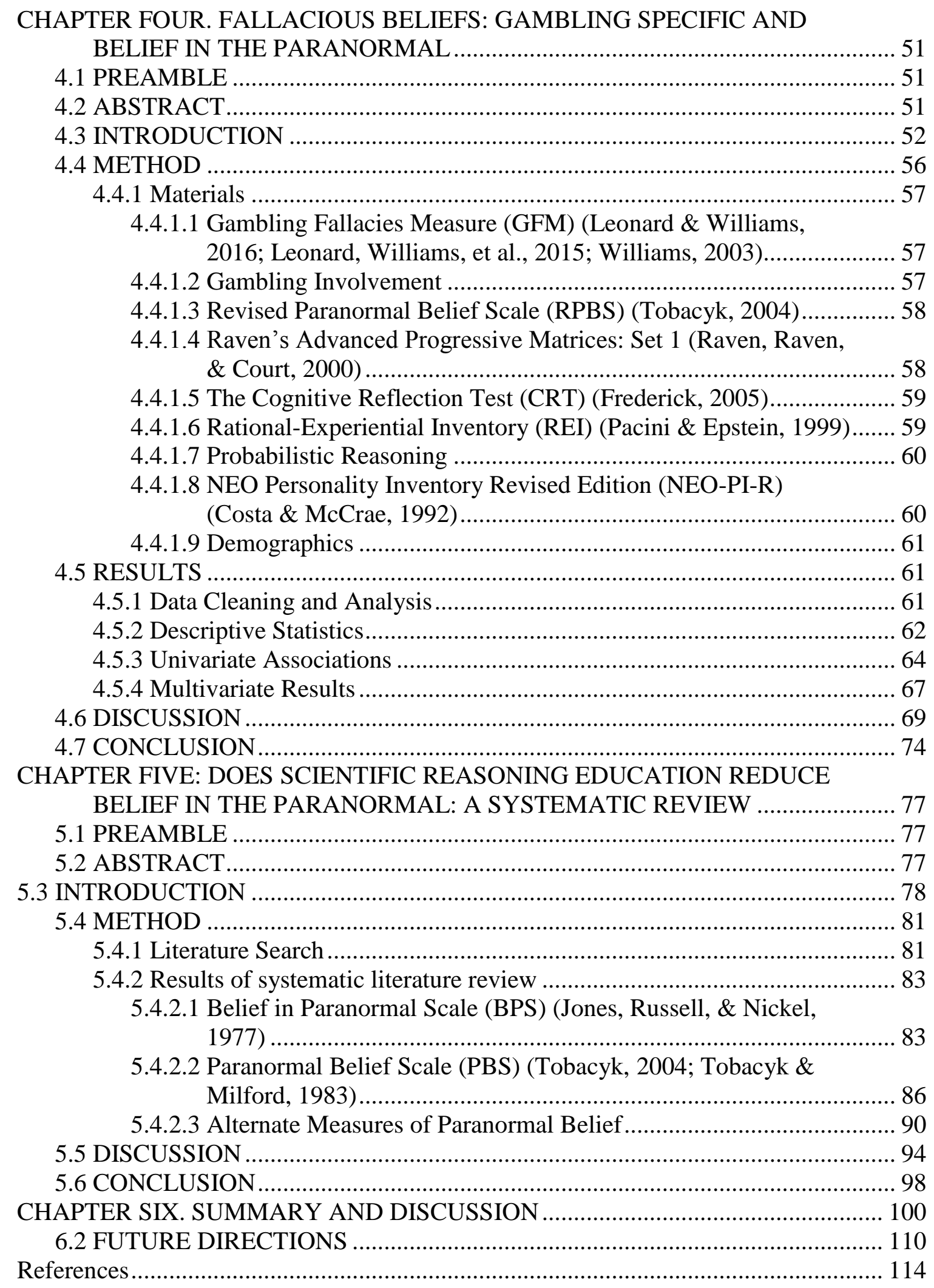


APPENDIX A: GAMBLING FALLACIES MEASURE (WILLIAMS, 2003).....

APPENDIX B: PROBLEM AND PATHOLOGICAL GAMBLING MEASURE

(PPGM) 


\section{List of Tables}

Table 2.1 Evaluation of Measures of Gambling Fallacies .......................................... 28

Table 3.1 Descriptive Statistics for Each Variable by Assessment Year ....................... 41

Table 3.2 Association between all Variables in Assessment 1 ..................................... 42

Table 3.3 Gambling Fallacy Measure Scores by Assessment Year and Gambling

Category. 43

Table 3.4 GFM Scores of Individuals who became Problem or Pathological

Gamblers in the Next Assessment Compared to GFM Scores of Individuals who

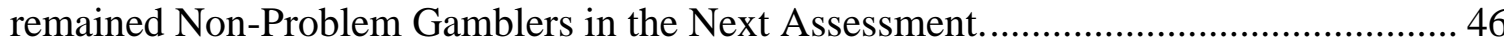

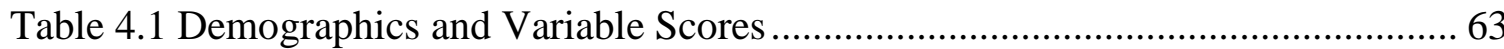

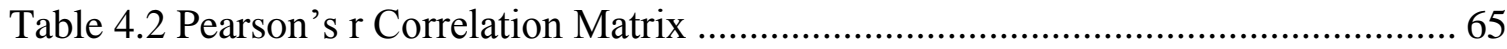

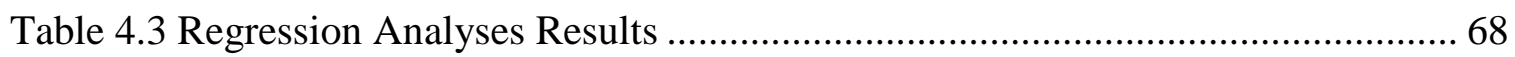

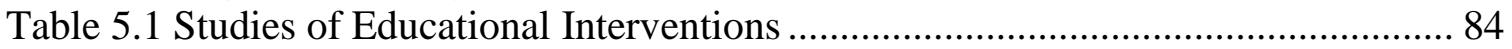




\section{List of Figures}

Figure 4.1. Scatter plot of gambling fallacy and paranormal belief scores.................... 70

Figure 5.1. Flow chart of systematic review process for identifying and including

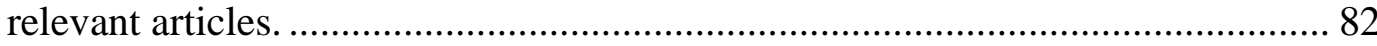




\section{CHAPTER ONE. INTRODUCTION}

\subsection{OVERVIEW}

Our brains have evolved to allow for complex cognitive functions, yet the very mechanisms that allow for complex thought are also error prone (e.g., Cosmides \& Tooby, 1997; Hate Pseudoscience, 2016; Pinker, 1999).To reduce the cognitive load of everyday information processing and decision-making, cognitive heuristics and biases are frequently used (e.g., Holyoak, 1995; Kahneman \& Tversky, 1982; Toplak, West, \& Stanovich, 2011; Tversky \& Kahneman, 1974). Whereas heuristics are mental shortcuts that allow individuals to quickly eliminate some unnecessary information, biases are best viewed as inclinations or tendencies in thinking. Although conclusions drawn from the use of these cognitive tools can be error prone, neither heuristics nor biases are necessarily fallacious in and of themselves. In fact, the conclusions drawn using these tools are often useful and sound. On the other hand, when the underlying logic is flawed, the conclusion drawn can be erroneous, and fallacious beliefs can ensue.

Numerous general logical errors have been identified (see for example: Dowden, 2017), and the fallacious beliefs generated from these errors can have serious consequences. Illusory correlations/patterns for example, are seen when the adaptive ability to seek and find patterns goes wrong, and patterns are identified where none actually exist. When one makes decisions based on these illusory patterns the consequences can be harmful. For example, it can be detrimental to one's financial situation if one bets hundreds of dollars on a sports team erroneously perceived to be on a winning streak. Also, opting to return to a faith healer who has 'cured' a previous ailment (e.g., the flu), instead of undergoing legitimate medical treatment when afflicted with a 
more serious disease such as cancer can be life threatening, if not life ending. Thus, although the phenomenon endorsed is fallacious (e.g., winning streaks; supposed abilities of a faith healer), these beliefs can become real in their consequences.

Hence, there is merit in understanding a) the precise role that fallacious beliefs have in leading to non-optimal decisions; b) the factors responsible for the development of these fallacious beliefs; and c) the most efficacious interventions to correct these fallacious beliefs. This, then, is the overarching purpose of the present thesis with a specific focus on gambling fallacies and paranormal beliefs.

The structure of this thesis is as follows:

- Chapter Two (Leonard, Williams, \& Vokey, 2015) is a comprehensive review of the gambling literature to identify the logical fallacies that lead to erroneous beliefs about how gambling works, and therefore should be categorized under the umbrella term "Gambling Fallacies". The second part of this paper then reviews the reliability and validity of the instruments designed to identify susceptibility to these fallacies.

- Building on the findings of Chapter Two, Chapter Three (Leonard \& Williams, 2016) consists of a re-evaluation of the relationship between gambling specific erroneous cognitions and the subsequent appearance of problem gambling using a secondary analysis of data from a large scale $(n=4,121)$ five-year longitudinal study of gambling using a psychometrically sound measure of gambling fallacies ('Gambling Fallacies Measure').

- Chapter Four (Leonard \& Williams, submitted for publication) is a detailed empirical examination of whether the demographic, personality, cognitive, and 
gambling-related variables that are predictive of gambling fallacies in a sample of 266 adults are the same or different from the variables predictive of paranormal belief.

- Building on the findings of Chapter Four, Chapter Five (Leonard, Jackson, \& Williams, submitted for publication) is a systematic review of interventions designed to reduce paranormal beliefs with a specific focus on their effectiveness and the elements contained within these interventions that appear to be particularly important.

- Chapter Six is a summary of the findings of each study, the collective implications of these studies, and directions for future research. 


\section{CHAPTER TWO. GAMBLING FALLACIES: WHAT ARE THEY AND HOW ARE THEY BEST MEASURED}

Leonard, C.A., Williams, R.J., \& Vokey, J. (2015). Gambling fallacies: What are they and how are they best measured? Journal of Addiction Research \& Therapy, 6 (4), 256. http://dx.doi.org/10.4172/2155-6105.1000256

\subsection{ABSTRACT}

Objective: Gambling fallacies are believed to be etiologically related to the development of problem gambling. However, this evidence is tenuous due to the lack of consensus on which things constitute gambling fallacies and the adequacy of instruments that ostensibly measure them. The purpose of this paper is to comprehensively identify the main gambling fallacies and examine the reliability and validity of the instruments designed to measure them.

Methods: All known gambling fallacies and instruments measuring them were identified via a keyword search of social science, medical, and gambling specific databases. The reliability and validity of each assessment instrument was then examined.

Results: Six primary gambling fallacies were consistently reported in the literature. Eighteen instruments were found to measure one or more of these fallacies, with 9 assessing specific fallacies and 9 intended to be comprehensive instruments. Most instruments were found to have good internal consistency as well as adequate convergent and external validity. Relatively few demonstrated test-retest reliability and/or discriminant validity. However, the main area of concern was content validity. Although instruments focusing on a particular fallacy tended to have adequate content validity, this was not true of the comprehensive instruments. In addition to insufficient coverage of the fallacies, most comprehensive instruments included questions pertaining to 
motivations for gambling, attitudes about gambling, and/or problem gambling symptomatology (e.g., chasing losses), which likely inflates their statistical association with problem gambling. Many of these comprehensive instruments also wrongly assume that no skill is involved in any form of gambling.

Conclusions: The inadequate content validity of most comprehensive gambling fallacy instruments draws into question the strong etiological relationship gambling fallacies are presumed to have with problem gambling. This concern is compounded by the fact that all research reporting this association has been cross-sectional and correlational in nature. Re-examination of this relationship using improved instrumentation in a longitudinal context is required.

Keywords: gambling fallacy, cognitive error, cognitive bias, distortion, superstition, illusion of control

\subsection{BACKGROUND}

Many general cognitive biases and heuristics are known to interfere with optimal decision-making and judgement (e.g., Baron, 2000; Hogarth, 1987; Kahneman \& Tversky, 1982; Nisbett \& Ross, 1980; Pohl, 2004). Most of these biases also have the potential to directly or indirectly compromise decision making in gambling. The term 'gambling fallacies' refers to specific erroneous beliefs about how gambling works that derive from these general cognitive biases. That is also the meaning of this term in the present paper. 'Gambling fallacy' is used in preference to 'cognitive distortion' and 'cognitive bias' to make it clear that the focus is on erroneous thoughts and beliefs rather than general cognitive biases and distortions that may interfere with optimal judgement and decision-making, but do not necessarily create erroneous gambling-related beliefs. 
Gambling fallacies appear to be common among gamblers (Delfabbro, 2004; Delfabbro \& Winefeld, 2000; Gaboury \& Ladouceur, 1989; Toneatto, Blitz-Miller, Calderwood, Dragonetti, \& Tsanos, 1997; Walker, 1992a, 1992b, Wohl \& Enzle, 2002, 2003) and especially common among problem gamblers (Goodie \& Fortune, 2013).

Because of this consistent association there is a strong presumption that gambling fallacies are etiologically involved in the development of problem gambling (Fortune \& Goodie, 2012; Jacobsen, Knudsen, Krogh, Pallesen, \& Molde, 2007; Joukhador, Maccallum, \& Blaszczynski, 2003; MacKay \& Hodgins, 2012; Miller \& Currie, 2008; Toneatto, 1999; Xian et al., 2008). Following on this belief, correcting erroneous gambling cognitions is central to most programs designed to prevent and/or treat problem gambling (Fortune \& Goodie, 2012; Ladouceur et al., 2001; Ladouceur, Sylvain, Letarte, Giroux, \& Jacques, 1998; Toneatto, 2002; Williams, West, \& Simpson, 2012).

However, the presumption of an etiological relationship with problem gambling may be premature. First, all of the research documenting a relationship between problem gambling and gambling fallacies has been cross-sectional and correlational in nature. The co-occurrence of gambling fallacies and problem gambling does not establish whether gambling fallacies caused problem gambling, or whether problem gambling caused gambling fallacies, or whether they developed at the same time. Second, as noted by several authors (e.g., Goodie \& Fortune, 2013), the field lacks consensus on 1) what specific things constitute gambling fallacies and, 2) which instruments best assess them. As will be discussed in the present article, a comprehensive review of these two issues would suggest that the relationship between gambling fallacies and problem gambling 
has been artifactually inflated due to the inadequate content validity of most existing instrumentation.

\subsection{WHAT ARE THE SPECIFIC GAMBLING FALLACIES?}

As is the case with cognitive biases more generally, there is no well agreed-upon list or categorization of gambling fallacies, although different categorizations have been proposed (e.g., Ejova, Delfabbro, \& Navarro, 2015; Fortune \& Goodie, 2012; Ladouceur, 2004; McInnes, Hodgins, \& Holub, 2014; Toneatto, 1999; Wagenaar, 1988).Thus, the first step was to identify all the potential gambling fallacies via a keyword search of all the social science and medical databases (e.g., PsycINFO, MEDLINE, ABI/INFORM Global, PubMed, Science Direct, etc.) through two omnibus search engines (the university library's SUMMON search engine and Google Scholar). As a significant portion of scholarly gambling research is not contained in academic journals, this search was supplemented by a keyword search of gambling specific databases so as to better identify gambling fallacies cited in the "grey literature" (Australasian Gaming Council eLibrary, Gamblib, Problem Gambling Foundation of New Zealand eLibrary, Responsible Gambling infohub, Canadian Partnership for Responsible Gambling elibrary, Alberta Gambling Research Repository). Depending on the specific database examined, the keywords and phrases used were: gambling fallacy, fallacy, cognitive distortion, cognitive bias, errors in thinking, superstition, illusion of control, hot hand.

Six distinct fallacies were repeatedly identified in the literature, with the first four being the most often cited. These four are inter-related to each other because they are generally reflective of a misunderstanding of the random and uncontrollable nature of many gambling games: 
- Hot Hand Fallacy. Many gambling devices (e.g., dice, electronic gambling machines, roulette wheels, lottery and bingo ball machines) have been specifically created to produce random outcomes, with the previous outcome having no influence on future outcomes. Nonetheless, many people fail to appreciate this, erroneously believing that a winning streak on these devices portends more winning and/or that winning numbers are more likely than other numbers to appear again (Ayton \& Fischer, 2004; Croson \& Sundali, 2005; Holtgraves \& Skeel, 1992; Oskarsson, Van Boven, McClelland, \& Hastie, 2009). Another manifestation of this fallacy is the common perception of a 'hot hand' in sporting performances, even though research shows that random chance accounts for most of these streaks (Gilovich, Vallone, \& Tversky, 1985; Koehler \& Conley, 2003; Oskarsson et al., 2009)

- Monte-Carlo Fallacy' ${ }^{1}$ This fallacy, which is also known as the classic 'gamblers fallacy' is also related to the failure to understand the independence of random events, but results in people betting on the opposite outcome to occur, due to the erroneous belief that statistical deviations in one direction will be corrected by statistical deviations in the other direction to even things out (Ayton \& Fischer, 2004; Croson \& Sundali, 2005; Terrell, 1994). Examples of this are the belief that an electronic gambling machine that has not paid out in some time is increasingly likely to pay out, and/or that a machine that has just paid out a large win is less likely to do so again in the near future. Another indirect manifestation of this fallacy is the belief that an orderly sequence of numbers (e.g., 1, 2, 3, 4, 5) is less likely to win the lottery compared to a nonorderly sequence (e.g., 7, 25, 2, 33, 1). The 'representativeness

\footnotetext{
${ }^{1}$ The term 'Monte-Carlo fallacy' is used to avoid confusion with the more generic use of 'gambling fallacies' used in this paper.
} 
heuristic'(Kahneman \& Tversky, 1972) is the more general bias that helps create this gambling specific fallacy.

- Belief that Luck is Dispositional. This is the erroneous belief that randomly determined events consistently favor or disfavor some things over others (e.g., Darke \& Freedman, 1997; Wagenaar \& Keren, 1988; Wohl \& Enzle, 2002, 2003; Wohl, Stewart, \& Young, 2011; Wohl, Young, \& Hart, 2005). This could be certain people, time periods, colours (e.g., red), numbers (e.g., 7, 9 versus 4, 13), etc.

- Illusion of Control. It is a common tendency to believe that one's actions can influence random events (Langer, 1975). In gambling, this erroneous belief takes the form of believing that choosing one's own lottery numbers (Rogers, 1998) or roulette numbers (Dixon, 2012) is preferable to having them randomly selected, or that certain betting techniques or strategies can better assure success in games with random outcomes (e.g., Cantinotti, Ladouceur, \& Jacques, 2004; Goodie \& Fortune, 2005; Ladouceur, Mayrand, Dussault, Letarte, \& Tremblay, 1984; Ladouceur \& Sévigny, 2005; Wolfgang, Zenker, \& Viscusi, 1984). Superstitious conditioning is one of the processes contributing to this illusion of control. A basic principle of operant and classical conditioning is that the context and actions associated with a rewarding event become associated with the reward, even though very few of these actions and elements have any direct causal relationship. People then commonly re-invoke these extraneous elements and/or actions the next time they confront this situation in the belief it may facilitate a rewarding outcome (e.g., Guttentag \& Havitz, 2010; Windross, 2003). 
Two other specific gambling-related errors in thinking, although being related to the above fallacies, have more to do with failure to take mathematical and statistical principles into account. The large majority of commercial gambling offerings are provided in a way that ensures high variability of short-term outcomes, but long-term statistical advantage to the gambling provider (Epstein, 2012). Failure to be aware of these mathematical principles or disavowal of these facts are common gambling specific errors in thinking (Lambos \& Delfabbro, 2007; Pelletier \& Ladouceur, 2007; Williams \& Connolly, 2006; Williams, Connolly, Wood, \& Nowatzki, 2006). Two specific aspects of this deficient statistical knowledge particularly relevant to gambling are as follows:

- Insensitivity to Sample Size. People commonly fail to realize that deviations from expected probabilities are common with small samples, but increasingly uncommon with large samples (Tversky \& Kahneman, 1971). So, for example, many people will erroneously report that a roulette wheel that has produced $80 \%$ reds is just as likely to have occurred with 5 spins as 500 spins. The consequence of this failure to take sample size into account is the person failing to understand that winning is common with small samples but increasingly rare with extended play.

- Base Rate Neglect. People often ignore general statistical probabilities in judging how frequently an outcome occurs (Bar-Hillel, 1980). Rather, they often estimate frequency by how available instances of the event are in their memory (Tversky \& Kahneman, 1973). One gambling-related manifestation of this bias is the belief that participating in commercial forms of gambling is a good way of making money. Another example is the perception that winning the lottery is more likely than it 
actually is due to the number of people a person is aware of that have won the lottery over the years.

\subsection{HOW ARE GAMBLING FALLACIES BEST MEASURED?}

A good assessment instrument needs to be both reliable and valid. What exactly constitutes reliability and validity in the context of a gambling fallacies instrument is the subject of the present section. The main types of reliability are test-retest, parallel forms, inter-rater, and internal consistency. The applicability of each of these to a gambling fallacies assessment instrument is explored below:

- Test-retest. Stable answers to erroneous beliefs about gambling over a short period of time is a good index of reliability, as it provides reassurance that the questions are clear and that the answers are definitive and speak to a belief that has some stability. Extremely short periods of time (1 hour - few days) are not optimal, as memory for previous responses may shape current responding. Similarly, very long periods of time (e.g., one year) are not optimal as these beliefs should be malleable to some extent. Thus, a period of time between a week and a month would theoretically seem to be an optimal time frame to establish test-retest reliability of gambling fallacies.

- Parallel forms. If different versions of a gambling fallacies instrument exist, then the results of the two instruments should be strongly correlated with each other. However, as it is not essential that parallel forms should exist, this type of reliability is also not essential.

- Inter-rater. In general, third party assessment of gambling fallacies would appear to be a less direct and efficient way of assessing fallacies compared to a set of questions 
the person answers themselves. Hence, this type of reliability would also not appear to be needed.

- Internal consistency. Adequate levels of internal consistency are desirable for each factor underlying a gambling fallacies instrument. As will be discussed in greater depth later, the number of factors underlying gambling fallacies is somewhat unclear as most existing comprehensive instruments have included general non-fallacious biases, attitudes, and/or behaviours in the instruments, which could account for multiple factors being identified. Although a few studies have found just one gambling fallacies factor (Breen \& Zuckerman, 1999; Jefferson \& Nicki, 2003; Xian et al., 2008) it has been more common to find multiple factors. More specifically, two factors (Ejova et al., 2015; Ferland, Ladouceur, \& Vitaro, 2002; Jefferson, Doiron, Nicki, \& MacLean, 2004; McInnes et al., 2014; Steenbergh, Meyers, May, \& Whelan, 2002; Williams, 2003) and five factors (Moodie, 2008; Oei, Lin, \& Raylu, 2007; Raylu \& Oei, 2004). Thus, it is would seem that high levels of overall internal consistency is likely not desirable for a gambling fallacies instrument, unless measured for each factor and/or using a hierarchical measure of consistency (e.g., coefficient omega).

There are several different ways of dimensionalizing validity and several different terms used to describe similar types. The main dimensions used in the present paper are construct and external validity, with content, concurrent, convergent, and discriminant being subtypes of construct validity. A case will be made that all of these types of validity need to be demonstrated in a gambling fallacies instrument. 
- Content. Content validity for a comprehensive gambling fallacies instrument requires comprehensive and even coverage of the previously identified fallacies. Instruments that just focus on one fallacy (e.g., superstitions (Joukhador, Blaszczynski, \& Maccallum, 2004); luck (Darke \& Freedman, 1997; Maltby, Day, Gill, Colley, \& Wood, 2008; Thompson \& Prendergast, 2013; Wohl et al., 2011, 2005); illusion of control (Moore \& Ohtsuka, 1999) do not provide adequate coverage. Similarly, instruments that include questions on general attitudes or motivations (e.g., gambling to win money), biases (e.g., choosing to focus more on wins than losses), and/or behaviour (e.g., always wearing red while gambling; chasing losses) are not measuring fallacies in the absence of a direct attribution to a false belief (e.g., playing electronic gambling machines because it is a good way of making money; wearing red because it improves luck). Instruments or questions that wrongly presume that no skill is involved in any form of gambling and/or fail to specify that the questions only pertain to pure chance games also lack content validity (e.g. Gambling Cognitions Inventory; (McInnes et al., 2014)) as an element of skill is involved in sports betting, horse race handicapping, and certain card games such as poker (Leonard, Staples, \& Williams, 2015). Finally, instruments that assess generic errors in thinking or fallacious beliefs without specific reference to a gambling situation also do not have sufficient content validity for a gambling fallacies instrument (e.g., Irrational Belief Measure (Jones, 1969); Irrational Belief Scale (Malouff \& Schutte, 1986);

Paranormal Belief Scale (Tobacyk, 2004)). 
- Concurrent. This refers to whether the test is correlated with another measure of the same construct that has been previously validated. As no prior instruments have received unambiguous validation, this type of validity is not examined here.

- Convergent. This refers to whether the test is correlated with similar constructs, beliefs, and behaviour theoretically reflective of the construct (either concurrently, or in the future). It has been common to show convergent validity of a gambling fallacies instrument by its current or future correlation with gambling and/or problem gambling. There is some logic to this, as it reasonable to expect that erroneous beliefs about the potential for winning should contribute to gambling involvement and over involvement. However, the extent to which these instruments have also included nonfallacious motivations or attitudes correlated with gambling involvement and/or signs of problem gambling (as they often have) is the extent to which these correlations will be artificially inflated. It needs also to be recognized that gambling fallacies are also very common in the general population, most of whom gamble very little or not at all (e.g., Williams et al., 2015). Hence, the relationship with gambling and/or problem gambling will always be relatively weak. There are other constructs that bear a much stronger theoretical connection to gambling fallacies and should be used to demonstrate convergent validity. These include: general errors in thinking, paranormal beliefs, lower educational attainment, lower mathematical skill or training, and lower intelligence.

- Discriminant. A gambling fallacies instrument needs not only to show association with related constructs, but lower and/or lack of association with theoretically 
unrelated behaviour, concepts, or measures (e.g., marital satisfaction, perceived stress, etc.).

- External. External validity of a gambling fallacies instrument is demonstrated by the generalizability of its scores across gambling situations as well as generalizability of its application across different age groups, educational levels, clinical and nonclinical populations, countries, and cultures.

\subsection{WHAT IS THE RELIABILITY AND VALIDITY OF EXISTING GAMBLING}

\section{FALLACY INSTRUMENTS?}

The same search of the literature described earlier identified 18 instruments intended to either comprehensively assess gambling fallacies, a subset of gambling fallacies, a specific fallacy relevant to gambling (e.g., belief in luck), and/or to assess gambling fallacies as part of a broader gambling-related instrument. A brief description of each of these instruments as a candidate for a comprehensive, reliable, and valid gambling fallacies instrument is provided below. They are presented in order of their publication date.

- Belief in Good Luck Scale (BIGL) (Darke \& Freedman, 1997). The BIGL is a 12 item Likert scale assessment (strongly agree $=1$ to strongly disagree $=6$ ) of the extent to which individuals believe in personal good luck. Studies were conducted with Ontario Science Centre visitors (Study 1: $n=231$ ), Toronto university students (Study 2; $n=$ 1453), and students at New York University (Study $3 ; n=494$ ). Factor analysis found a single factor underlying the instrument. Internal consistency was good (Cronbach $\alpha$ ranging from .78 to .85 depending on the study). Test-retest reliability over a period of one to two months was adequate $(r=.63)$. Convergent validity was established by 
a significant correlation with locus of control and discriminant validity was established by BIGL's lack of correlation with general optimism, academic pessimism, self-esteem, desire for control, and achievement motivation. AsianAmericans were more likely to believe in personal luck compared to non-Asians. In a subsequent study, Chiu and Storm (2010) found problem gamblers to have higher scores on the BIGL compared to other types of gamblers. In another study, Prendergast and Thompson (2008) found that belief in being personally lucky was associated with selecting a lucky draw over other sales promotions options. These investigators also found the scale to be composed of two factors: a general belief in luck and a belief in being personally lucky.

- Gambling Attitudes and Beliefs Survey (GABS) (Breen \& Zuckerman, 1999). The GABS is a 35 item Likert scale assessment $(1=$ strongly agree to $4=$ strongly disagree) of gambling-related cognitions, behaviours, and attitudes. Although three fallacies are included in the measure (illusion of control, luck, and the Monte Carlo fallacy), the GABS does not comprehensively evaluate all gambling fallacies, nor does it differentiate susceptibility to fallacies from motivation for gambling and problem gambling behaviours (i.e., it includes questions on whether the person gambles to feel excitement, to improve mood, as a means to escape everyday problems, and whether person loses track of time while gambling). Factor analysis of this measure indicates a single construct, aptly named "affinity towards gambling". In their pilot sample of 625 U.S. students in introductory psychology university classes and a treatment seeking sample of 86 , Cronbach alpha was excellent $(\alpha=.90$ and .93 , respectively). GABS scores were significantly correlated with gambling engagement 
and problem gambling scores. Subsequent studies using the GABS to compare treatment seeking samples to university samples in the United States have found it to discriminate between the groups and to be correlated with gambling involvement (Strong, Breen, \& Lejuez, 2004; Tochkov, 2009).

- Belief About Control Over Gambling (BAC) (Moore \& Ohtsuka, 1999). Rather than assessing the full scope of gambling fallacies, the 19 item Likert scale BAC $(5=$ strongly agree to $1=$ strongly disagree) was developed to evaluate perceived control over gambling in a large sample of Australian secondary school $(n=757)$ and first year post-secondary students $(n=250)$. Factor analysis identified five factors. The Cronbach alpha of all factors except the 'cynicism about winning' factor, was good (at or above .80). The 'illusion of control' factor was found to significantly predict gambling frequency, but was not a significant predictor of problem gambling.

- Questionnaire of Attitudes and Beliefs about Gambling (QABQ) (Ferland et al., 2002). The QABQ is a 16 item Likert scale questionnaire ( $1=$ totally disagree to $4=$ totally agree) that evaluates knowledge about gambling (i.e., "the lottery is a gambling game"), and beliefs about gambling (i.e., "betting money can become a problem like alcoholism and drug addiction"). A subset of the seven items assessing beliefs about gambling evaluate fallacious thought (i.e., "I don't have more chances to win at the lottery if I choose the numbers myself"). The QABC was not intended to be a comprehensive evaluation of gambling-related erroneous cognitions. Rather, it was designed as a pre- post-test measure for an intervention designed to reduce the incidence of problem gambling in 424 Canadian middle-school aged children. Factor analysis confirmed two distinct factors, with a low Cronbach alpha for the 
misconception factor (.58) and a good Cronbach alpha (.74) for the gambling knowledge factor. This questionnaire has been translated into Italian (Capitanucci, Smaniotto, \& Biganzoli, 2010), and similarly used to evaluate the efficacy of a problem gambling intervention program among Italian high school students (Donati, Primi, \& Chiesi, 2014).

- Gambling Belief Questionnaire (GBQ) (Steenbergh et al., 2002). The 21 item Likert scale GBQ $(1=$ strongly agree to $7=$ strongly disagree $)$ evaluates the full range of gambling fallacies. However, it also includes questions about problem gambling behaviours (e.g., chasing losses, borrowing money for gambling, lying to loved ones) as well as other extraneous items (e.g., valuation of the excitement of gambling engagement). The GBQ also erroneously considers all references to skill at gambling to be fallacious (e.g., "gambling is more than just luck"; "gambling wins provide evidence of skill and knowledge"). Statistical analysis has identified two factors, described as: luck/perseverance and illusion of control. The Cronbach alpha of each factor and the full scale are good to excellent $(.90, .84$, and .92 , respectively). The two-week test-retest reliability of each factor and the total questionnaire are also good $(r=.71, .77$, and .77$)$. In a U.S. sample comprised of both undergraduates $(n=200)$ and community members ( $n=203$ ), problem gamblers scored significantly higher than non-problem gamblers (which is to be expected considering the inclusion of problem gambling behaviours). The full GBQ score and the luck/perseverance scores were also significantly related to self-reported gambling session lengths $(r=.43$, and .48). 
- Gambling Fallacies Measure (GFM) (Williams, 2003). The GFM (Appendix A) consists of 10 multiple-choice items, each with only one correct answer. Higher scores reflect greater resistance to gambling fallacies. The GFM comprehensively assesses all of the identified gambling fallacies: hot hand fallacy (questions 2, 4, 10); Monte-Carlo fallacy (questions 1, 2, 4, 10); belief that luck is dispositional (questions 3,4 ); illusion of control (questions 5, 8, 9); insensitivity to sample size (question 6); and base rate neglect (question 7). Unlike most instruments, the GFM does not include any non-fallacious motivations, attitudes, biases or problem gambling behaviours. Factor analysis across multiple datasets has found a two factor solution to be most consistent: a failure to understand the random and uncontrollable nature of most gambling games (questions $1,2,3,4,5,8,9,10$ ) and a failure to take statistical probabilities into account (questions 6,7). The hierarchical coefficient omega (Dunn, Baguley, \& Brunsden, 2014) shows adequate (.61) internal consistency. The overall one-month test-retest reliability of the instrument is good (.70). The measure has been successfully employed in multiple samples comprising over 17,000 people, with these samples spanning ages 13 - 89, dozens of different countries, and including over 1,000 problem gamblers (el-Guebaly et al., 2015; Williams et al., 2015; Williams, Lee, \& Back, 2013; Williams, Wood, \& Currie, 2010; Wood \& Williams, 2009) Depending on the dataset, GFM scores have been found to be consistently and significantly associated with intelligence, educational attainment, paranormal beliefs, and gambling 'to win money' as a primary motivation. The GFM has also usually (but not always) been significantly associated with problem gambling $(r=-.03$ to -.16$)$ and various measures of gambling involvement ( $r=.06$ to -.12$)$. Discriminant validity 
has been demonstrated with findings of near zero associations between GFM scores and marital satisfaction, general life happiness, and past year perceived stress.

- Gambling Belief Questionnaire (GBQ22) (Joukhador et al., 2003). This questionnaire contains 56 Likert scale items $(0=$ not at all to $4=$ very much $)$ intended to evaluate 12 facets of gambling-related thought. Seven of the 12 facets evaluate non-fallacious biases and problem gambling behaviours. Furthermore, all references to skill at gambling are erroneously classified as fallacious. The Cronbach alpha of the full scale is extremely high (.97), which is related to the very large number of questions in the questionnaire. No internal consistencies were reported for the 12 facets. Participants included in the validation of the GBQ2 included Australian problem gambling treatment seekers $(n=56)$ and a group of social gamblers $(n=52)$. Significantly higher scores were obtained by the treatment seeking sample as compared to the social gambling sample on all facets except "denial" (a facet evaluating whether the person acknowledges gambling related problems). Two subsequent studies in Scotland (Moodie, 2007, 2008) have used a shortened 48 item variant of this measure (GBQ2). Moodie (2007) found no significant differences on GBQ2 scores between problem and social gamblers. However, Moodie (2008) did find significant differences between problem video lottery terminal gamblers and non-problem gamblers. The GBQ2 was also found to correlate with level of gambling involvement. Factor analysis by Moodie (2008) found five factors in a 24 item version of the scale that did not support the theoretically driven facets identified by the original authors.

\footnotetext{
2 The current authors use 'GBQ2' to reference Joukhador et al.'s (2003) Gamblers Belief Questionnaire and to differentiate Joukhador et al.'s GBQ2 from the GBQ of Steenbergh et al. (2002).
} 
- Superstitious Beliefs in Gambling (SBG) (Joukhador et al., 2004). The SBG was not developed to assess the full scope of gambling fallacies. Rather, the eight-item Likert scale assessment $(0=$ not at all to $4=$ very much $)$ was developed just to evaluate superstitious beliefs. There is no information on the reliability of this instrument. Concurrent validity was demonstrated by the significant positive relationships between the SBG and scores on the South Oaks Gambling Screen (SOGS) (Lesieur \& Blume, 1987) as well as typical time spent in gambling sessions. It is possible that these associations were artificially inflated as more than half this Australian sample were treatment seeking problem gamblers $(n=56$ treatment seeking versus $n=45$ non-problem gamblers).

- The Informational Bias Scale (IBS) (Jefferson et al., 2004; Jefferson \& Nicki, 2003). The IBS is a 25 item Likert scale instrument $(1=$ don't agree at all to $7=$ strongly agree) developed to evaluate irrational beliefs in video lottery terminal players. The IBS does not evaluate the full scope of gambling fallacies. It also contains items that evaluate problem gambling behaviours (i.e., chasing losses), as well as non-fallacious biases (e.g., choosing to focus on wins rather than losses, preferring to play on specific electronic gambling machines). Principal component analysis on a sample of 96 predominantly Canadian problem gamblers identified a single component. In a subsequent study (Jefferson et al., 2004) with a larger and non-problem gambling Canadian sample $(n=228)$, two components were identified: the Monte Carlo fallacy and the tendency to make erroneous inferences concerning VLT outcomes. The Cronbach alpha of each component was good to excellent (.81 and .90). Education regarding how video lottery terminals work (Jefferson et al., 2004, experiment 2) was 
found to significantly reduce IBS scores. IBS scores were found to account for $10 \%$ of the variance in SOGS scores, and 5\% of the variance in DSM-IV pathological gambling lifetime scores.

- Gambling Related Cognitions Scale (GRCS) (Raylu \& Oei, 2004). The GRCS is a 23 item Likert scale instrument $(1=$ strongly disagree to $7=$ strongly agree $)$ comprised of five factor analysis derived subscales: interpretive bias, illusion of control, predictive control, gambling-related expectancies, and perceived inability to stop gambling. The GRCS does not evaluate the full scope of gambling fallacies and only the illusion of control subscale evaluates purely fallacious gambling-related thought. The other subscales include several extraneous items (e.g., my desire to gamble is overpowering; gambling makes me happier; having a gamble helps reduce tension and stress; I prefer to focus on wins). High internal consistencies are reported for the total scale $($ Cronbach alpha $=.93)$ and each of the factors (range: .77-.91). Initial validation of this measure was undertaken using a large $(n=968)$ demographically diverse Australian community sample. Additional studies of the GRCS have led to creation and validation of Italian (Iliceto et al., 2015), Turkish (Arcan \& Karanci, 2015), and Chinese (Oei et al., 2007) versions of the measure (with the original factor structure supported in these subsequent studies). Higher GRCS scores have been found to be associated with problem gambling (Cosenza, Baldassarre, Matarazzo, \& Nigro, 2014; Marmurek, Switzer, \& D'Alvise, 2014, 2015), the increased likelihood of relapse in problem gambling (Smith et al., 2015), neuroticism (Iliceto et al., 2015), and "proneness to delusion" (Abdollahnejad, Delfabbro, \& Denson, 2015). The initial validation report indicated significant gender differences on GRCS total scores and all 
subscales except illusion of control (Raylu \& Oei, 2004). Subsequent studies have not consistently replicated this finding (Cosenza et al., 2014; Marmurek et al., 2015).

- Perceived Personal Luck Scale (PPLS) (Wohl et al., 2005). The PPLS is the 10 luck/perseverance Likert scale items from Steenbergh et al.'s (2002) GBQ (1 = strongly agree to $5=$ strongly agree). As mentioned earlier, these items erroneously classify all references to skill in gambling as fallacious. As was the case during the original measure, the Cronbach alpha associated with this measure is good (.88). In a sample drawn from a Canadian university, the PPLS was used to evaluate differences between problem gamblers with an affinity for pure chance games $(n=19)$ as compared to problem gamblers who prefer mixed chance/skill games $(n=19)$. Between group differences were detected, with pure chance game enthusiasts reporting lower belief in personal luck.

- Drake's Belief About Chance Inventory (DBC) (Wood \& Clapham, 2005). The 22 item Likert scale DBC ( 1 = strongly disagree to $5=$ strongly agree $)$ measures two dimensions derived by principal component analysis: superstition and illusion of control. This measure was not designed to evaluate the full scope of gambling fallacies. It includes questions about non-gambling related paranormal beliefs (e.g., belief in astrology, using lucky pen/pencil while taking tests, general superstitious beliefs, etc.). Wood \& Clapham (2005) report good to excellent Cronbach alphas for each dimension (superstition $=.85$, illusion of control $=.88$ ) as well as for the whole scale (.91). DBC scores were shown to be significantly positively associated with gambling frequency in a U.S. sample of treatment seekers $(n=68)$ and members of the general public $(n=239)$. 
- Andre (2006). Andre (2006) developed an unnamed 18 item Likert scale test $(1=$ strongly agree to $5=$ strongly disagree) of fortune, luck, and opportunity in a sample of 195 French university students. Principal component analysis identified four components: bad fortune, good fortune, luck, and opportunity. The questions on 'opportunity' (e.g., "I am able to seize the opportunity") are not directly relevant to gambling. Cronbach alphas for the four components ranged from .70 to .88. Luck was significantly positively correlated with self-esteem and achievement motivation and negatively correlated with anxiety. Good fortune was positively correlated with selfesteem. Bad fortune was positively correlated with anxiety and negatively correlated with self-esteem. Opportunity was positively correlated with self-esteem and achievement motivation and negatively correlated with anxiety.

- Beliefs Around Luck Scale (BALS) (Maltby et al., 2008). This 22 item Likert scale test is an expansion of the Belief in Good Luck Scale (BIGL) (Darke \& Freedman, 1997) to include belief in bad luck (strongly agree $=1$ to strongly disagree $=6$ ). Maltby et al. (2008) found four components underlying this revised scale (belief in luck, rejection of luck, being lucky, and being unlucky) across two samples derived from workplaces and community groups in the United Kingdom $(n=250 ; n=145)$. Each of the components had adequate to good internal consistency ( $\alpha$ ranging from .69 to .89). One month test-retest reliability of the four components was low, ranging from .48 to .58 . The subscales showed the expected associations with measures of personality and subjective well-being (e.g., belief in being unlucky being associated with neuroticism). 
- Gambling Related Cognitive Distortions (GRCD) (Xian et al., 2008). The GRCD is comprised of 12 Likert scale questions $(1=$ never to $5=$ always $)$. Not all gambling fallacies are addressed within the GRCD. Furthermore, half of the GRCD items assess non-gambling specific concepts (i.e., "you identified a pattern in the way outcomes or events were happening", "you have had a hunch or a gut feeling about a future event, or thought you could predict the outcome of a future event") and/or nonfallacious experiences (i.e., "you have had a big win on a previous bet"; "you have had a long shot opportunity"). Factor analysis conducted on data collected from 790 U.S. male twins found a single factor with a Cronbach alpha of .89. A significant association was observed between scores on the GRCD and problem gambling scores.

- Personal Luck Usage Scale (PLUS) (Wohl et al., 2011). The PLUS is a one dimensional eight-item scale derived and subsequently confirmed among universityaged gamblers in Canada ( $n=347$ in Study 1 and $n=361$ in Study 2). Importantly, the PLUS was distinguishable from a general belief in luck (Study 2). In Study 3 ( $n=60$ ), a behavioural consequence of belief in personal luck was assessed among a community sample of gamblers. PLUS scores were found to be positively associated with the average amount of money spent in a gambling session.

- Belief in Luck and Luckiness Scale (BLLS) (Thompson \& Prendergast, 2013). The BLLS is a 16 item Likert scale ( $1=$ strongly disagree to $5=$ strongly agree $)$ list of questions about luck. A series of studies (total $n=1202$ ) using British university employees as well as university students in Britain, Japan, and Hong Kong found two dimensions underlying the scale: 'belief in luck', and 'luckiness'. The 2 month testretest reliability was .56 for the Belief in Luck dimension and .75 for Personal 
Luckiness. Belief in luck correlated positively with locus of control. Personal luckiness correlated positively with extraversion, conscientiousness, life satisfaction, positive affect, and negatively with neuroticism, locus of control, and negative affect.

- Gambling Cognitions Inventory (GCI) (McInnes et al., 2014). The GCI is a 33 item Likert scale $(1=$ strongly disagree to $3=$ strongly agree $)$ list of gambling-related biases, behaviours, and fallacies. The GCI does evaluate the full range of gambling fallacies. However, it also includes problem gambling behaviours (e.g., chasing losses) as well as predispositions that are not necessarily fallacious (e.g., tendency to focus on wins rather than losses). Nine of the $33 \mathrm{GCI}$ items also erroneously classify endorsement of perceived skill in gambling as fallacious (without contextualizing the questions as referring to just pure chance games). Two factors underlie the GCI: attitude/skill and luck/chance. The GCI was validated by re-analysis of four Canadian problem and pathological gambling sample datasets $(n=710)$. Reported Cronbach alpha for the entire GCI ranges from $.91-.95$, and between .77 to .92 for the subscales. Significant positive associations exist between GCI scores and scores on the Magical Ideation Scale (Eckblad \& Chapman, 1983), the Measure of Irrational Belief (Malouff \& Schutte, 1986), and problem gambling as measured by the NODS (Gerstein et al., 1999) and/or SOGS (Lesieur \& Blume, 1987). Discriminant validity was established by its low association with the Perceived Stress Scale (Cohen \& Williamson, 1988), and the Beck Depression Inventory (Beck, Ward, Mendelson, Mock, \& Erbaugh, 1961). No significant gender differences on subscale or total GCI scores have been found. 


\subsection{SUMMARY, CONCLUSION, AND FUTURE DIRECTIONS}

Six primary gambling fallacies were consistently reported in the literature.

Eighteen instruments were found to measure one or more of these fallacies, with 9 assessing specific fallacies and 9 intended to be comprehensive instruments. A summary of the reliability and validity of each of these instruments for the assessment of gambling fallacies is presented in Table 1. Correlation coefficients and/or measures of internal consistency of .70 or higher (good to excellent) are identified with two asterisks, values between .60 and .69 (adequate) are identified with a single asterisk, and values below .60 and/or that are not reported have an empty cell.

As can be seen, most of these instruments have good internal consistency, as well as adequate convergent and external validity. Relatively few instruments have demonstrated test-retest reliability and/or discriminant validity.

However, the main area of concern is content validity. Although instruments focusing on a particular aspect of gambling fallacies (i.e., luck, control, superstitions) tend to have adequate content validity, this is not true for most instruments intended to more comprehensively capture gambling fallacies. Rather, almost all comprehensive instruments have one of more of the following problems: a) they do not assess all the known fallacies; b) they erroneously identify any belief in gambling-related skill to be fallacious; c) they include the assessment of non-fallacious attitudes (e.g., enjoyment of 
Table 2.1 Evaluation of Measures of Gambling Fallacies

\begin{tabular}{|c|c|c|c|c|c|c|c|c|}
\hline Author & Measure & Focus & $\begin{array}{c}\text { Internal } \\
\text { Consistency }\end{array}$ & $\begin{array}{l}\text { Test Re-Test } \\
\text { Reliability }\end{array}$ & $\begin{array}{l}\text { Content } \\
\text { Validity }\end{array}$ & $\begin{array}{l}\text { Convergent } \\
\text { Validity }\end{array}$ & $\begin{array}{l}\text { Discriminant } \\
\text { Validity }\end{array}$ & $\begin{array}{l}\text { External } \\
\text { Validity }\end{array}$ \\
\hline Darke \& Freedman (1997) & BIGL & Good luck & $* *$ & $*$ & $*$ & $*$ & $*$ & $* *$ \\
\hline Breen \& Zuckerman (1999) & GABS & Comprehensive & $* *$ & & & $*$ & & $*$ \\
\hline Moore \& Ohtsuka (1999) & BAC & $\begin{array}{l}\text { Control over } \\
\text { Gambling }\end{array}$ & $* *$ & & $* *$ & $*$ & & \\
\hline Ferland et al (2002) & QABQ & Comprehensive & $*$ & & & $*$ & & $*$ \\
\hline Steenbergh et al. (2002) & GBQ & Comprehensive & $* *$ & $* *$ & & $*$ & & $*$ \\
\hline Williams (2003) & GFM & Comprehensive & $*$ & $* *$ & $* *$ & $*$ & $*$ & $* *$ \\
\hline Joukhador et al. (2003) & GBQ2 & Comprehensive & & & & $*$ & & $*$ \\
\hline Joukhador et al. (2004) & SBG & Superstitions & & & $*$ & $*$ & & \\
\hline Jefferson \& Nicki, (2004) & IBS & Comprehensive & $* *$ & & & $*$ & & $*$ \\
\hline Raylu \& Oei (2004) & GRCS & Comprehensive & $* *$ & & & $*$ & & $* *$ \\
\hline Wohl et al. (2005) & PPLS & Personal luck & $* *$ & & & $*$ & & \\
\hline Wood \& Clapham (2005) & DBC & Chance & $* *$ & & & $*$ & & $*$ \\
\hline Andre (2006) & -- & $\begin{array}{l}\text { Fortune, Luck, } \\
\text { Opportunity }\end{array}$ & $* *$ & & $*$ & $*$ & $*$ & \\
\hline Maltby et al. (2008) & BALS & Luck & $* *$ & & $* *$ & $*$ & $*$ & \\
\hline Xian et al. (2008) & GRCD & Comprehensive & $* *$ & & & $*$ & & \\
\hline Wohl et al (2011) & PLUS & Personal luck & & & $* *$ & $*$ & & \\
\hline $\begin{array}{l}\text { Thompson \& Prendergast } \\
\text { (2013) }\end{array}$ & BLLS & Luck & & $*$ & $* *$ & $*$ & $*$ & $* *$ \\
\hline McInnes et al. (2014) & GCI & Comprehensive & $* *$ & & & $*$ & $*$ & $*$ \\
\hline
\end{tabular}

Note: Blank cell $=$ inadequate or not reported, $*=$ adequate $(.60-.69) * *=$ good or excellent $(.70$ and higher $)$. 
gambling), motivations (e.g., gambling to improve mood), biases (e.g., choosing to focus on wins rather than losses), or behaviours (e.g., chasing losses). The GFM appears to be the only comprehensive instrument that does not have these problems. To be fair, some of these comprehensive instruments were likely designed to assess more general motivations, behaviours, and biases rather than strictly erroneous beliefs about gambling. Although this may be true, it is also true that understanding the relationship between gambling and gambling-related errors in thinking requires an unambiguous measure of these errors in thinking.

The inclusion of items measuring problem gambling tendencies in most of these comprehensive instruments almost certainly inflates their statistical association with problem gambling and draws into question the previously established "robust association" between gambling fallacies and problem gambling reported in a recent metaanalysis of this relationship by (Goodie \& Fortune, 2013). This, in turn, casts some doubt on the cognitive model of problem gambling which posits that erroneous gamblingrelated cognitions are key in the development and maintenance of problem gambling (e.g., Fortune \& Goodie, 2012; Ladouceur et al., 2001, 1998; Toneatto, 2002; Williams, West, et al., 2012).

Reassuringly, the GFM, a purer measure of fallacies, has still typically obtained significant relationships with both gambling and problem gambling in diverse samples. However, the magnitude of these correlations has been very low and sometimes nonsignificant $(-.03-.16)$.

Furthermore, it is important to remember that this research, indeed, all research documenting a relationship between problem gambling and gambling fallacies has been 
cross-sectional and correlational in nature. The co-occurrence of gambling fallacies and problem gambling does not establish whether gambling fallacies caused problem gambling, or whether problem gambling caused gambling fallacies, or whether they developed at the same time. The only way of disentangling this relationship is through longitudinal research. However, to date there has never been a published longitudinal study showing that high levels of gambling fallacies creates risk for subsequent development of problem gambling. Re-examination of this relationship using improved instrumentation in a longitudinal context is required. 


\section{CHAPTER THREE. THE RELATIONSHIP BETWEEN GAMBLING FALLACIES AND PROBLEM GAMBLING}

Leonard, C.A., \& Williams, R.J. (2016). The relationship between gambling fallacies and problem gambling. Psychology of Addictive Behavior, 30 (6), 694-704.

\subsection{ABSTRACT}

The cognitive model of problem gambling posits that erroneous gambling-related fallacies are key in the development and maintenance of problem gambling. However, this contention is based on cross-sectional rather than longitudinal associations between these constructs, and gambling fallacy instruments that may have inflated this associated by their inclusion of problem gambling symptomatology. The current research reevaluates the relationship between problem gambling and gambling specific erroneous cognitions in a five-year longitudinal study of gambling using a psychometrically sound measure of erroneous gambling-related cognitions. The sample used in this study $(n=$ $4,121)$, was recruited from the general population in Ontario, Canada, and the retention rate over five years was exceptionally high (93.9\%). The total sample was similar, in age and gender distributions, to the census data at the time of data collection for Canadian adults (18-24 years, $n=265,55.8 \%$ female; $25-44$ years, $n=1667,56.4 \%$ female; $45-64$ years, $n=1731,55.4 \%$ female; $65+$ years, $n=458,44.75 \%$ female). Results of both cross-sectional and longitudinal analyses confirm that gambling specific fallacies appear to be etiologically related to the subsequent appearance of problem gambling, but to a weaker degree than previously presumed, and in a bidirectional manner.

Keywords: gambling, problem gambling, cognitive error, gambling fallacy, illusion of control. 


\subsection{INTRODUCTION}

Erroneous beliefs about gambling, also known as 'gambling fallacies' and 'cognitive errors/distortions', have long been thought to have an etiological role in both the onset of gambling and the development of problem gambling (Blaszczynski \& Nower, 2002; Delfabbro, 2004; Delfabbro \& Winefeld, 2000; Gaboury \& Ladouceur, 1989; Goodie \& Fortune, 2013; Jacobsen et al., 2007; Joukhador et al., 2003; MacKay \& Hodgins, 2012; Miller \& Currie, 2008; Myrseth, Brunborg, \& Eidem, 2010; Toneatto et al., 1997; Wohl, Young, \& Hart, 2007; Xian et al., 2008). Following on this belief, correcting erroneous gambling cognitions is central to many programs designed to prevent and/or treat problem gambling (Fortune \& Goodie, 2012; Ladouceur et al., 2001; Ladouceur, Sylvain, Boutin, \& Doucet, 2002; Ladouceur et al., 1998; Toneatto, 2002).

However, there are some problems with this assumption. First, all of the research documenting a relationship between problem gambling and gambling fallacies has been cross-sectional and correlational in nature. The co-occurrence of gambling fallacies and problem gambling does not establish whether gambling fallacies caused problem gambling, or whether problem gambling caused gambling fallacies, or whether they developed at the same time. The only way of disentangling this relationship is through longitudinal research. However, to date there has never been a published longitudinal study showing that high levels of gambling fallacies creates risk for subsequent development of problem gambling.

Second, most instruments designed to comprehensively assess gambling fallacies have weak construct validity (Leonard, Williams, et al., 2015). One issue concerns insufficient coverage of the gambling fallacies. While it has been common to include the 
'hot hand fallacy', Monte-Carlo fallacy ${ }^{3}$, and 'illusion of control', many of these instruments do not assess the belief that luck is dispositional, base rate neglect, and insensitivity to sample size (Leonard, Williams, et al., 2015) ${ }^{4}$. Another issue is that some of these instruments include questions that wrongly presume that no skill is involved in any form of gambling and/or fail to specify that the questions only pertain to pure chance games (i.e., Gambling Belief Questionnaire - GBQ, Joukhador et al., 2003; Steenbergh et al., 2002; Gambling Cognitions Inventory; (McInnes et al., 2014). ${ }^{5}$ However, the most serious problem is that virtually all of these instruments include extraneous questions concerning general gambling motivations (e.g., gambling to improve mood), biases (e.g., choosing to focus on wins rather than losses); and problem gambling symptomatology (e.g., chasing losses, lying to loved ones, preoccupation, etc.). ${ }^{6}$ These instruments almost certainly inflate the association between problem gambling and gambling fallacies because of having some of the same items in both measures. ${ }^{7}$ Thus, although a recent

\footnotetext{
${ }^{3}$ Also known as the 'gambler's fallacy'.

${ }^{4}$ The hot hand fallacy is the belief that success in a series of random events (e.g., dice rolls in craps) predicts further success, or that a streak of random outcomes predicts continuation of the streak (e.g., a series of reds in roulette increases the likelihood of more reds). The Monte Carlo fallacy is the opposite of the hot hand fallacy, whereby the person believes that a streak of random outcomes (red in roulette) causes an increasing likelihood of chance correcting itself and the opposite outcome occurring (i.e., black). The illusion of control is the belief that one's actions can exert influence chance events (e.g., choosing ones lottery numbers being preferable to having them randomly determined). The luck is dispositional belief is the sentiment that luck consistently favors some things over others (e.g., numbers, colors, people, etc.). Base rate neglect is not knowing the long-term odds or being insensitive to them (e.g., believing that playing electronic gambling machines is a good way to make money). Insensitivity to sample size is the failure to appreciate that deviation from long-term odds (e.g. winning streaks) are common in short time periods but increasingly rare with longer time periods.

${ }^{5}$ Sports betting, horse race handicapping, and certain card games (e.g., poker) involve an element of skill (e.g., Leonard, Staples, \& Williams, 2015).

${ }^{6}$ These extraneous questions are seen in the Gambling Attitudes and Beliefs Survey (Breen \& Zuckerman, 1999); Questionnaire of Attitudes and Beliefs about Gambling (QABQ; Ferland, Ladouceur, \& Vitaro, 2002); Gambling Belief Questionnaire (Steenbergh et al., 2002); Informational Bias Scale (Jefferson, Doiron, Nicki, \& MacLean, 2004; Jefferson \& Nicki, 2003); Gambling Related Cognitions Scale (Raylu \& Oei, 2004); Gambling Related Cognitive Distortions (Xian et al., 2008); Gambling Cognitions Inventory (McInnes, Hodgins, \& Holub, 2014).

${ }^{7}$ To be fair, some of these instruments were likely designed to assess more general motivations, behaviours, and biases rather than strictly gambling fallacies. While this may be true, it is also true that
} 
meta-analysis (Goodie \& Fortune, 2013) concluded there to be a "robust association" between problem gambling and gambling fallacies (as measured by the aforementioned instruments $)^{8}$, this conclusion may be premature in light of this confound.

The primary purpose of the current research is to re-evaluate the relationship between problem gambling and gambling specific fallacies in a five-year longitudinal dataset of gambling using a measure designed to capture solely erroneous gamblingrelated cognitions ('Gambling Fallacies Measure'; Leonard, Williams, et al., 2015; Williams, 2003).

\subsection{METHOD}

\subsubsection{Sample}

A secondary analysis of the Quinte Longitudinal Study (QLS; Williams et al., 2015) was undertaken. The QLS was a prospective study of gambling and problem gambling conducted in Ontario, Canada from 2006 to 2011, in a geographic region with very similar gambling opportunities to the rest of Canada. The sample $(n=4,121)$ was recruited from the general population via random digit telephone dialing. Age $(18-24 ; 25-$ $44 ; 45-64 ; 65+$ ) by gender (male; female) quotas were used to ensure the sample was roughly representative of the demographic profile of the Canadian adult population. Twenty-one percent of the sample $(n=1,056)$ was recruited concurrent to the main sample based on having a higher level of gambling involvement. No demographic quotas were used for this subsample. An overall response rate of $21.3 \%$ was attained. The cohort was assessed annually over five years. Assessments were computerized and self-

understanding the relationship between gambling and gambling-related errors in thinking requires an unambiguous measure of these errors in thinking.

${ }^{8}$ The Hedge's g effect size of the relationship between cognitive distortions and gambling severity ranged between .77 to 2.5 depending on the cognitive distortion instrument. 
administered and were completed either online at the person's home or at the QLS office. An exceptionally high retention rate of $93.9 \%$ after five years was achieved.

\subsubsection{Measures}

The QLS assessment collected comprehensive annual information on demographics, gambling behaviour, gambling fallacies, problem gambling, physical health, mental health, substance use and abuse, stressors, personal values, social functioning, personality, leisure activity, and intelligence (roughly 135 variables).

\subsubsection{Gambling Fallacies Measure (Leonard, Williams, et al., 2015; Williams, 2003)}

The GFM consists of 10 multiple-choice items, each with only one correct answer (see Appendix A). Scores on this measure are the summation of correct responses, with higher scores denoting higher resistance to gambling fallacies. The GFM comprehensively assesses all of the main gambling fallacies: hot hand fallacy; MonteCarlo fallacy; belief that luck is dispositional; illusion of control; insensitivity to sample size; and base rate neglect. The GFM, designed to capture solely gambling specific fallacious thought, does not include any non-fallacious motivations, attitudes, biases or problem gambling behaviours (Leonard, Williams, et al., 2015). Factor analysis across multiple datasets, including the present dataset, has found a two factor solution to be most consistent (with some degree of correlation between the factors): a failure to understand the random and uncontrollable nature of most gambling games (questions $1,2,3,4,5,8,9,10)$ and a failure to take statistical probabilities into account (questions 6,7). The hierarchical coefficient omega for this measure within the present data set indicates adequate internal consistency (.61) (Dunn et al., 2014). The overall one-month test-retest reliability of the instrument is good (.70). The measure has been successfully employed 
in multiple samples comprising over 17,000 people, with these samples spanning ages 13 - 89, dozens of different countries, and including over 1,000 problem gamblers (elGuebaly et al., 2015; Williams et al., 2015, 2013, 2010; Wood \& Williams, 2009). Depending on the dataset, GFM scores have been found to be consistently and significantly associated with variables that theoretically should be related to a poor understanding of how gambling works (i.e., gambling fallacies): intelligence $(r=.25)$; educational attainment ( $r=.10$ to .27$)$; paranormal beliefs ( $r=-.14$ to -.22$)$; and gambling 'to win money' as a primary motivation $(r=-.11)$. Although the magnitude of these relationships is fairly low, it is remains an empirical question as to how strong the associations between these theoretically related constructs should actually be. Discriminant validity has been demonstrated with findings of near zero associations between GFM scores and marital satisfaction, general life happiness, and past year perceived stress.

\subsubsection{Problem and Pathological Gambling Measure (PPGM; Williams \& Volberg,} 2010, 2014)

Problem gambling was assessed with the Problem and Pathological Gambling Measure (PPGM; Williams \& Volberg, 2010, 2014; see Appendix B), which is a 14-item instrument designed for use in both clinical samples and population surveys. The PPGM classifies people into 5 categories: non-gambler; recreational gambler; at risk gambler; problem gambler; and pathological gambler (Williams \& Volberg, 2010, 2014). The PPGM has demonstrated good internal consistency (Cronbach alpha $=.76-.81$ depending on the dataset) as well as one-month test-retest reliability $(r=.78$; Williams \& Volberg, 2010, 2014). Most importantly, Williams and Volberg $(2010,2014)$ found the 
PPGM to have excellent sensitivity, specificity, and overall classification accuracy $($ Cohen's kappa $=.96)$ relative to clinical assessment of problem gambling status.

The focus of the present study was on the relationship between gambling fallacies and problem gambling, However, to better contextualize the relative importance of gambling fallacies as a predictor of problem gambling a small number of other variables with a well-established cross-sectional (Williams, Volberg, \& Stevens, 2012) and/or prospective relationship with problem gambling (Volberg \& Williams, 2013; Williams et al., 2015) were included in the analyses:

\subsubsection{Number of Gambling Formats Engaged in Within Past Year}

Participants were asked about their past year participation in lottery tickets; instant win tickets; electronic gambling machines; casino table games; games of skill for money against other people; sports betting; horse or dog racing; high risk stocks, option futures or day trading; internet gambling; and 'any other' forms of gambling. An aggregate measure of number of types of gambling engaged in was calculated (range of 0 to 11$)$.

\subsubsection{Frequency of Gambling in Past Year}

For each type of gambling a person engaged in they were asked about the number

of days in a typical month within the past year they participated. An aggregate measure of past year gambling frequency was calculated by adding up the number of days reported for each type (capped at 30) and multiplying this value by 12 .

\subsubsection{Net Aggregate Gambling Expenditure in Past Year}


An aggregate measure of gambling expenditure was calculated by adding up the reported expenditures on each type of gambling (in a typical month in the past year) and multiplying this value by 12 .

\subsubsection{Biggest Gambling Win in Past Year}

All participants were asked to identify the largest amount of money they had won on gambling on a single day in the past 12 months.

\subsubsection{One or More Family Members being Problem Gamblers while Growing up}

All participants were asked whether any of their family members were regular gamblers when they were growing up. Individuals who indicated yes were then asked:

"Were any of these people 'problem gambler(s)? Someone is a "problem gambler' if significant problems (e.g., psychological, health, financial, school/employment, social, illegal activity) have occurred to the individual, someone in the person's immediate social network, or for the person's community as a consequence of that person's gambling".

Response options available were yes, no, and unsure (yes and unsure were collapsed into a single category).

\subsubsection{Impulsivity}

Personality was assessed with the Impulsivity facet from the NEO Personality Inventory - Revised (NEO PI-R) (Costa \& McCrae, 1992). The NEO is currently the dominant instrument in the assessment of personality, providing a score in the 5 major personality domains of introversion versus extraversion; neuroticism versus emotional stability; openness versus close-mindedness; and conscientiousness versus lack of conscientiousness. Impulsivity is one of the facets of the neuroticism versus emotional stability domain. Internal reliability of the NEO-PI-R domain scores are known to be high, ranging from .86 to .92 , and the internal reliabilities of the facets range from .58 
to .82 (Costa \& McCrae, 1992). The concurrent and discriminant validity of the NEO has been well established in both normal and clinical populations (Costa \& McCrae, 1992).

\subsubsection{Analysis}

The relationship between gambling fallacies and problem gambling was examined cross-sectionally within each assessment period, as well as prospectively (i.e., gambling fallacies in one assessment period in relation to problem gambling in the next assessment period). Given the large sample size, and in consideration of the multiple planned analyses, a priori alpha level of $\alpha=0.01$ was set for all analyses. In addition, and in acknowledgement of the difference between clinical and statistical significance, associations lower than 0.17 will be considered 'weak' (Hemphill, 2003). As a couple of the variables were quite skewed (biggest gambling win in past year, net gambling expenditure), non-parametric and semi-parametric tests were used for all analyses and previous year big win and net gambling expenditure were winsorized to reduce the impact of outliers.

Three cross-sectional analyses were undertaken: a) the association (i.e., tau-b) between all variables in Assessment 1; b) Kruskal-Wallis tests to evaluate differences in gambling fallacies scores as a function of PPGM gambling category for each assessment year; and c) a generalized estimating equation (GEE) to evaluate the relationship between gambling fallacies, gambling involvement, biggest win, family history of problem gambling, impulsivity, and concurrent PPGM gambling category.

Three prospective analyses were conducted. The first was a comparison of gambling fallacy scores of individuals who became problem or pathological gamblers in the following assessment to the fallacy scores of individuals who remained non- 
problem/pathological gamblers (using a Mann-Whitney $U$ test). The second was a lagged GEE to evaluate the relationship between all aforementioned variables, and future PPGM gambling category. The third was a lagged GEE to evaluate the ability of these variables to predict future GFM scores.

\subsection{RESULTS}

Descriptive statistics for each of the variables and sample sizes (overall and by gambling category) for each year are reported in Table 1 . Table 2 presents a matrix of the tau-b associations between all variables.

\subsubsection{Cross-Sectional Results}

Table 3 displays the mean GFM score by year for each PPGM gambling category (i.e., non-gambler, recreational gambler, at risk gambler, problem gambler, pathological gambler). As can be seen, GFM scores are consistently highest among non-gamblers and lowest among pathological gamblers. A Kruskal-Wallis test found significant differences in GFM scores between PPGM gambling categories in all years: Year 1: $X^{2}(4, N=$ $4,120)=87.91, p<.01 ;$ Year $2, X^{2}(4, N=3,936)=95.74, p<.01 ;$ Year $4, X^{2}(4, N=$ $3,823)=48.53, p<.01$; Year $5, X^{2}(4, N=3,797)=68.15, p<.01$. In all years this represented more fallacies among problem and pathological gamblers with progressively fewer fallacies among at-risk gamblers, recreational gamblers, and non-gamblers.

Although there are consistent differences in gambling fallacies as a function of gambling category, the magnitude of the differences is relatively small, ranging from a raw score difference of only 0.99 to 1.47 between non-gamblers and pathological 
Table 3.1 Descriptive Statistics for Each Variable by Assessment Year

\begin{tabular}{|c|c|c|c|c|c|c|c|c|c|c|c|c|c|}
\hline Year & $N$ & GFM $^{\mathrm{a}}$ & 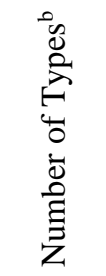 & 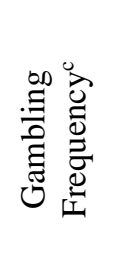 & 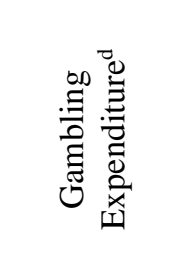 & 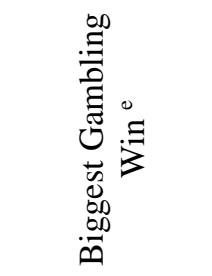 & 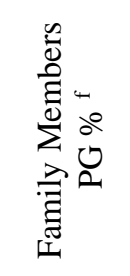 & 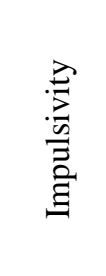 & 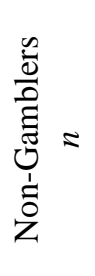 & 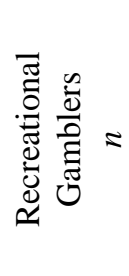 & 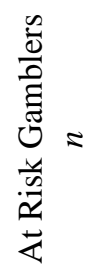 & 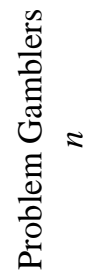 & 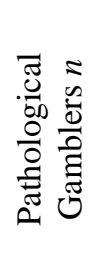 \\
\hline 2 & 3940 & $\begin{array}{c}7.14 \\
(1.39)\end{array}$ & $\begin{array}{c}2.95 \\
(1.71)\end{array}$ & $\begin{array}{c}74.8 \\
(84.5)\end{array}$ & $\begin{array}{l}-\$ 2,231 \\
(43,291)\end{array}$ & $\begin{array}{c}\$ 26,051 \\
(\$ 1,593,956)\end{array}$ & $19.82 \%$ & $\begin{array}{l}46.51 \\
(9.79)\end{array}$ & 298 & 3092 & 436 & 70 & 43 \\
\hline 3 & 3905 & na & $\begin{array}{l}2.60 \\
(1.58)\end{array}$ & $\begin{array}{c}70.1 \\
(83.3)\end{array}$ & $\begin{array}{l}-\$ 3,685 \\
(64,793)\end{array}$ & $\begin{array}{c}\$ 500 \\
(\$ 4418)\end{array}$ & $19.90 \%$ & $\begin{array}{l}46.25 \\
(9.97)\end{array}$ & 363 & 3034 & 401 & 71 & 32 \\
\hline 5 & 3801 & $\begin{array}{c}7.34 \\
(1.27)\end{array}$ & $\begin{array}{l}2.44 \\
(1.55)\end{array}$ & $\begin{array}{c}64.9 \\
(79.6)\end{array}$ & $\begin{array}{l}-\$ 1,143 \\
(45,142)\end{array}$ & $\begin{array}{l}\$ 2.6330 \mathrm{E}+60 \\
(\$ 1.623 \mathrm{E}+62)\end{array}$ & $19.96 \%$ & $\begin{array}{l}46.54 \\
(9.79)\end{array}$ & 406 & 2951 & 365 & 43 & 34 \\
\hline
\end{tabular}

a. Gambling Fallacies Measure. Range $=0$ to 10. Higher scores indicate greater resistance to gambling fallacies and lower scores indicate greater endorsement of gambling fallacies. Average score and (standard deviation) reported. The GFM was not administered in Year 3.

b. Number of different types of games gambled on in past year. Range 0 to 11 . Average number of types and (standard deviation) reported.

c. Total number of days in the past year gambling for all types of gambling combined. Range $=0$ to 365 . Average score and (standard deviation) reported. d. Net gambling expenditure on all types of gambling in the past year in Canadian dollars. Negative sign indicates net loss. Average net loss and (standard deviation) reported. Note that the data reported are the unwinsorized averages and standard deviations and that a few large outliers have a major influence. e. Unwinsored biggest gambling win in past year.

f. Percentage of respondents reporting growing up with a family member who was a problem gambler. 
Table 3.2 Association between all Variables in Assessment 1

\begin{tabular}{|c|c|c|c|c|c|c|c|c|c|c|c|c|}
\hline & 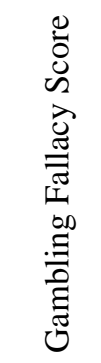 & 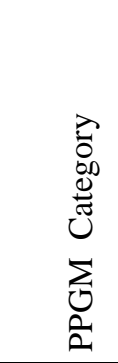 & 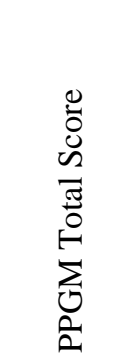 & 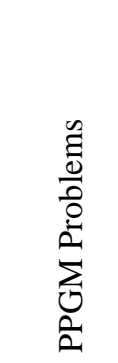 & 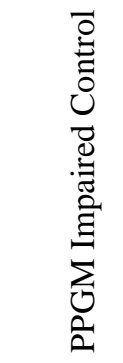 & $\begin{array}{l}\bar{\Xi} \\
\stackrel{ \pm}{0} \\
\sum_{0}^{0} \\
0\end{array}$ & 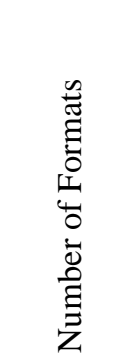 & 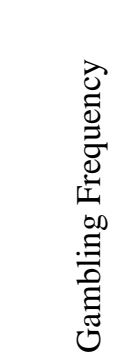 & 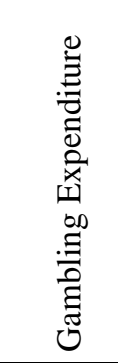 & 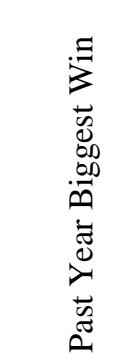 & 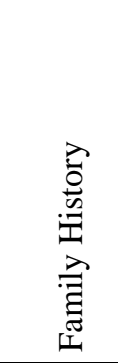 & 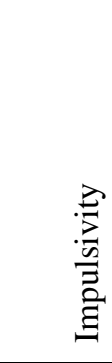 \\
\hline Gambling Fallacy Score & 1.000 & $-.125^{* *}$ & $-.126^{* *}$ & $-.097^{* *}$ & $-.092^{* *}$ & $-.082^{* *}$ & $-.076^{* *}$ & $-.102^{* *}$ & $.073^{* *}$ & $-.038^{* *}$ & $-.066^{*}$ & $-.065^{* *}$ \\
\hline PPGM Category & & 1.000 & $.908^{* *}$ & $.586^{* *}$ & $.712^{* *}$ & $.581^{* *}$ & $.433^{* *}$ & $.450^{* *}$ & $-.303^{* *}$ & $.393^{* *}$ & .020 & $.137^{* *}$ \\
\hline PPGM Total Score & & & 1.000 & $.628^{* *}$ & $.762^{* *}$ & $.647^{* *}$ & $.205^{* *}$ & $.212^{* *}$ & $-.162^{* *}$ & $.241^{* *}$ & $.107^{* *}$ & $.171^{* *}$ \\
\hline PPGM Problems & & & & 1.000 & $.363^{* *}$ & $.355^{* *}$ & $.101^{* *}$ & $.147^{* *}$ & $-.116^{* *}$ & $.146^{* *}$ & $.194^{* *}$ & $.145^{* *}$ \\
\hline PPGM Impaired Control & & & & & 1.000 & $.368^{* *}$ & $.188^{* *}$ & $.178^{* *}$ & $-.156^{* *}$ & $.222^{* *}$ & .047 & $.133^{* *}$ \\
\hline PPGM Other & & & & & & 1.000 & $.131^{* *}$ & $.151^{* *}$ & $-.095^{* *}$ & $.169^{* *}$ & $.081^{*}$ & $.141^{* *}$ \\
\hline Number of Formats & & & & & & & 1.000 & $.590^{* *}$ & $-.318^{* *}$ & $.449^{* *}$ & $-.092^{* *}$ & $.080^{* *}$ \\
\hline Gambling Frequency & & & & & & & & 1.000 & $-.331^{* *}$ & $.413^{* *}$ & $-.095^{* *}$ & $.061^{* *}$ \\
\hline Gambling Expenditure & & & & & & & & & 1.000 & $-.264^{* *}$ & .013 & $-.044^{* *}$ \\
\hline Past Year Biggest Win & & & & & & & & & & 1.000 & -.042 & $.037^{* *}$ \\
\hline Family History & & & & & & & & & & & 1.000 & $.057^{*}$ \\
\hline Impulsivity & & & & & & & & & & & & 1.000 \\
\hline
\end{tabular}

Note: Tau-b measure of association reported. Significant two-tailed associations indicated by: **.01, and * .05. 
Table 3.3 Gambling Fallacy Measure Scores by Assessment Year and Gambling Category

\begin{tabular}{|c|c|c|c|c|c|c|}
\hline & Non-Gambler & $\begin{array}{c}\text { Recreational } \\
\text { Gambler }\end{array}$ & $\begin{array}{l}\text { At Risk } \\
\text { Gambler }\end{array}$ & $\begin{array}{l}\text { Problem } \\
\text { Gambler }\end{array}$ & $\begin{array}{c}\text { Pathological } \\
\text { Gambler }\end{array}$ & \\
\hline Year & $\begin{array}{c}M(\mathrm{SD}) \\
\text { Range }\end{array}$ & $\begin{array}{c}M(\mathrm{SD}) \\
\text { Range }\end{array}$ & $\begin{array}{c}M(\mathrm{SD}) \\
\text { Range }\end{array}$ & $\begin{array}{c}M(\mathrm{SD}) \\
\text { Range }\end{array}$ & $\begin{array}{c}M(\mathrm{SD}) \\
\text { Range }\end{array}$ & $X^{2}$ \\
\hline 1 & $\begin{array}{c}7.22(1.31) \\
2,10\end{array}$ & $\begin{array}{c}6.97(1.40) \\
1,10\end{array}$ & $\begin{array}{c}6.42(1.79) \\
0,10\end{array}$ & $\begin{array}{c}6.26(1.76) \\
1,10\end{array}$ & $\begin{array}{c}6.06(2.08) \\
0,10\end{array}$ & $87.9 * *$ \\
\hline 2 & $\begin{array}{c}7.49(1.16) \\
2,10\end{array}$ & $\begin{array}{c}7.20(1.31) \\
0,10\end{array}$ & $\begin{array}{c}6.69(1.71) \\
1,10\end{array}$ & $\begin{array}{c}6.34(1.84) \\
1,10\end{array}$ & $\begin{array}{c}6.02(1.90) \\
0,9\end{array}$ & $95.7 * *$ \\
\hline 3 & na & na & na & na & na & na \\
\hline 4 & $\begin{array}{c}7.44(1.27) \\
2,10\end{array}$ & $\begin{array}{c}7.28(1.30) \\
0,10\end{array}$ & $\begin{array}{c}6.90(1.56) \\
2,10\end{array}$ & $\begin{array}{c}6.80(1.69) \\
1,10\end{array}$ & $\begin{array}{c}6.40(2.15) \\
0,10\end{array}$ & $48.5^{* *}$ \\
\hline 5 & $\begin{array}{c}7.57(1.13) \\
1,10\end{array}$ & $\begin{array}{c}7.37(1.02) \\
1,10\end{array}$ & $\begin{array}{c}7.00(1.50) \\
2,10\end{array}$ & $\begin{array}{c}6.33(2.14) \\
2,10\end{array}$ & $\begin{array}{c}6.26(2.04) \\
1,9\end{array}$ & $68.1 * *$ \\
\hline
\end{tabular}

Note: Gambling status based on Problem and Pathological Gambling Measure scores. $M=$ Mean Gambling Fallacy Measure (GFM) scores, standard deviation in parentheses. Range = minimum followed by maximum GFM score (Min, Max) for each gambling category within the assessment year. GFM scores not available in Year 3. $* * p<.01$. 
gamblers depending on the year. Furthermore, there is a wide range of GFM scores within each PPGM gambling category, including examples of pathological gamblers who endorse no gambling fallacies as well non-gamblers who endorse almost all gambling fallacies. Indeed, in Assessment 1, 10.2\% of pathological gamblers had a score of 9 or 10, compared to only $7.1 \%$ of non-gamblers and $5.8 \%$ of recreational gamblers.

A GEE was conducted to analyze the importance of gambling fallacies, relative to other included variables, in predicting concurrent PPGM gambling category in each of the five assessment periods. The independent variables entered into the model were GFM score, number of types of gambling engaged in, gambling frequency, gambling expenditure, biggest gambling win in past year, family members being problem gamblers, and impulsivity. The variable 'year' was also included to account for both repeated assessment effects (e.g., practice, or learning) and inter-period correlations between variables. As the GFM was not administered in Assessment 3, GFM values were imputed using the average of the person's GFM score from Assessment 2 and 4. In order of resultant Wald statistic, the following variables significantly predicted concurrent gambling category: gambling expenditure ( Wald $=2800.4, p<.001$ ), number of types of gambling $($ Wald $=634.9, p<.001)$; having a big win in past year $($ Wald $=467.9, p$ $<.001)$, gambling frequency $($ Wald $=314.0, p<.001)$, impulsivity $($ Wald $=76.6, p$ $<.001)$, GFM scores $($ Wald $=50.4, p<.001)$, and family members being problem gamblers while growing up $($ Wald $=20.9, p<.001)$. Year was not a significant predictor $($ Wald $=9.4, p=.052)$. 


\subsubsection{Prospective Results}

Table 4 reports the gambling fallacy scores of individuals who became problem or pathological gamblers in the next assessment relative to individuals who did not. People in the 'became problem or pathological gamblers in the next assessment' group consist of participants who did not meet criteria for PPGM problem or pathological gambling in any previous year; i.e., they became problem gamblers for the first time during the study. Problem gamblers who reported a lifetime history of problem gambling were also excluded from this group, as were problem gamblers missing prior year data, and problem gamblers who were problem gamblers in any previous assessment. People in the 'stayed non-problem gamblers in the next assessment' group consisted of everyone who was a non-gambler, recreational gambler, or at risk gambler in the prior assessment and continued to be either a non-gambler, recreational gambler, or at risk gambler in the next assessment. As can be seen, although the averages for the two groups are all in the expected direction, only one of these three comparisons is significant (Assessment 1 GFM scores predicting Assessment 2 problem gambling status). That being said, the small sample sizes in Assessment 2 and 4 limit statistical power (see Table 4).

A GEE was conducted to analyze the importance of gambling fallacies, relative to other included variables, in predicting future PPGM gambling category over the five assessment periods. Listed in order of the magnitude of the resultant Wald coefficient, the following variables significantly predicted PPGM gambling category in future assessments: number of types of gambling (Wald $=161.01, p<.001)$, gambling frequency $($ Wald $=116.26, p<.001)$, impulsivity $($ Wald $=74.94, p<.001)$, family members being problem gamblers while growing up (Wald $=55.92, p<.001)$ GFM 
Table 3.4 GFM Scores of Individuals who became Problem or Pathological Gamblers in the Next Assessment Compared to GFM Scores of Individuals who remained Non-Problem Gamblers in the Next Assessment.

\begin{tabular}{cccc}
\hline & $\begin{array}{c}\text { GFM Scores of } \\
\text { People who Became } \\
\text { Problem Gamblers } \\
\text { in Next Assessment }\end{array}$ & $\begin{array}{c}\text { GFM Scores of } \\
\text { People who Stayed } \\
\text { Non-Problem } \\
\text { Gamblers in Next } \\
\text { Assessment }\end{array}$ & Mann-Whitney $U$ \\
\hline Assessment 1 & $\begin{array}{c}6.35(1.69) \\
n=55\end{array}$ & $\begin{array}{c}6.92(1.47) \\
n=3826\end{array}$ & $\begin{array}{c}2.66, p=.008 \\
(2 \text { sided })\end{array}$ \\
Assessment 2 & $6.93(1.54)$ & $7.16(1.37)$ & $\begin{array}{c}99, p=.323 \\
(2 \text { sided })\end{array}$ \\
Assessment 3 & $n=40$ & $n=3741$ & na \\
Assessment 4 & na & na & $1.64, p=.104$ \\
& $6.42(2.11)$ & $7.26(1.33)$ & $(2$ sided $)$ \\
\end{tabular}

Note: GFM was not evaluated in the $3^{\text {rd }}$ annual assessment. 
scores $($ Wald $=30.37, p<.001)$, gambling expenditure $($ Wald $=20.33, p<.001)$, having a big win in past year $($ Wald $=5.53, p<.001)$, and assessment year $($ Wald $=4.53, p>.01)$.

For comparison purposes, all of the above variables were used as independent variables in their ability to predict future GFM scores. Listed in order of the magnitude of resultant Wald coefficient, the following variables significantly predicted gambling fallacies in future assessments: gambling expenditure ( Wald $=783.43, p<.001)$, having a big win in past year $($ Wald $=286.17, p<.001)$, year $($ Wald $=99.60, p<.001)$, impulsivity $($ Wald $=17.54, p<.001)$, PPGM gambling category $($ Wald $=12.70, p<.001)$, number of types of gambling (Wald $=6.37, p=.01$ ). Gambling frequency was not a significant predictor $($ Wald $=4.66, p=.03$ ), nor was having family members that were problem gamblers while growing up (Wald $=0.58, p>.05)$.

\subsection{DISCUSSION}

The cognitive model of problem gambling contends that susceptibility to gambling specific fallacious thought is key in the development and maintenance of problem gambling. This belief is based in part on a 'robust association' (Goodie \& Fortune, 2013) observed between problem gambling and instruments ostensibly measuring gambling fallacies. However, this evidence has been cross-sectional in nature and based on gambling fallacy instruments that have included confounding items such as gambling motivations, nongambling specific erroneous thought, problem gambling symptoms, and non-fallacious biases. Moreover, the inclusion of problem gambling symptomatology within some of these gambling fallacy measures has likely artificially inflated previously reported associations. The current research re-evaluated this relationship in a five-year longitudinal study of gambling using a measure 
designed to capture solely erroneous gambling-related cognitions.

Results confirmed there is a consistent significant relationship both crosssectionally and prospectively between gambling fallacies and problem gambling. That being said, the magnitude of the difference in gambling fallacy scores between nongamblers and problem/pathological gamblers was relatively small and there was considerable variability of scores within each category, with many nongamblers having high levels of fallacies and many pathological gamblers evidencing no fallacies. In general, gambling fallacies appear prevalent in the general population, albeit more common amongst problem/pathological gamblers. Gambling fallacies were also not a strong predictor of both concurrent and future gambling category relative to measures of gambling involvement (i.e., number of types engaged in, frequency), having a big win in the past year, impulsivity, and family history of problem gambling. Not only is the predictive relationship relatively modest, but there is evidence of bidirectionality, with gambling expenditure and having a big win being important predictors of future GFM scores (along with a few other variables). The implication here is that gambling engagement also facilitates the development of gambling fallacies (e.g., Cote, Caron, Aubert, Desrochers, \& Ladouceur, 2003; Ladouceur \& Sévigny, 2005; Wohl \& Enzle, 2003).

The relatively modest influence of gambling fallacies on problem gambling makes sense from two perspectives. First, problem gamblers' over-involvement in gambling does not appear to be primarily due to a fallacious belief that they can win money over the long run, only $52 \%$ of problem and pathological gamblers reported this to be one of their primary motivations in the present dataset (see also (Neighbors, Lostutter, 
Cronce, \& Larimer, 2002; Nower \& Blaszczynski, 2010; Williams et al., 2015). Rather, the primary motivation for most problem gamblers is the same as recreational gamblers, which is 'for excitement/fun', with another significant minority reporting gambling primarily 'to escape' ( $65 \%$ and $23 \%$ respectively in the present dataset; see also Ledgerwood \& Petry, 2006; Neighbors et al., 2002; Nower \& Blaszczynski, 2010; Williams et al., 2015; Wood \& Griffiths, 2007).

Second, addictions tend to have a biopsychosocial etiology, with there being a large number of both risk and protective factors (Kumpfer, Trunnell, \& Whiteside, 1990; Marlatt, Baer, Donovan, \& Kivlahan, 1988; Wallace, 1993). Recent large-scale longitudinal studies (Billi, Stone, Marden, \& Yeung, 2014; el-Guebaly et al., 2015; Romild, Volberg, \& Abbott, 2014; Williams et al., 2015) have shown this to be also true of problem gambling. These studies have found there is no single variable overwhelmingly present in future problem gamblers and absent in people who do not become problem gamblers. Rather there are dozens of different variables that each increase risk of future problem gambling, and are present to differing degrees in future problem gamblers. Gambling fallacies are simply one of these variables (el-Guebaly et al., 2015; Williams et al., 2015).

Thus, although gambling fallacies are etiologically related to problem gambling, there will always be limited utility to problem gambling prevention and intervention methods that rely exclusively on rectifying erroneous beliefs about the odds involved or how gambling works (see also Williams \& Connolly, 2006). Rather, as is the case with addictions more generally, effective prevention of problem gambling requires the 
employment of a wide array of educational and policy initiatives to address its multifaceted biopsychosocial etiology (Williams, West, et al., 2012; Williams et al., 2010). Despite the strengths of the current research design, there are a couple of limitations that require acknowledgement. First, the overall response rate for the QLS sample recruitment was low. Second, both the GFM and the PPGM are relatively new instruments that have not received extensive independent validation. Future research should attempt to replicate (or refute) the present findings using alternative assessment measures. 


\section{CHAPTER FOUR. FALLACIOUS BELIEFS: GAMBLING SPECIFIC AND BELIEF IN THE PARANORMAL}

Leonard, C.A., \& Williams, R.J. (submitted to the Canadian Journal of Behavioural Science). Fallacious beliefs: Gambling specific and belief in the paranormal.

\subsection{PREAMBLE}

In the second study in this series (Chapter Three) it was demonstrated that gambling fallacies and problem gambling have a bidirectional relationship wherein gambling fallacies contribute to future problem gambling, but also that increased gambling involvement contributes to more gambling fallacies. It was also demonstrated that gambling fallacies are common throughout the general population, even among nongamblers. Thus, the question arose: Beyond gambling engagement, what individual differences contribute to susceptibility to gambling fallacies? Furthermore, as there are some general errors common to both gambling fallacies and paranormal beliefs (e.g., misperception of randomness), it was hypothesized that gambling fallacy susceptibility might be driven by a profile of individual differences similar to that of the paranormal believer.

\subsection{ABSTRACT}

Erroneous beliefs about gambling, known collectively as gambling fallacies, are known to be prevalent in the general population. However, relatively little is understood about the individual differences that lead to increased susceptibility to this collection of fallacious beliefs. It was hypothesized that factors responsible for gambling fallacies may be similar to factors that create susceptibility to other types of fallacious beliefs, such as belief in the paranormal. Using a sample of 266 Lethbridge community members and university students, the current study identified the individual differences associated with, 
and predictive of, endorsement of gambling fallacies. Comparisons were then made between these factors and the factors predicting belief in the paranormal. Consistent with our hypothesis, it was found that a very similar set of factors were predictive of belief in both gambling fallacies and paranormal phenomenon. More specifically, greater reliance on intuitive thought, a less rational cognitive style, and poorer probabilistic reasoning ability predicted both belief in the paranormal and endorsement of gambling fallacies. Directions for future research and interventions are discussed.

Keywords: individual differences, gambling fallacy, paranormal, risk factors, false belief

\subsection{INTRODUCTION}

Erroneous beliefs about gambling, known collectively as 'gambling fallacies', include gambling specific versions of the general Monte Carlo and Hot Hand fallacies, the Illusion of Control, belief in luck, as well as the misunderstanding or disregard of key statistical principles such as the law of large numbers and base rate neglect (Leonard \& Williams, 2016; Leonard, Williams, et al., 2015). It has been demonstrated that endorsement of these fallacies is prevalent in the general population (Leonard \& Williams, 2016). Research investigating these beliefs however, has focused predominantly on their etiological role in problem gambling where it has been shown that gambling fallacies play a weak but significant causal role in both the onset of gambling and the development of problem gambling (Delfabbro, 2004; Delfabbro \& Winefeld, 2000; Gaboury \& Ladouceur, 1989; Goodie \& Fortune, 2013; Jacobsen et al., 2007; Joukhador et al., 2003; Leonard \& Williams, 2016; MacKay \& Hodgins, 2012; Miller \& 
Currie, 2008; Myrseth et al., 2010; Toneatto et al., 1997; Wohl et al., 2007; Xian et al., 2008).

Within this area of research, there is a relative dearth of investigation into the factors that create susceptibility to gambling fallacies in the first place. Only two prospective studies have examined this issue, with both studies finding that greater gambling involvement was associated with greater development of gambling fallacies (Leonard \& Williams, 2016; Yakovenko et al., 2016). That being said, the reported associations in both studies were fairly weak. Otherwise, factors that contribute to gambling specific fallacious beliefs have been identified only indirectly or in association with a select few of these fallacies. For example, several interventions have been designed to correct these erroneous cognitions, (e.g., Williams \& Connolly, 2006; Williams et al., 2010). Virtually all of these studies have demonstrated that educating people about randomness, probability, base rates, and the effects of sample sizes does effectively reduce these fallacies. Studies investigating a limited scope of gambling specific fallacies, specifically the Monte Carlo fallacy (i.e., the classic Gambler's Fallacy), have also shown a negative association between this specific gambling fallacy and rational cognitive style and cognitive ability (Toplak et al., 2011; West \& Stanovich, 2003; West, Toplak, \& Stanovich, 2008). Thus, it would seem that probabilistic reasoning, or lack thereof, may also contribute to gambling fallacy susceptibility. What remains unknown, however, is whether gambling engagement and a general misunderstanding of statistics are the predominant, or the only, risk factors associated with gambling fallacy formation. It may be the case that there are additional individual 
characteristics that play an important role in gambling fallacy susceptibility, but this line of research is largely undeveloped.

Fallacious beliefs are not unique to gambling and, as such, the study of susceptibility factors for other fallacious beliefs, such as belief in the paranormal, may be informative. Paranormal phenomena are defined as beliefs for which there is no robust scientific evidence, as they ostensibly exist beyond the realm of natural science. Some examples include ghosts, PSI (extrasensory perception (ESP) and telekinesis), demons and demonic possession, spiritual healing, astrology, reincarnation, and magical powers. As is the case with gambling fallacies, belief in paranormal phenomenon are also fairly common in the general population. In the United States, over $70 \%$ of the general population believes in at least one paranormal phenomenon, and similar rates of belief are seen in Canada and the United Kingdom (Moore, 2005; Pechey \& Halligan, 2011; Tyson, Jones, \& Elcock, 2011).

There exists a substantial body of evidence that supports the contention that lower probabilistic reasoning ability also facilitates paranormal belief susceptibility (Blackmore \& Troscianko, 1985; Bressan, 2002; Brotherton \& French, 2014; Dagnall, Parker, \& Munley, 2007; Musch \& Ehrenberg, 2002; Pennycook, Cheyne, Koehler, \& Fugelsang, 2013; Rogers, Davis, \& Fisk, 2009; Rogers, Fisk, \& Wiltshire, 2011). Additional cognitive-based individual susceptibility factors have been identified. These include lower general intellectual ability (Messer \& Griggs, 1989; Musch \& Ehrenberg, 2002; Pennycook, Cheyne, Seli, Koehler, \& Fugelsang, 2012; Pennycook et al., 2013; Smith, Foster, \& Stovin, 1998), and lower analytic and higher intuitive cognitive style (Aarnio \& Lindeman, 2005; Gervais, 2015; Gervais \& Norenzayan, 2012; Leonard \& Williams, 
2017; Lindeman \& Aarnio, 2007; Pennycook et al., 2012, 2013; Svedholm \& Lindeman, 2013).

In addition to these cognitive factors, a few other individual differences have been associated with belief in the paranormal. With respect to personality, it has been found that paranormal believers are higher in the traits of extraversion (Rattet \& Bursik, 2000; Thalbourne, 1981; Thalbourne \& Haraldsson, 1980; Windholz \& Diamant, 1974), openness to experience (Smith, Johnson, \& Hathaway, 2009; Swami, ChamorroPremuzic, \& Shafi, 2010), and neuroticism (Fichten \& Sunerton, 1983; Leonard \& Williams, 2017; Thalbourne, Dunbar, \& Delin, 1995; Windholz \& Diamant, 1974). Beyond personality traits, it has been found that belief in paranormal phenomenon is associated with the demographic variables of younger age and female gender (Irwin, 2001; Lange \& Thalbourne., 2002; Leonard \& Williams, 2017; Messer \& Griggs, 1989; Rogers, Qualter, \& Wood, 2016), as well as lower educational attainment (Aarnio \& Lindeman, 2005; Blagrove, French, \& Jones, 2006; Otis \& Alcock, 1982).

Although gambling specific fallacies seem quite distinct from the belief in paranormal phenomenon, both types of beliefs are nonetheless fallacious. Furthermore, as alluded to earlier, it may be the case that the factors that facilitate susceptibility to all fallacious belief are similar, regardless of the phenomenon endorsed. This was the purpose of the present study: to determine whether the variables that best predict gambling fallacies are the same or different from the variables that best predict paranormal beliefs. It was hypothesized that the variables that best predict gambling fallacies would be similar to those that predict belief in the paranormal. 


\subsection{METHOD}

The sample for this study consisted of 266 participants recruited from both University of Lethbridge psychology students $\left(n=166 ; 71 \%\right.$ female; $M_{\text {age }}=22.06, S D=$ 5.40) and Lethbridge community members $\left(n=100 ; 29 \%\right.$ female; $M_{\text {age }}=28.50, S D=$ 14.46). The university student sample was recruited via advertisement on the university's psychology participant pool soliciting participation for a study of individual differences in decision-making biases and errors with students receiving $2 \%$ course credit for participation. The community sample was recruited via both word of mouth and poster advertisement for a study of individual differences in relationship to gambling and stock market trading. The community sample participated for a chance to win one of 5 prepaid visa cards (valued at $\$ 500, \$ 400, \$ 300, \$ 200$, or $\$ 100$, depending on performance on a behavioural measure of investment trading). All participants completed a selfadministered computerized survey that assessed intelligence, cognitive style, measures of biased thinking, gambling fallacies, delusional beliefs, belief in the paranormal and religiosity, personality, gambling engagement and problems, mental health, demographics, and risk taking behaviours. The student sample completed the survey remotely via an online link and the community sample completed the computerized survey in person at the University of Lethbridge. The measures of specific interest for the current study are detailed below. This study was reviewed and approved by the University of Lethbridge Human Subject Research Committee. The study was conducted from February 2016 to December 2016. 


\subsubsection{Materials}

4.4.1.1 Gambling Fallacies Measure (GFM) (Leonard \& Williams, 2016; Leonard, Williams, et al., 2015; Williams, 2003)

The Gambling Fallacies Measure is a 10 item questionnaire that assesses two factors: a) respondents' understanding of chance and randomness as illustrated by their resistance to the Illusion of Control, the Monte Carlo Fallacy, the Hot Hand Fallacy, and perceptions of personal luck (e.g., luck as a dispositional trait), as well as b) their knowledge of basic statistical principles (specifically, base rates and the law of large numbers). Higher scores indicate greater resistance to these fallacies. The hierarchical coefficient omega for this measure is adequate (.61), as is the one month test-retest reliability of $r=.70$ (Leonard, Williams, et al., 2015). The GFM also has well established content, convergent, discriminant, and external validity (Leonard, Williams, et al., 2015).

\subsubsection{Gambling Involvement}

Three measures of gambling involvement were collected. The first was the number of different types of gambling that participants had engaged in within the past year, ranging from 0 to 10 (i.e., lotteries, instant win games, electronic gambling machines, casino table games, poker, sports betting, horse or dog racing, bingo, private betting on other games (e.g., mah-jong, other card games, etc.), and 'other types of gambling not listed'). The second was frequency of involvement. For each type of gambling engaged in, participants were asked to indicate how many days in the past month they engaged in that format. The gambling frequency variable was calculated by summing the number of days participants reported engaging in each type of gambling (with a 30 day cap), and multiplying by 12 . The third was expenditure, with participants 
being asked to indicate their net win/loss in a typical month in the past year for each type of gambling engaged in. Total gambling expenditure was calculated by adding up the reported net expenditure (profits minus losses) for each type of gambling participants reported engaging in, and then multiplying this value by 12 .

\subsubsection{Revised Paranormal Belief Scale (RPBS) (Tobacyk, 2004)}

The 26 item RPBS assesses belief in 7 paranormal domains using a 7 point Likert type response scale with labeling endpoints $1=$ Strongly Disagree and $7=$ Strongly Agree. The typical scoring for the R-PBS yields scores for each of the seven paranormal belief domains, each derived by averaging domain specific items, and a global paranormal belief score (PBS) that is calculated from the sum of all domain scores. In the current study, only the global paranormal belief scores are used. Lower scores indicate greater disbelief; average scores indicate uncertainty, and higher scores indicating greater belief in paranormal phenomenon. Tobacyk (2004) reports very high (.92) 4-week test retest reliability for global paranormal belief scores. As noted, the R-PBS is a multi-factor measures, and there is debate regarding the factor structure of the paranormal belief domains measured within this instrument. Some suggest that instead of the originally identified seven factor/domains, there should be only five with the psychic items collapsed into one domain (Lawrence \& De Cicco, 1997; Lawrence, Roe, \& Williams, 1997), and others finding only two factors when Rasch scaling is applied (e.g., Lange, Irwin, \& Houran, 2000). Nonetheless, the current research makes use of the originally defined global paranormal belief scores and thus the factor structure of this instrument is of no concern.

4.4.1.4 Raven's Advanced Progressive Matrices: Set 1 (Raven, Raven, \& Court, 2000) 
Participants completed Set 1 of the Advanced Progressive Matrices. This set of matrices consists of 12 incomplete pictorial matrices and respondents are asked to indicate which of the provided 8 response options best fits the pattern. The split-half and test-retest reliabilities of the matrices are high (both >.80) (Raven et al., 2000), and adults' scores on this set correlate highly with scores on the revised WAIS full scale IQ ( $r$ $=.74+$ depending on age) (O’Leary, Rusch, \& Guastello, 1991). These matrices are also considered to be more culturally fair than other (similar) measures of general cognitive function (O'Leary et al., 1991). As per Set I administration, participants were given two un-scored practice matrices to ensure they understood the task. However, whereas this test is normally untimed, participants in the current study were given 15 minutes to complete the test.

\subsubsection{The Cognitive Reflection Test (CRT) (Frederick, 2005)}

The CRT is comprised of three questions each of which assesses intuitive (but erroneous) thinking versus reflective (correct) thinking. For example, the question: "In a lake, there is a patch of lily pads. Every day, the patch doubles in size. If it takes 48 days for the patch to cover the entire lake, how long would it take for the patch to cover half of the lake?" Whereas the intuitive but incorrect response is 24 days, the correct answer is 47 days. Each correct answer earns a score of 1, and sum of correct responses (maximum $=3$ ) provides an indication of the respondents' ability to suppress intuitive thinking.

\subsubsection{Rational-Experiential Inventory (REI) (Pacini \& Epstein, 1999)}

The Rational-experiential Inventory is used to evaluate a respondents' preference for rational analytic thought (Rational Style) versus intuitive experiential thought (Experiential Style). Respondents indicate the degree to which they agree with each of 
the 40 inventory items on a 5 point Likert type scale with labeling endpoints $1=$ completely true and $5=$ completely false. After adjusting for negatively worded items, summation of thinking style specific items responses yields thinking style scale totals. Each thinking style scale takes into account both the respondents' perceived ability for, and the respondents' enjoyment derived from, engaging in the specified thinking style (e.g., ability to think logically and the enjoyment associated with analytic thinking). Pacini and Epstein (1999) report high reliabilities for each scale: rationality (.90) and experiential (.87). Importantly, they also note that the rational and experiential thinking styles are largely independent of one another.

\subsubsection{Probabilistic Reasoning}

Probabilistic reasoning ability was assessed via a collection of five heuristic bias tasks drawn from (Toplak et al., 2011). Collectively, these tasks assesse respondents' ability to use probability maximizing (rather than matching) decision strategies, to overcome outcome bias, to use large-number data during decision making, to recognize cases of regression to the mean, and to detect covariation when making causal attributions. Percent of maximum possible (POMP) scores were calculated for each respondent, based on (Cohen, Cohen, Aiken, \& West, 1999) formula (observed scoreminimum scale $) /($ maximum scale-minimum scale $) * 100($ pomp $=$ percentage of maximum possible).

4.4.1.8 NEO Personality Inventory Revised Edition (NEO-PI-R) (Costa \& McCrae, 1992)

The NEO-PI-R-FFI is a 60 -item measure of the five personality domains of Neuroticism, Extraversion, Openness, Agreeableness, and Conscientiousness, as well as six facets associated with each of the five domains (Costa \& McCrae, 1992). The NEO- 
PI-R is currently the dominant instrument in the assessment of personality. Its validity, concurrent and discriminant, has been well established in both normal and clinical populations (Costa \& McCrae, 1992). Internal reliability of the domain scores are high, ranging from .86 to .92 , and the internal reliabilities of the facets range from .58 to .82 (Costa \& McCrae, 1992).

\subsubsection{Demographics}

Each participant reported their birth date, gender, educational attainment, ancestral ethnicity, and whether English was their first language.

\subsection{RESULTS}

\subsubsection{Data Cleaning and Analysis}

Less than 5\% of the data were missing, with the GFM variable containing the most missing values (1\%). Missing values were replaced with the series mean, and although more sophisticated methods of imputation are available, given the low percentage of missing it is expected that any imputation methods would result in similar imputed values. The highest level of education attained variable was re-coded as an ordinal variable with the lowest levels of education reported (less than high school completion $)=1$, and the highest category (Master's or Doctorate degree) $=8$. All variables were checked for skew and outliers. Several outliers were detected in the gambling involvement variables and these outliers were winsorized ${ }^{9}$. All variables were normally distributed, except for the GFM and gambling engagement variables which were somewhat skewed even after the removal of outliers.

\footnotetext{
${ }^{9}$ Winsorization is an alternative to full variable transformation in which the impact of outliers is reduced. There is variation in winsorizing procedures; in this study the winsorization process consisted of replacing outliers with the next highest non-outlier value in the distribution plus one.
} 


\subsubsection{Descriptive Statistics}

Demographic information and variable scores (means and standard deviations) can be seen in Table 1 . While data was collected from the community sample with the intention of diversifying the whole sample with respect to age, gender, and educational attainment, there was a possibility of differences in executive functioning between groups, due to age differences for example. As this study focused in large part on cognitive abilities, disparity in executive functioning between groups could confound the study results. Based on their associations with executive functioning, general intelligence and task completion times were compared between groups (Gilinsky \& Judd, 1994; Markovits, Doyon, \& Simoneau, 2002; Salthouse, 1996; Stanovich \& West, 1997, 2000). No statistically significant differences between the student and community samples were detected on measures of general intelligence $(t=-.89, p=.37)$, time taken to complete intelligence measure $(t=-.37, p=.71)$, or total time to complete the whole survey $(t=$ $-.94, p=.35)$. Non-significant differences on these measures were taken as an indication that the groups were comparable in executive functioning. Thus the samples were merged, yielding a total sample $(n=266)$ that included $56 \%$ female participants, with 81.95\% of participants report English being their first language, and $73.31 \%$ identifying as Caucasian ancestry. Educational attainment within the sample was varied with $1.5 \%$ reporting having a graduate or professional degree, $8.9 \%$ having attained a Bachelor's degree, $12.1 \%$ having attained some post-secondary certification, $58.1 \%$ with some postsecondary education, $1.2 \%$ having completed vocational training, $14.1 \%$ having completed high school, and $4 \%$ having less than a high school education. 
Table 4.1 Demographics and Variable Scores

\begin{tabular}{|c|c|c|c|}
\hline & $\begin{array}{c}\text { Psychology } \\
(n=166)\end{array}$ & $\begin{array}{c}\text { Community } \\
(n=100)\end{array}$ & Total Sample \\
\hline Gender (female) & $71 \%$ & $32 \%$ & $56 \%$ \\
\hline Age & $22.06(5.40)$ & $28.49(14.46)$ & $24.58(10.43)$ \\
\hline English first language & $78.92 \%$ & $87 \%$ & $81.95 \%$ \\
\hline Caucasian ancestry & $69.88 \%$ & $79 \%$ & $73.31 \%$ \\
\hline Raven's & $4.91(2.97)$ & $5.25(2.95)$ & $5.04(2.97)$ \\
\hline Paranormal Belief & $19.49(7.52)$ & $17.42(7.37)$ & $18.71(7.52)$ \\
\hline CRT & $.87(1.04)$ & $1.12(.99)$ & $.96(1.02)$ \\
\hline GFM & $6.14(2.08)$ & $6.72(2.41)$ & $6.36(2.33)$ \\
\hline $\mathrm{RS}$ & $71.40(11.26)$ & $76.55(10.57)$ & $73.38(11.27)$ \\
\hline $\mathrm{ES}$ & $65.78(10.43)$ & $65.29(10.15)$ & $65.59(10.30)$ \\
\hline PR & $44.45(24.79)$ & $55.14(26.44)$ & $48.05(26.03)$ \\
\hline \multicolumn{4}{|l|}{ Personality (T-score) } \\
\hline Neuroticism & $26.05(8.43)$ & $21.57(9.43)$ & $24.32(9.08)$ \\
\hline Extraversion & $26.95(6.35)$ & $28.90(5.83)$ & $27.70(6.21)$ \\
\hline Openness & $28.53(6.08)$ & $30.13(6.12)$ & $29.15(6.13)$ \\
\hline Agreeableness & $30.49(6.20)$ & $30.39(6.60)$ & $30.45(6.34)$ \\
\hline Conscientiousness & $31.07(6.44)$ & $32.40(5.80)$ & $31.58(6.22)$ \\
\hline \multicolumn{4}{|l|}{ Gambling Engagement } \\
\hline \# of Formats & $1.18(1.41)$ & $1.84(2.06)$ & $1.44(1.72)$ \\
\hline Frequency & $3.83(12.58)$ & $15.84(37.56)$ & $8.35(27.45)$ \\
\hline Expenditure & $\begin{array}{c}\$ 149.80 \\
(\$ 563.75)\end{array}$ & $\begin{array}{c}\$ 36,337.20 \\
(\$ 648,244.45)\end{array}$ & $\begin{array}{c}\$ 13,754.09 \\
(\$ 396,606.55)\end{array}$ \\
\hline
\end{tabular}

Note: Except where percentages are indicated, means with standard deviations in parentheses are reported. English = number of participants indicating that English was their first spoken language; Caucasian = number of participants self-reporting as Caucasian; Raven's = Raven's Progressive Matrices score; Paranormal Belief = Revised Paranormal Belief Scale scores; CRT = Cognitive Reflection Test; GFM = Gambling Fallacies Measure score; RS = Rational-experiential Inventory Rationality Scale score; $\mathrm{ES}=$ Rational-experiential Inventory Experiential Scale score. PR = Probabilistic reasoning percent of maximum possible (POMP) scores. Personality = NEO-PI-R-FFI (Tscores reported). 


\subsubsection{Univariate Associations}

Table 2 presents Pearson $r$ correlations between all variables of interest ${ }^{10}$. Unlike previous research, GFM scores in the present study were not significantly associated with either number of gambling formats engaged in or net gambling expenditure. However, a weak significant association was detected between GFM scores and gambling frequency $(r=-.19)$. Stronger associations were detected between GFM scores and various cognitive measures. More specifically, higher GFM scores (indicating greater resistance to fallacies) were significantly associated with higher levels of general intelligence (Raven's scores $r=.29)$, probabilistic reasoning POMP scores $(r=.43)$, CRT scores $(r$ $=.37)$, REI rationality scale $(r=.30)$, and REI experiential scale scores $(r=-.25)$. GFM scores were significantly, albeit weakly, associated with the personality trait of extraversion $(r=-.18)$. No other personality traits were significantly associated. The associations between GFM scores and demographic variables of age and attained education level were not significant whereas a significant moderate positive association was detected between GFM scores and gender $(r=.20)$, indicating females to be more susceptible to fallacious gambling related thoughts. Finally, one of the highest correlations was between GFM scores and our second type of fallacious belief, paranormal belief $(r=-.42)$. With the inverse nature of the GFM, this indicates that individuals that are susceptible to gambling fallacies are inclined to also endorse belief in paranormal phenomenon.

\footnotetext{
${ }^{10}$ Associations with winsorized and non-winsorized (raw data) gambling engagement variables presented.
} 
Table 4.2 Pearson's r Correlation Matrix

\begin{tabular}{|c|c|c|c|c|c|c|c|c|c|c|c|c|c|c|c|c|c|c|c|c|c|}
\hline & 1 & 2 & 3 & 4 & 5 & 6 & 7 & 8 & 9 & 10 & 11 & 12 & 13 & 14 & 15 & 16 & 17 & 18 & 19 & 20 & 21 \\
\hline 1. GFM & 1.00 & $-.41^{* *}$ & $.20^{* *}$ & -.01 & .01 & $.30 * *$ & $.43 *$ & $.37^{* *}$ & $.30 * *$ & $-.25^{* * *}$ & -.10 & $-.18^{* * *}$ & .10 & -.04 & -.07 & -.03 & $-.19 * *$ & .09 & -.04 & $-.23 * *$ & .09 \\
\hline 2. PBS & & 1.00 & $-.28 * *$ & .09 & -.08 & $-.16 *$ & $-.36^{* * *}$ & $-.28 * *$ & $-.31 * *$ & $.41 * *$ & $.21 * *$ & .13 & .02 & .03 & .00 & -.08 & -.06 & -.13 & -.09 & -.05 & -.13 \\
\hline 3. Gender & & & 1.00 & $.20 * *$ & .07 & .06 & $.35 * *$ & $.23 * *$ & $.27 * *$ & -.10 & $-.38^{* *}$ & .11 & .02 & $-.15^{*}$ & .02 & $.28 * *$ & $.25 * *$ & .05 & $.29 * *$ & $.23 * *$ & .05 \\
\hline 4. Age & & & & 1.00 & $.26^{* *}$ & $-.17 *$ & .06 & -.06 & -.02 & .07 & -.12 & -.01 & -.06 & .09 & .06 & -.07 & .10 & -.01 & -.07 & .12 & -.01 \\
\hline 5. Education & & & & & 1.00 & .08 & $.15^{*}$ & $.14 *$ & $.15^{*}$ & .02 & -.03 & -.12 & .01 & .06 & $.20^{* *}$ & .01 & .13 & -.12 & .02 & $.17^{*}$ & -.12 \\
\hline 6. Raven's & & & & & & 1.00 & $.44^{* * *}$ & $.43 * *$ & $.16^{*}$ & $-.14 *$ & .06 & -.13 & .09 & -.03 & -.12 & .02 & -.02 & -.03 & .01 & -.03 & -.03 \\
\hline 7. $P R$ & & & & & & & 1.00 & .41 ** & $.30^{* *}$ & $-.17 *$ & $-.17^{*}$ & -.10 & .13 & -.07 & -.03 & .13 & .13 & .10 & .13 & .13 & .10 \\
\hline 8. CRT & & & & & & & & 1.00 & $.24 * *$ & -.19 ** & -.04 & $-.18 *$ & $.15^{*}$ & .11 & -.06 & .06 & -.02 & .00 & .06 & -.02 & .00 \\
\hline 9. RS & & & & & & & & & 1.00 & .02 & $-.26 * *$ & .01 & $.44 * *$ & .00 & $.40 * *$ & .03 & .02 & .01 & .03 & .02 & .01 \\
\hline 10. ES & & & & & & & & & & 1.00 & .08 & $.20^{* *}$ & .13 & .01 & .10 & .10 & .02 & -.10 & .10 & .01 & -.10 \\
\hline 11. NEO - N & & & & & & & & & & & 1.00 & $-.32 * *$ & .03 & -.11 & $-.29 * *$ & -.10 & -.10 & -.03 & -.10 & -.10 & -.03 \\
\hline 12. NEO - E & & & & & & & & & & & & 1.00 & .06 & .14 & $.21 * *$ & $.26^{* * *}$ & .10 & -.02 & $.25 * *$ & .09 & -.02 \\
\hline 13. NEO - O & & & & & & & & & & & & & 1.00 & .05 & .08 & .03 & .02 & -.14 & .03 & .02 & -.14 \\
\hline 14. NEO - A & & & & & & & & & & & & & & 1.00 & .13 & $-.19 * *$ & $-.16^{*}$ & -.05 & $-.19 * *$ & $-.14 *$ & -.05 \\
\hline 15. NEO - C & & & & & & & & & & & & & & & 1.00 & -.06 & -.03 & .01 & -.05 & -.01 & .01 \\
\hline 16. Formats & & & & & & & & & & & & & & & & 1.00 & $.55^{* * *}$ & -.02 & $\begin{array}{c}1.00^{*} \\
*\end{array}$ & $.47^{* *}$ & -.03 \\
\hline 17. Frequency & & & & & & & & & & & & & & & & & 1.00 & -.02 & $.57 * *$ & $\begin{array}{c}1.00^{*} \\
*\end{array}$ & -.02 \\
\hline 18. Expenditure & & & & & & & & & & & & & & & & & & 1.00 & -.02 & -.02 & $1.00^{* *}$ \\
\hline 19. FormatsR & & & & & & & & & & & & & & & & & & & 1.00 & $.48^{* * *}$ & -.03 \\
\hline 20. FreqR & & & & & & & & & & & & & & & & & & & & 1.00 & -.02 \\
\hline 21. ExpendR & & & & & & & & & & & & & & & & & & & & & 1.00 \\
\hline
\end{tabular}

Note: $* p \leq .05$, ** $p \leq .01, n$ 's ranging from 231 to 265. GFM = Gambling Fallacies Measure; PBS = Revised Paranormal Belief Scale global scores; Education = highest level of education attained; Raven's = Raven's Progressive Matrices score; PR = Probabilistic reasoning POMP score; CRT $=$ Cognitive Reflection Test; RS = Rational-experiential Inventory Rationality Scale score; ES = Rational-experiential Inventory Experiential Scale score. NEO - = NEO-PI-R-FFI T-scores for Neuroticism, Extraversion, Openness, Agreeableness, and Conscientiousness; \# of Formats = number of gambling formats engaged in (winsorized); Frequency = number of days per year spent gambling (winsorized); 
Expenditure $=$ average annual gambling related expenditures (profits less losses) (winsorized). \# of FormatsR = number of gambling formats engaged in (raw data, not winsorized); FrequencyR = number of days per year spent gambling (raw data, not winsorized); Expenditure $=$ average annual gambling related expenditures (profits less losses) (raw data, not winsorized). 
Table 2 also illustrates the associations between PBS scores and all variables of interest. As can be seen, a very similar pattern of results was obtained. While PBS scores were not found to be significantly associated with any measure of gambling involvement, higher PBS scores (indicating greater paranormal belief) were significantly associated with general intelligence (Raven's scores $r=-.16$ ), probabilistic reasoning POMP scores $(r=-.36)$, CRT scores $(r=-.28)$, REI rationality scale $(r=-.31)$, and REI experiential scale scores $(r=.41)$. PBS scores were also significantly associated with the personality trait of neuroticism $(r=.21)$. No other personality traits were significantly associated. As was the case with GFM susceptibility, a significant moderate association was detected between PBS scores and gender $(r=-.28)$, indicating that females are more likely to hold paranormal beliefs.

\subsubsection{Multivariate Results}

Multiple regression analyses with simultaneous entry of variables were performed to identify the variables that collectively predicted each type of fallacious belief: i.e., gambling fallacies and paranormal belief. Only variables that were found in the univariate analyses to be significantly associated with the dependent variable were included in the models ${ }^{11}$. The exception to this was that PBS scores were not included in the model predicting GFM scores and GFM scores were not included in the prediction of PBS scores. Univariate outliers in the gambling expenditure were winsorized as previously discussed, and one multivariate outlier was removed from the analysis.

In the multivariate prediction of gambling fallacies $R$ was significantly different from zero, $F(9,198)=13.00, p<.001$. Table 3 reports the unstandardized regression

\footnotetext{
${ }^{11}$ Results discussion pertains to model using winsorized data. Model predicting GFM using non-winsorized (raw data) included in Table 3 for comparative purposes.
} 
Table 4.3 Regression Analyses Results

\begin{tabular}{|c|c|c|c|c|c|c|c|c|c|}
\hline & \multicolumn{3}{|c|}{ GFM1 } & \multicolumn{4}{|c|}{ GFM2 } & \multicolumn{2}{|c|}{ PBS } \\
\hline & $B$ & $\beta$ & $\left(s r_{i}^{2}\right)$ & $B$ & $\beta$ & $\left(s r_{i}^{2}\right)$ & $B$ & $\beta$ & $\left(s r_{i}^{2}\right)$ \\
\hline Constant & 5.37 & & & 5.33 & & & 13.39 & & \\
\hline Frequency & -.02 & $-.27 * *$ & .07 & .03 & $-.30 * *$ & .08 & & & \\
\hline PR & .02 & $.29 * *$ & .05 & .02 & $.28 * *$ & .05 & -.05 & $-.18 * *$ & .02 \\
\hline RS & .03 & $.17 * *$ & .02 & .04 & $.17 * *$ & .02 & -.14 & $-.21 * *$ & .04 \\
\hline ES & .03 & $-.14^{*}$ & .02 & -.03 & $-.14 *$ & .02 & .26 & $.37 * *$ & .13 \\
\hline CRT & .29 & .13 & .01 & .29 & .13 & .01 & -.52 & -.07 & .00 \\
\hline $\mathrm{NEO}-\mathrm{E}$ & -.03 & -.08 & .01 & -.03 & -.08 & .01 & & & \\
\hline Gender & .36 & .08 & .00 & .33 & .07 & .00 & -1.19 & -.08 & .00 \\
\hline Raven's & .03 & .04 & .00 & .03 & .04 & .00 & - & - & - \\
\hline $\mathrm{NEO}-\mathrm{N}$ & - & - & - & - & - & - & .05 & .06 & .00 \\
\hline $\mathrm{NEO}-\mathrm{O}$ & -.01 & -.02 & .00 & -.01 & -.02 & .00 & - & - & - \\
\hline & $\begin{array}{l}\mathrm{R}=.6 \\
\mathrm{R}^{2}=.3\end{array}$ & , Adjus & & & $\begin{array}{l}.61 * *, \\
.34 * *\end{array}$ & justed & $\begin{array}{l}\mathrm{R}= \\
=.3\end{array}$ & $7 * *, A$ & ted $\mathrm{R}^{2}$ \\
\hline
\end{tabular}

Note: $* p \leq .05, * p \leq .01$. GFM1 $=$ model with raw scores, GFM2 $=$ model with outliers winsorized. $B$ = beta; $(\beta)=$ standardized beta; $\left(s r_{i}^{2}\right)=$ semi-partial correlation; GFM = Gambling Fallacy Measure; PBS = Revised Paranormal Belief Scale global scores; Frequency $=$ average annual gambling engagement; Raven's = Raven's Progressive Matrices score; CRT = Cognitive Reflection Test; RS = Rational-experiential Inventory Rationality Scale score; ES = Rationalexperiential Inventory Experiential Scale score; PR = Probabilistic reasoning POMP score; NEO = NEO-PI-R-FFI T-scores for Extraversion, Neuroticism, and Openness. 
coefficients $(B)$, the standardized regression coefficients $(\beta)$ and the squared semi-partial

correlations $\left(s r_{\mathrm{i}}^{2}\right)$ that illustrate the unique contribution of each variable. As can be seen, four variables contributed significantly to prediction of increased GFM scores. In order of importance, these were: lower gambling frequency, higher probabilistic reasoning scores, higher REI rationality scale scores, and lower REI experiential scores. Altogether, $34.3 \%$ of the variability in GFM scores was predicted by knowing the scores on all nine independent variables.

In the multivariate prediction of paranormal belief, $R$ was also significantly different from zero, $F(7,201)=14.11, p<.001$. As seen in Table 3, three variables contributed significantly to prediction of increased PBS scores. In order of importance these were: higher REI experiential scale scores, lower REI rationality scale scores, and lower probabilistic reasoning scores. Altogether, $30.6 \%$ of the variability in paranormal belief scores was predicted by knowing the scores on these seven independent variables.

A scatterplot of the correlation between individual gambling fallacies scores and paranormal beliefs scores is presented in Figure 1.

\subsection{DISCUSSION}

Focusing first on gambling specific fallacious beliefs, we found that gambling fallacy susceptibility was significantly associated with greater gambling frequency at both the univariate and multivariate level. This finding adds partial support to previous investigations (Leonard \& Williams, 2016; Yakovenko et al., 2016). However, unlike previous prospective investigations, gambling fallacy endorsement was not significantly associated with other gambling engagement measures. However, part of the difference has 


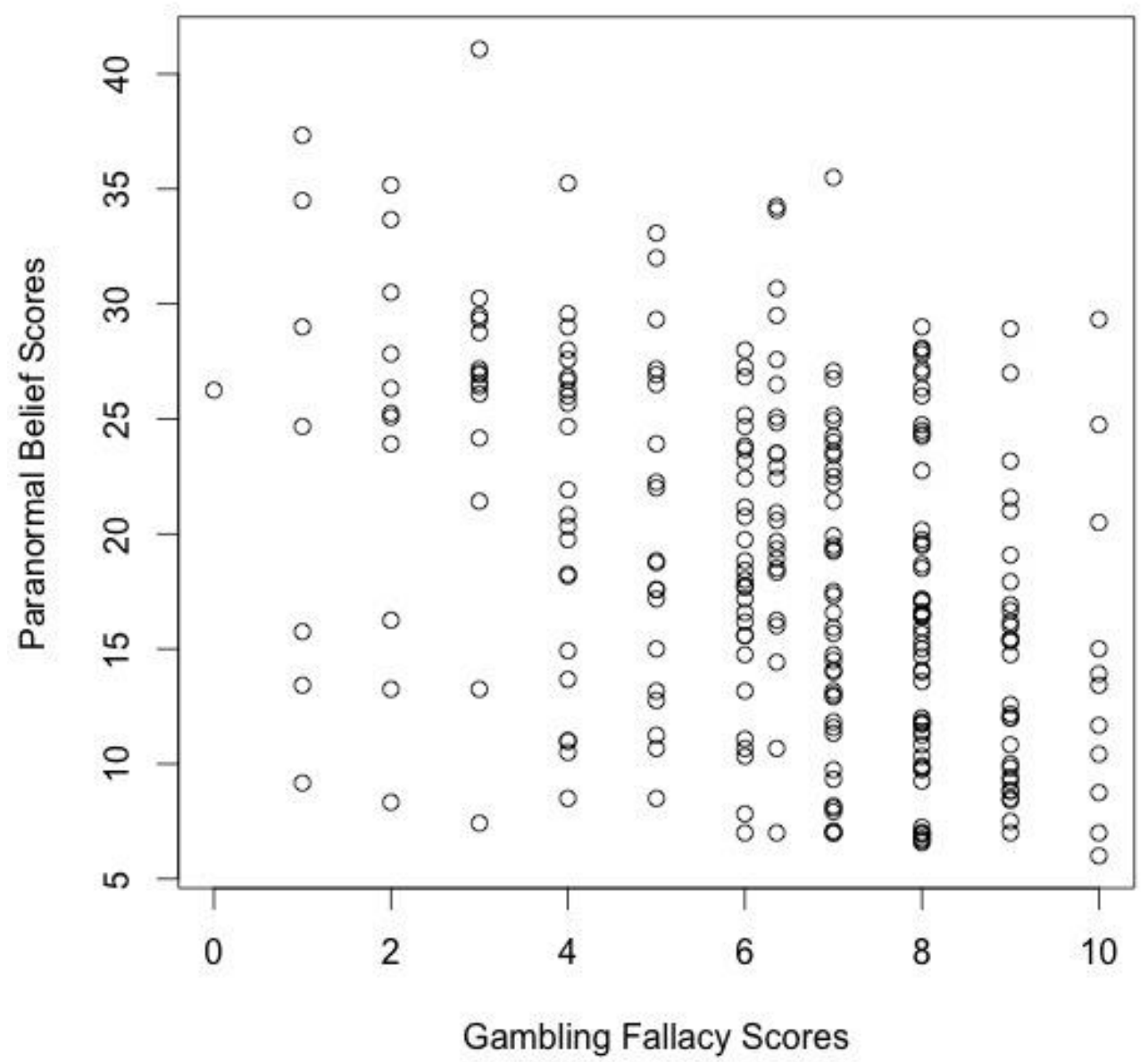

Figure 4.1. Scatter plot of gambling fallacy and paranormal belief scores. 
to do with the fact that much larger samples were used by Leonard \& Williams (2016) and Yakovenko et al. (2016), which allowed the correlations to be significant despite the fact that the magnitudes of the correlations was not markedly higher. Taken together, gambling engagement does seem to play a role in the development and maintenance of gambling fallacies.

The cognitive factors evaluated within the current study (general intelligence, probabilistic reasoning, and cognitive style) were all also significantly associated with greater gambling fallacy endorsement. Poor probabilistic reasoning ability, less rational cognitive style, and greater reliance on intuitive judgment were also significant predictors of GFM scores in our multivariate analysis. Based on these results, it appears that lower ability to reason probabilistically as well as the tendency to forego rational thinking in lieu of intuitive thought, are robust individual differences that lend to gambling fallacy susceptibility. It is no surprise then, that interventions focused on teaching individuals to use, and rely on, statistical knowledge have had success in reducing gambling specific fallacies (e.g., Williams \& Connolly, 2006; Williams et al., 2010). What remains unclear is if the fallacy reductions evidenced post-educational interventions are stable across time. Educating individuals to engage in probabilistic reasoning may be sufficient to reduce gambling specific fallacies for short periods of time, but this training may not be sufficient to over-ride intuitive cognitive style in the long run.

In general, personality was not a strong predictor of gambling fallacies, although greater extraversion and lower openness to experience were associated with gambling fallacy susceptibility at the univariate level. Similarly, of the demographic variables included in each of the analyses conducted, only female gender was a significant 
associate with gambling fallacy susceptibility at the individual level. Given our previous discussion of cognitive style, it seems reasonable to conclude that the cognitive style of rationality, which is more often characteristic of males, is the mechanism driving this association rather than identification with the male gender in and of itself. Further support for this notion comes from the lack of significant predictive ability of gender in the multivariate analysis.

With respect to belief in the paranormal, supporting previous research, lower probabilistic reasoning ability (Blackmore \& Troscianko, 1985; Bressan, 2002;

Brotherton \& French, 2014; Dagnall et al., 2007; Musch \& Ehrenberg, 2002; Pennycook et al., 2013; Rogers et al., 2009; Rogers et al., 2011), less ability to suppress intuitive thought, less reliance on analytic thinking style, and greater reliance on intuitive thought (Aarnio \& Lindeman, 2005; Gervais, 2015; Gervais \& Norenzayan, 2012; Leonard \& Williams, 2017; Lindeman \& Aarnio, 2007; Pennycook et al., 2013), were all significantly associated with greater belief in the paranormal at both the univariate and multivariate level. Of the cognitive factors included, the penchant for intuitive thought was the strongest multivariate predictor for belief in the paranormal.

Similar to gambling fallacies, personality was not a strong predictor of paranormal belief in the present study. The exception to this was that greater paranormal belief was significantly associated with increased neuroticism at the univariate level. This is a finding that has been found in previous research (Fichten \& Sunerton, 1983; Leonard \& Williams, 2017; Thalbourne et al., 1995; Windholz \& Diamant, 1974). Unlike previous research, extraversion and openness to experience were not significantly related 
to paranormal belief (Rattet \& Bursik, 2000; Smith et al., 2009; Swami et al., 2010;

Thalbourne, 1981; Thalbourne \& Haraldsson, 1980; Windholz \& Diamant, 1974).

Similar to gambling fallacies, of the demographic variables included, only female gender was significantly associated with paranormal belief at the univariate level. Here again, it is likely the case that greater rational ability and style which is often more typical of males, rather than gender in and of itself, is driving the evidenced association. It is interesting to note that previously detected differences between male and female responses on this measure of paranormal belief is the basis for the argument for alternative scoring of R-PBS, such as Rasch scaling (e.g., Lange et al., 2000). Considering the results of the current study, specifically the results pertaining to cognitive style, gender differences reported in the literature may be an artifact better explained by cognitive style than true differences between males and females.

These findings, when taken together, suggest that there does seem to be a similar profile of individual characteristics that culminate in a general predisposition to fallacious thought. As noted, this profile includes greater reliance on intuitive cognitive style, less reliance on rational thinking, and lower probabilistic reasoning ability. The similarity of predictive factors, in addition to the significant association between fallacious belief types, also indicates that fallacious beliefs tend to cluster. Meaning, when one endorses belief in one type of fallacious belief they are likely to also endorse belief in other types of fallacious belief. This is clearly evident when comparing the scatterplot of GFM and PBS scores (Figure 1). There are a few individuals with high levels of gambling fallacies and low levels of paranormal beliefs and a few individuals with relatively high levels of paranormal belief and an absence of gambling fallacies. However, it is clear that the 
large majority of people have low, moderate, or high levels of both. One of the important implications of this finding is that it would suggest that educational interventions that have been found to be successful for correcting gambling specific fallacies may also be effective in reducing belief in the paranormal and vice versa.

Two interrelated limitations to the current study should be acknowledged. The first pertains to the correlational and cross sectional nature of the current study. While it seems reasonable to infer that the profile of the fallacious belief susceptible individual exists prior to fallacious belief formation, given our study design it is not possible to demonstrate this. It is possible for example, that intuitive cognitive style (one of the strongest predictors of paranormal belief) leads one to misattribute paranormal cause to a natural event and thus leads to belief endorsement. It is also possible however, that fallacious paranormal beliefs may reinforce the reliance on intuitive thinking. A paranormal believer has no incentive to engage in effortful logical thought when the intuitive answer is easily attained and fits within their belief framework. Longitudinal research should investigate the role these susceptibility factors play in the development of erroneous beliefs.

The second limitation pertains to variance not accounted for within our models of fallacious belief. Although the multivariate analyses explained a reasonable amount of variance, substantial variance is left unexplained.

\subsection{CONCLUSION}

The current study aimed to determine whether the variables that best predict gambling fallacies are the same or different from the variables that best predict paranormal beliefs. It was hypothesized that susceptibility to fallacious belief might be 
somewhat generic rather than contingent on the type fallacious beliefs endorsed. Herein, we found that lower probabilistic reasoning ability, a less rational cognitive style, and more intuitive cognitive style were robust predictors of fallacy endorsement for both gambling fallacies and paranormal belief. Together, these individual difference factors form a profile of fallacious belief susceptibility. Supporting the notion that fallacy susceptibility is generic, fallacious belief endorsement was also found to cluster, whereby individuals who endorse gambling specific fallacies tended also to endorse belief in the paranormal.

Frequent engagement in gambling contributed significantly to the prediction of gambling specific fallacious belief. Thus, in addition to the fallacious belief profile, experience with fallacy-type-specific activities also contributes to endorsement of fallacious belief. Fallacious belief types then, could be characterized as different feathers from the same bird, with experience in fallacy-type-specific engagement being the factor that decides which feather is plucked. Future research should investigate, more thoroughly, the impact of experience (personal and vicarious) on fallacious belief formation and endorsement.

As both types of fallacious belief, gambling and paranormal, have been implicated in harms for the believer and the community (e.g., problem gambling, choosing faith healing over science based medicine, etc.), correcting these beliefs should be a priority. As previously noted, some educational interventions that focused on increasing probabilistic reasoning have been effective in reducing gambling specific fallacious beliefs (e.g., Williams \& Connolly, 2006; Williams et al., 2010). Future research should ascertain if similar educational interventions are efficacious in 
paranormal belief reduction, and longitudinal research is necessary to evaluate the longterm efficacy of these interventions in fallacious belief reduction, regardless of fallacious belief type. 


\section{CHAPTER FIVE: DOES SCIENTIFIC REASONING EDUCATION REDUCE BELIEF IN THE PARANORMAL: A SYSTEMATIC REVIEW}

Leonard, C.A., Jackson, C., \& Williams, R.J. (submitted to Teaching of Psychology) Scientific reasoning education reduces belief in the paranormal.

\subsection{PREAMBLE}

In the third study of this series (Chapter Four), it was found that a similar profile of individual differences contributed to susceptibility for both gambling fallacies and paranormal beliefs. This profile included the increased reliance on intuitive thought, decreased reliance on rational thinking, and decreases in probabilistic reasoning ability. As noted in Chapter Four, few studies have investigated interventions designed to reduce gambling fallacies. Given the similar profile of susceptibility factors between gambling fallacy and paranormal believers, it may be reasonable to presume that intervention efforts designed to reduce one type of fallacious belief (i.e., paranormal beliefs) would be effective for reducing both types of fallacious beliefs (i.e., gambling specific and paranormal). The systematic review detailed in this chapter investigated the efficacy of interventions in reducing paranormal beliefs.

\subsection{ABSTRACT}

Both the American and Canadian Psychological Associations assert that critical thinking skills, including scientific reasoning and the ability to evaluate the quality of evidence, are a primary goal of psychology undergraduate education. The current research sought to identify and review the results of studies assessing the efficacy of educational interventions intended to reduce scientifically unsubstantiated paranormal beliefs. The results of a large-scale systematic review ( $n=917$ articles) revealed few 
relevant pre- and post-test intervention studies $(n=15)$. Each of the relevant studies indicates that explicit educational interventions that aim to teach scientific reasoning skills do have a robust reduction effect on belief in paranormal phenomenon. There is also some evidence that the reductions evidenced are enduring. In contrast, some evidence indicates that indirect efforts to impart scientific reasoning within core psychology courses do not reduce belief in paranormal phenomenon. Several methodological issues are discussed, and avenues for future research are identified.

Keywords: scientific reasoning, critical thinking, paranormal, education, belief change

\subsection{INTRODUCTION}

A paranormal belief is defined as a belief in phenomena that are outside the bounds of established natural science. Typical examples of these scientifically unsubstantiated phenomena include ghosts, extrasensory perception (ESP) and telekinesis (also referred to collectively as PSI), cryptids, alien abduction, demonic possession, spiritual healing, astrology, reincarnation, and magical powers. Research has found that belief in paranormal phenomenon is fairly high in the general population, with over $70 \%$ of Americans believing in at least one paranormal domain, and similar rates of belief seen in Canada and the UK (Chapman University, 2017; D. W. Moore, 2005; Pechey \& Halligan, 2011; Tyson et al., 2011).

It is important to recognize that belief in unfounded phenomena is not benign, but is very real in its consequences (Novella, 2016). Two recent cases demonstrate harmful outcomes that have manifest from belief in the paranormal. In the first case (Ellis \& Hicken, 2016; Office of Public Affairs, 2016), the U.S. government found it appropriate to take civil action against those associated with the Maria Duval psychic scheme. The 
Maria Duval psychic group has induced people around the world to pay for 'psychic guidance' and tokens (e.g., crystals, charms, etc.) that ostensibly induce good fortune. While the revenues received by this group from individuals in Canada and Europe have not yet been determined, US citizens alone have paid the group in excess of 180 million dollars. The decision of the US courts in response to the civil action taken by the US government against the Maria Duval psychic group was to institute an injunction prohibiting the Maria Duval psychic group from soliciting US citizens (Office of Public Affairs, 2016).

In the second case (Kyung Kim, 2016), 20-year-old Mariah Walton is aiding an appeal for legislation change in Idaho that would require parents to seek medical treatment for children with serious illnesses. Walton was born with a treatable heart defect. Yet Walton's parents opted for prayer healing instead of surgery to repair Walton's heart. Walton's condition deteriorated as she aged, and she is now awaiting heart and lung transplantation. Although recent, these two cases are in no way isolated (for example see: Hall, 2014; Wilson, 2015). These examples demonstrate that paranormal beliefs can lead to serious outcomes for individuals and society. Fortunately, these beliefs may be malleable.

One theory for belief in the paranormal asserts that a lack of training in 'scientific reasoning' (i.e., understanding scientific methodology and what differentiates good from poor evidence) creates a susceptibility to these erroneous beliefs. In support of this theory, Diaz-Vilela and Alvarez-Gonzalez (2004) found lower levels of belief in all paranormal phenomenon among biology and physics majors as compared to both education and tourism majors. They also found both sociology and psychology majors 
held significantly less belief in the domains of witchcraft, extraterrestrials, and traditional religion than those majoring in education or tourism. Standing and Huber (2003) found a significant and negative association between the number of psychology courses taken and psychological myth endorsement, including some paranormal specific myths (i.e., PSI, Lunar-Lunacy Effect, Illusion of Control). Taken together, these findings suggest that the students reporting fewer beliefs are those who have been trained to assess phenomenon through a critical scientific lens. Standing and Huber's (2003) findings therefore, should be expected as some core psychology courses (e.g., abnormal psychology, social psychology, the psychology of perception) invariably touch on scientific explanations for some paranormal phenomena domains (for discussion see: Jones \& Zusne, 1981). What is surprising is that, despite a rise in western cultures engagement in post-secondary education of the physical and social sciences (e.g., National Center For Education Statistics, 1993), belief in the paranormal remains high in the general population. In one early review of the paranormal belief literature, Irwin (1993) identified only a few studies that have investigated paranormal belief reduction after scientific reasoning course interventions (i.e., Banziger, 1983; Emme, 1940; Gray, 1985; McBurney, 1976). Irwin (1993) reports that each of these studies found that scientific reasoning courses did significantly reduce paranormal beliefs. Since this review, numerous articles and books have been penned to help in the design and delivery of scientific reasoning courses (for example see: Calvin, 2009; D. McBurney, 2002; Nisbett, 2015; Shermer, 2002; J. C. Smith, 2010; Wesp \& Montgomery, 1998). Yet no recent studies have attempted to synthesize the results of all available studies that used this approach to reduce paranormal beliefs. 
Evaluating the impact of scientific reasoning education interventions on paranormal belief reduction is the primary objective of the current research. Aside from being of theoretical interest, understanding this relationship will potentially inform the design of interventions to mitigate the development of and/or reduce present paranormal beliefs.

\subsection{METHOD}

\subsubsection{Literature Search}

A comprehensive and systematic review of the literature on interventions for paranormal beliefs was undertaken. PsychINFO, PubMed, EBM Reviews (Cochrane Collection), ERIC, Dissertations \& Theses (A \& I), as well as the conference proceedings of the National Institute on the Teaching of Psychology (NITOP) and the Association for Psychological Science Teaching Institute (APS-TI) were searched from the earliest available date through February 2016, using the sole search term "paranormal belief". This search was supplemented by examination of the reference lists of each identified relevant article, and by contacting the authors of relevant studies to identify any studies that have not been disseminated. See Figure 1 for an illustration of the search process.

A single search term was employed, as there was too much variability in the way in which interventions were described. Each individual article $(n=917)$ was subsequently reviewed to determine whether any type of formal intervention had been used and evaluated. Articles were excluded if they did not specifically evaluate paranormal beliefs and/or if they did not include a formal pre-post evaluation. Two researchers independently conducted the literature review to ensure no relevant materials 


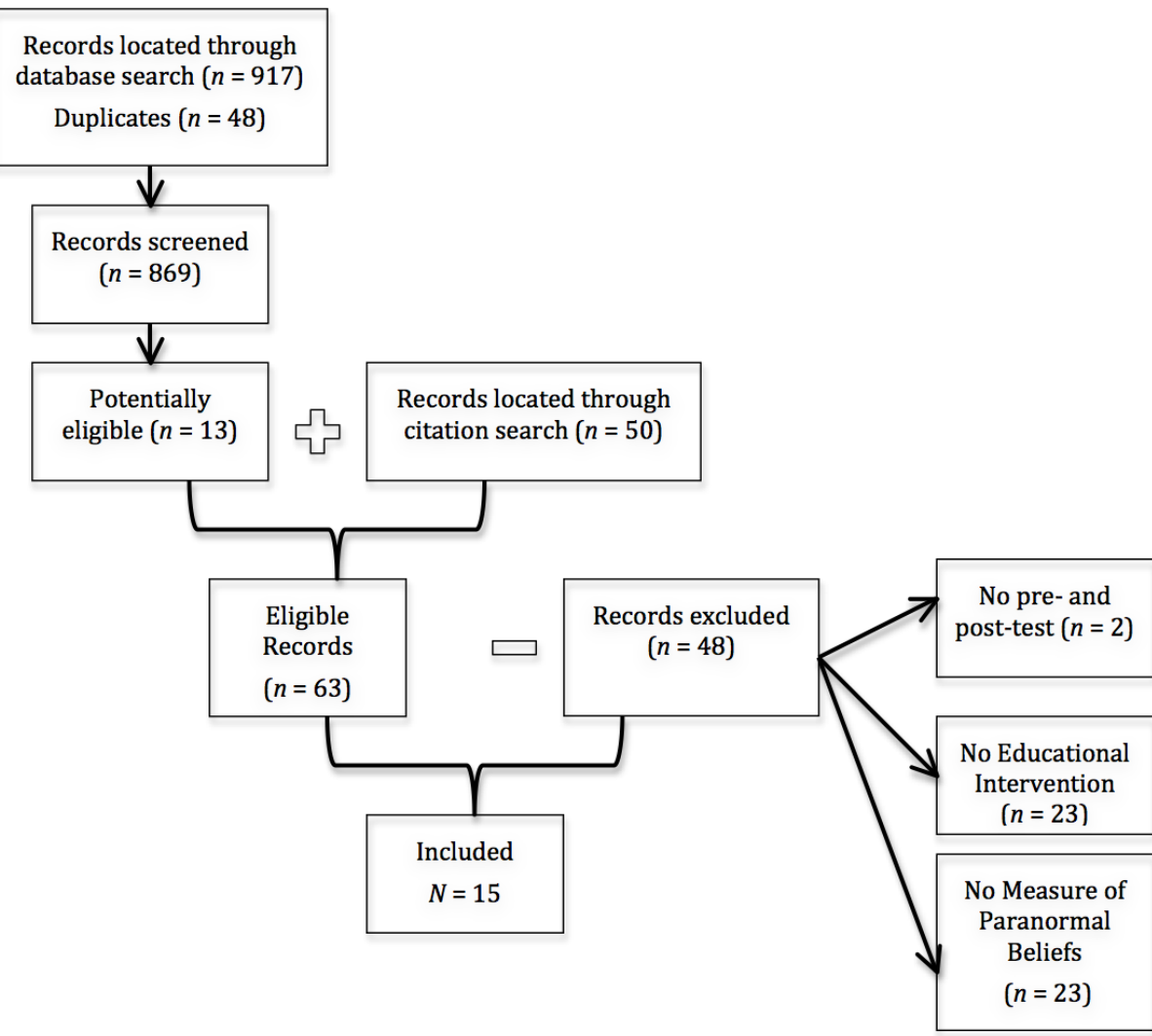

Figure 5.1. Flow chart of systematic review process for identifying and including relevant articles. 
were overlooked. Relevant studies identified through these search techniques are displayed in Table $1^{12}$.

\subsubsection{Results of systematic literature review}

Fifteen studies were identified that had used a pre- post-test design to assess the efficacy of an intervention intended to reduce paranormal beliefs ${ }^{13}$. Except where noted, each of these interventions consisted of a one-term university-based program intended to facilitate the development of "scientific reasoning" by using paranormal research examples to emphasize differences between good (reliable) evidence and poor evidence. Delivery of the program was typically in a psychology class. Thus, hereinafter, courses of this structure will be referred to as the "typical" intervention. A variety of paranormal belief measures were used within these studies, each assessing somewhat different domains of paranormal beliefs. The reported results of the identified studies are organized in relation to the specific paranormal measure used, with these being grouped into studies that used the Belief in Paranormal Scale, the Paranormal Belief Scale, and custom instruments created specifically for the study.

\subsubsection{Belief in Paranormal Scale (BPS) (Jones, Russell, \& Nickel, 1977)}

The BPS is a 25-item instrument designed to capture belief in six paranormal domains: supernatural, occult, divination, psychic phenomenon, physical manifestations of paranormal, and creatures. This measure uses a Likert-type response scale format with labeling endpoints $1=$ Strongly Disagree to $5=$ Strongly Agree, and a neutral response of $3=$ Undecided or Don't Know. A global paranormal belief score for this measure is

\footnotetext{
${ }^{11}$ No relevant studies were identified through the search of the conference proceedings of both the NIT and the APSTI, and the conference proceedings reviewed are not included in the total article count $(n=917)$.

13 Samples were comprised of post secondary students in the U.S.A. unless otherwise stated.
} 
Table 5.1 Studies of Educational Interventions

\begin{tabular}{|c|c|c|c|c|c|c|c|}
\hline Measure & Study & Group & $\mathrm{N}$ & Participants & $\begin{array}{c}\text { Pre-test M } \\
\text { (SD) }\end{array}$ & $\begin{array}{c}\text { Post-test M } \\
\text { (SD) }\end{array}$ & Effect Size $(95 \%$ CI) \\
\hline Belief in & Banziger (1983) & Intervention & 53 & Older Adults & $74.9(16.9)$ & $67.1(18.1)$ & $0.44(0.06,0.83)$ \\
\hline Paranormal & Morier (1994) & Intervention & 34 & Students & $69.4(14.4)$ & $53.4(14.8)$ & $1.08(0.57,1.59)$ \\
\hline \multirow[t]{3}{*}{ Scale } & & Comparison & 28 & Students & $64.8(18.8)$ & $62.8(19.7)$ & $0.10(-0.42,0.63)$ \\
\hline & Jones (1981) & Intervention & 48 & Students & $82.9(10.6)$ & $68.4(7.42)$ & $1.57(1.11,2.03)$ \\
\hline & Tobacyk (1983) & Intervention & 11 & Students & $77.9(14.07)$ & $59.9(14.07)$ & $1.23(0.30,2.16)$ \\
\hline Paranormal & Stark (2012) & Intervention & 78 & Students & $2.51(0.51)$ & $2.26(0.51)$ & $0.48(0.17,0.89)$ \\
\hline \multirow{9}{*}{$\begin{array}{l}\text { Belief Scale } \\
\text { (Original } \\
\text { and } \\
\text { Revised) }\end{array}$} & McLean (2010) & Intervention & $23 / 30$ & Students & $83.57(21.12)$ & $56.5(13.11)$ & $1.49(0.80,2.17)$ \\
\hline & & Comparison & $30 / 27$ & Students & $79.5(18.05)$ & $79.92(18.19)$ & $-0.02(-0.05,0.50)$ \\
\hline & Manza (2010) & Intervention & 15 & Students & $71.00(22.10)$ & $38.70(15.30)$ & $1.65(0.81,2.50)$ \\
\hline & & Comparison & 15 & Students & $60.00(20.50)$ & $59.70(16.80)$ & $0.02(-0.70,0.73)$ \\
\hline & & Int 2 & 16 & Students & $58.50(18.90)$ & $53.10(17.90)$ & $0.81(-0.41,0.98)$ \\
\hline & Burke (2014) & Intervention & 12 & Students & $89.70(38.09)$ & $63.90(21.04)$ & $0.81(-0.03,1.65)$ \\
\hline & & Comparison & $90 / 14$ & Students & $86.21(21.15)$ & $84.29(17.74)$ & $0.09(-0.47,0.66)$ \\
\hline & & Int 2 & 128 & Students & $81.74(27.65)$ & $67.90(22.25)$ & $0.55(0.30,0.80)$ \\
\hline & Irwin (1990) & Intervention & NR & Students & 74.95 (NR) & 72.18 (NR) & \\
\hline Created for & Kane (2010) & Intervention & $340 / 95$ & Students & $25.11(0.87)$ & $17.56(1.41)$ & $6.69(6.26,7.14)$ \\
\hline \multirow[t]{9}{*}{ Study } & & $\begin{array}{l}\text { Intervention } \\
\text {-hindsight }\end{array}$ & $340 / 95$ & Students & $25.00(0.91)$ & $23.64(0.74)$ & $1.55(1.30,1.80)$ \\
\hline & & Comparison & $238 / 63$ & Students & $25.99(0.93)$ & $25.66(3.51)$ & $0.35(0.14,0.56)$ \\
\hline & & $\begin{array}{l}\text { Comparison } \\
\text { - hindsight }\end{array}$ & $238 / 72$ & Students & $25.72(0.94)$ & $25.04(0.91)$ & $0.73(0.46,0.99)$ \\
\hline & Gilliland (1929) & Intervention & 103 & Students & $9.44(4.36)$ & $5.99(3.51)$ & $0.87(0.58,1.15)$ \\
\hline & & Intervention & 46 & Mature Students & $12.02(3.57)$ & $6.48(3.98)$ & $1.45(0.99,1.91)$ \\
\hline & Gray (1985) & Intervention & 71 & Students & 19.87 (NR) & $11.31(\mathrm{NR})$ & \\
\hline & Emme (1940) & Intervention & 96 & Students & $2.67(\mathrm{NR})$ & $0.67(\mathrm{NR})$ & \\
\hline & Dougherty (2004) & Intervention & NR & Students & $1.97(\mathrm{NR})$ & 1.24 (NR) & \\
\hline & Swords (1990) & Intervention & NR & Students & $6.00(\mathrm{NR})$ & $5.10(\mathrm{NR})$ & \\
\hline
\end{tabular}

Note: Effect size is standardized mean difference with $95 \%$ confidence intervals, calculated from reported data. Intervention $=$ Intervention scientific reasoning course. Int $2=$ alternate intervention course. $\mathrm{NR}=$ not reported. 
calculated by summation across all item responses yielding a minimum score of 25 , and a maximum of 125 . Scores near 75 indicate uncertainty about belief, and scores greater than 75 indicating greater belief in paranormal phenomenon. Jones, Russell, and Nickel (1977) present the normative data for college students on the BPS ( $n=475, M=69.1, S D$ $=13.4)$, and report the reliability of the measure to be .92 .

Four education intervention studies used the BPS as the dependent measure. Three of these studies employed the 'typical intervention' to reduce paranormal beliefs (Jones \& Zusne, 1981; Morier \& Keeports, 1994; Tobacyk, 1983). Both, Jones and Zusne (1981) and Tobacyk (1983), report significant reductions in BPS scores at the end of the course ( $p$ 's $=.01$ and .008 , respectively). Tobacyk (1983) states that at pre-test, BPS scores indicated that many students report belief in multiple paranormal domains and that a significant number of these participants reported being "non-believers" at post-test. Morier and Keeports (1994) used students from an advanced level seminar "Psychology and Law" course as a comparison group for the typical intervention course ${ }^{14}$. At pre-test, no statistically significant differences in reported paranormal belief were detected between the intervention and comparison groups. The reported belief in paranormal at post-test did differ significantly between intervention and comparison groups $(p=.03)$, with a significant reduction in reported beliefs from pre- to post-test for the intervention group ( $p=.001)$, and no significant reduction in reported beliefs of comparison participants $(p>.05)$.

\footnotetext{
${ }^{14}$ It should be noted that the participants surveyed in each of these studies were not randomly assigned to conditions (i.e., intervention nor control course), and do not meet the criteria for being true 'experimental' or 'control' participants.
} 
Banziger's (1983) intervention on the other hand, was offered to older American adults (aged 55+), lasted one week, and included about 12 hours of instruction. This course is otherwise comparable to the typical interventions in that it included explanations of the history of parapsychology, flaws in the experimental designs of ESP experiments, statistical disconfirmation of astrology and biorhythms, and the psychology of belief. Banziger (1983) reports a significant reduction in global BPS scores at post-test $(p<.001)$, and that attained reductions were maintained at 6-month follow up $(p<.01)$.

\subsubsection{Paranormal Belief Scale (PBS) (Tobacyk, 2004; Tobacyk \& Milford, 1983)}

The original PBS is a 25 -item questionnaire that uses a 5 point Likert scale with labeling endpoints $1=$ Strongly Disagree and $5=$ Strongly Agree. The response scale also includes a neutral response option for respondents to indicate uncertainty about the phenomena (i.e., 3 = Uncertain or Don't Know). The original PBS assesses belief in seven paranormal domains: traditional religious belief, PSI, witchcraft, superstition, spiritualism, extraordinary life forms, and precognition. The 4-week test re-test reliability and normative data of $n=424$ university student participants on the original PBS paranormal domains were reported by Tobacyk and Milford (1983) to be: traditional religious belief $=.75(M=4.24, S D=.90), \mathrm{PSI}=.84(M=3.19, S D=.84)$, witchcraft $=.69(M=2.77, S D=.85)$, superstition $=.67(M=2.08, S D=.82)$, spiritualism $=.66(M$ $=2.64, S D=.79)$, extraordinary life forms $=.82(M=2.82, S D=.83)$, precognition $=.60$ $(M=3.52, S D=.84)$, and global $=.89(M=76.87, S D=11.97)$. The PBS underwent revision to increase reliability, and reduce the impact of the restricted range of responses. The revised PBS assesses belief in the same 7 paranormal domains, but uses 26 items and a 7 point Likert type response scale with labeling endpoints $1=$ Strongly Disagree and 7 
$=$ Strongly Agree. A response of 4 on this scale is used to indicate uncertainty. Tobacyk (2004) reports the 4-week test re-test reliability and normative data of $n=217$ university student participants on the revised measure and paranormal domains to be: global $=.92$ $(M=89.1, S D=21.9)$, traditional religious belief $=.95(M=6.3, S D=1.2)$, PSI $=.71(M$ $=3.1, S D=1.5)$, witchcraft $=.93(M=3.4, S D=1.7)$, superstition $=.89(M=1.6, S D=$ $1.2)$, spiritualism $=.91(M=2.8, S D=1.4)$, extraordinary life forms $=.91(M=3.3, S D=$ $1.3)$, and precognition $=81(M=3.0, S D=1.3)$. For both, the original and the revised measures, a global PBS score is calculated from the sum of all item scores, and averaging domain specific item scores derives specific domain scores. With lower scores indicating greater disbelief, average scores indicating uncertainty, and higher scores indicating greater belief. As the domains assessed in both the original and the revised PBS are the same, for the purpose of this review studies using either version will be compared without distinction.

Five one-semester post secondary educational intervention studies were found that used the PBS to assess belief in paranormal domains.

McLean and Miller (2010) used an advanced research methods course as a comparison for their intervention course entitled: "Parapsychology". No significant differences in belief levels were detected between the intervention and comparison groups at pre-test. However, the global PBS scores at post-test were significantly lower at post-test for the intervention group $(p<.001)$, but not for the comparison group.

Manza et al., (2010) employed two intervention courses and a behavioral sciences statistics course as a control course in their study. The first intervention course aimed to increase scientific reasoning by analyzing the claims of phenomena believers. This course 
however, deviated from the typical intervention as claims for both paranormal and nonparanormal pseudoscientific phenomenon were examined therein. The second intervention course was a behavioral sciences statistics a course, but differed from the comparison course in that half of the analyses discussed and conducted within the class used data from paranormal experiments. No significant differences in $\mathrm{PBS}^{15}$ scores were detected between groups at pre-test. However, the PBS scores in the scientific reasoning intervention group were significantly lower at post-test $(p<.001)$. No significant reductions were evidenced in the intervention statistics or the comparison statistics courses.

Burke, Sears, Kraus, and Roberts-Cady (2014) also included the evaluation of both paranormal and non-paranormal pseudoscientific phenomenon in their intervention course. Two comparison groups were included in this study. A "treatment as usual" group comprised of participants enrolled in core psychology courses ${ }^{16}$ that have scientific reasoning components embedded in the curriculum, and a "philosophy" group comprised of student participants in two philosophy courses designed to identify and evaluate arguments and their underlying assumptions. It is important to note that the philosophy students did discuss paranormal domains (i.e., religious beliefs and superstitions) within the course, and it is not stated as to whether or not paranormal topics were directly addressed within the "treatment as usual" psychology courses. Regardless, no significant differences were detected between groups at pre-test. At post-test significantly lower global PBS scores are reported for both the intervention course and philosophy course

\footnotetext{
${ }^{15}$ The PBS in this study, despite its item similarity with Tobacyk and Milford (1983), is reported as being created by Sparks, Nelson, and Campbell (1997).

${ }^{16}$ Comparison courses comprised of student participants from 7 psychology courses ranging from Introductory Psychology to Senior Level Seminar.
} 
( $p$ 's $=.02$ and .01 , respectively). No significant changes in PBS scores were detected among the "treatment as usual" groups.

The other two of these five studies differed in notable ways from the typical intervention courses.

Irwin's (1990) study did employ a typical scientific reasoning intervention in which paranormal claims were directly addressed. Throughout the course however, Australian student participants were reminded of Irwin's sympathetic perspective on paranormal beliefs. Irwin (1990) does not report conducting a manipulation check to ensure student participants accepted the instructor/investigator's sympathetic view on the paranormal. As Irwin's biography is highlighted on the Parapsychological Association (PA) website (The Parapsychological Association, 2017a), and the PA states the goal of ensuring that mainstream science does not dismiss or ignore paranormal phenomenon (The Parapsychological Association, 2017b), it is likely Irwin's sympathetic view was perceived as genuine. It is reported that, in addition to the experimenter's perspective on the legitimacy of paranormal phenomenon, the sympathetic perspective was taken to avoid demand effects potentially associated with skeptical courses. There was no comparison group in this study, but it is reported that the pre-test mean score corresponds to the neutral response on the PBS (i.e., 75) and so, despite the absence of a comparison group, it appears that the course did not appeal predominantly to individuals with a penchant for paranormal topics. Irwin (1990) found a significant reduction global PBS scores, from neutral towards disbelief, after the education intervention $(p=.01)$.

Stark's (2012) intervention also aimed to increase scientific reasoning by emphasizing the differentiation of science from pseudoscience via claim evaluation. 
However, this intervention differed from the typical interventions in that examples of paranormal phenomenon were explicitly avoided. Despite the lack of direct assessment of paranormal phenomena, significant reductions at post-test were obtained on global PBS scores $(p<.001)$, and on PSI $(p<.05)$, witchcraft $(p<.05)$, spiritualism $(p<.05)$, and precognition $(p<.05)$ domains of the PBS.

\subsubsection{Alternate Measures of Paranormal Belief}

The other six identified studies reporting on the effects of educational interventions in paranormal belief reduction used alternate, often created for the study, measures of paranormal beliefs. The results of these studies are reported in order of year of publication.

Gilliland (1929) compared the "superstition and prejudices" of two postsecondary samples, one university sample and one college sample, before and after a course covering related topics. It is important to note that although no test of significance is reported, Gilliland (1929) does state that the age of the college sample is markedly older than the university sample. A review of the items used in this survey ${ }^{17}$ shows that paranormal domains (i.e., PSI, astrology, luck/superstition, and spiritual healing) were assessed along side of psychological myths. Nonetheless, Gilliland (1929) reported that a significant reduction in superstitions and prejudices were detected in both the university and the college samples post educational intervention $(p$ 's $<.001)$.

Emme (1940) surveyed 34 student participants and reports that, at pre-test, only 10 held preexisting "superstitious" beliefs. Beliefs assessed in the study survey included graphology, astrology, phrenology, fortune telling and mind reading, palmistry, rod-

\footnotetext{
${ }^{17}$ The survey used herein was adapted from Nixon (1925).
} 
divining, faith healing and spiritualism, superstitions, as well as myths pertaining to physical appearance, anger, and the effects of handedness. Emme (1940) found that after a course examining such topics, the earlier reported strong beliefs for these individuals were reduced to weak belief or disbelief ( $p$-values not reported).

Gray (1985) created a survey that assessed 10 paranormal or otherwise pseudoscientific domains: ESP, UFOs, astrology, ghosts, the Bermuda triangle, VonDaniken, psychic healing and surgery, miracles, biorhythms, and reincarnation/life after death. Canadian university student participants responded to items on this survey by first indicating either Do not believe or Believe. Second, those who indicated belief were asked to indicate the strength of belief: $1=$ Weak to $4=$ Strong. Three intervention groups ${ }^{18}$ and one comparison group, a third year psychology course, completed the survey at the beginning and the end of the term. One intervention group was also surveyed a third time, for a one-year follow-up. Gray (1985) reports that a significant number of respondents changed from a pre-test belief perspective to a reported non-belief position at post-test for the following phenomenon: ESP, UFOs, the Bermuda triangle, VonDaniken, psychic healing, and reincarnation $(p$ 's $<.05)$. Also, for those that still reported belief in any of the ten phenomena, strength of belief was significantly reduced at post-test $(p$ 's $<.05)$. No changes however, were detected in the comparison group. Importantly, while reported level of belief at one-year follow up had increased since the initial post-test, the levels of belief one year after the course were still significantly lower than pre-test levels $(p$ 's $<.05)$.

\footnotetext{
${ }^{18}$ The typical scientific reasoning course intervention was administered in three different terms. As no significant pre-test differences were detected in intervention groups, data from these groups was collapsed into one intervention group condition.
} 
Swords (1990) used a 30-item belief survey, wherein respondents are instructed to indicate their belief in the reality of each item using a 10-point scale with labeling endpoints: $1=$ No chance at all, and $10=$ Absolute certainty. Swords (1990) reports results collapsed across multiple terms of the intervention course, and did not use a control/comparison group in this study. Regardless, across multiple terms of the intervention course significant decreases in belief were detected in the following phenomena: general, taking a beating, paraPSI, resisting the flow, ET, cryptozoology, religion \& spirit, and subtle energy ( $p$-values not reported). That being said, it is not clearly stated what survey items are used to assess each specific phenomenon. Nor is it evident what phenomena are represented by the categories labeled "taking a beating" and "resisting the flow".

Dougherty (2004) created a survey that assesses belief in 13 paranormal domains: psychic healing, ESP, haunted houses, the Devil, ghosts, telepathy, ET, clairvoyance, talking to the dead, astrology, witches, reincarnation, and channeling. Participants responded to each domain with: Believe, Do not believe, or Not sure. It is reported that significant increases in skepticism were detected at post-test for the domains of spiritual healing, ESP, ghosts, alien visitation, clairvoyance, the Devil, and astrology ( $p$ 's $<.001)$. Changes in these categories also contributed to a significant change in over-all skepticism levels.

The intervention used by Kane, Core, and Hunt (2010) was much the same as others, but included the evaluation of evidence for paranormal and non-paranormal pseudoscientific claims. Student participants from three core $1^{\text {st }}, 3^{\text {rd }}$ and $4^{\text {th }}$ year psychology courses were used as a control group. A 52-item belief measure was created 
for this study that assessed belief in seven paranormal or otherwise pseudoscientific domains: ESP/psychics, alternative medicine/healing, omens/superstitions, UFOs and alien abductions, astrology, creationism, and Judeo-Christian/biblical beliefs. The measure used a 7 point Likert type response scale, with labeling endpoints $1=$ Strongly Disbelieve to 7 = Strongly Believe. No significant between group differences were detected on any belief category at pre-test. In an effort to circumvent demand effects, Kane, Core, and Hunt (2010) pseudo-randomly assigned half of their intervention and comparison participants to a 'hindsight' condition for the post-test. In the hindsight condition, participants were instructed not to report their current level of belief, but instead to recall and report the strength of their beliefs at pre-test. After attitude change, hindsight bias lessens one's ability to accurately recall the strength of previously held attitudes/beliefs (for discussion see: Kahneman, 2013). As such, these investigators hypothesized that at post-test, those in the hindsight condition would "recall" weaker levels of pre-test belief, if levels of paranormal belief had in fact been reduced during the intervention.

With the exception of the creationism and Judeo-Christian/biblical belief categories, which remained unchanged in all groups, significant reductions in paranormal and pseudoscience beliefs were evident at post-test for the regular intervention group ( $p$ $<.001)$. No significant reductions in belief were detected in the regular comparison group. Participants in the intervention-hindsight group "recalled" themselves being significantly more skeptical at pre-test $(p<.001)$, and no significant differences were detected between the pre- and post-test belief levels in the hindsight-comparison group. This finding suggests that the reduction of paranormal belief levels evidenced in the 
intervention groups were not merely an artifact of experimental design (i.e., demand effects due to direct debunking of phenomena).

\subsection{DISCUSSION}

The current study aimed to assess whether interventions designed to improve overall scientific reasoning reduced belief in paranormal phenomenon. The results of the systematic review revealed that, despite the earliest study being published in 1929, relatively few studies have empirically evaluated the effects of such interventions. For the studies that have been conducted however, all report statistically significant reductions in these erroneous beliefs. This could lead one to conclude that teaching young and older adults to reason scientifically does reduce their beliefs in scientifically unsubstantiated paranormal phenomena. The efficacy of these interventions has even led some researchers to assert that scientific reasoning courses, like the interventions examined herein, might be a necessary addition to the psychology undergraduate curriculum (e.g., Banziger, 1983; Borgo, 2018; Stark, 2012).

The systematic review did however reveal methodological issues among the relevant studies that need to be considered. First, as noted by Irwin (1990), the resultant post-test reductions in paranormal beliefs may be attributable to demand effects. Participants may have been reporting lower belief in phenomenon due to perceived experimenter expectations rather than due to a real corresponding personal belief change. Given their methodologies, the results reported by Stark (2012) with no paranormal course content, Kane, Core, and Hunt (2010) with the hindsight bias condition, and Irwin (1990) with a "sympathetic" perspective, do provide reassurance that the reduction effects post education intervention are not solely a manifestation of demand effects. 
Additional research is required to be confident in the efficacy of these interventions however.

Second, the longevity of the reduction effects evidenced is uncertain. Only two studies assessed paranormal belief level beyond the initial post-test time periods: Banziger (1983) included a 6 month follow-up and Gray (1985) included a one year follow-up. It is reassuring that reported belief levels remained significantly lower than pre-test levels in both of these studies. Although these two studies suggest that the intervention effects are somewhat enduring, additional research is required to ascertain the long-term stability and the magnitude of these effects.

Third, and arguably most important, with one exception, all reviewed interventions directly addressed and debunked the specific phenomena that interventions were designed to reduce. Aside from the potential for inducing demand effects at posttest as was previously discussed, critically evaluating these specific phenomena leads to the question of whether the generic scientific reasoning skills conveyed during the intervention were actually learned, and whether these skills generalize to evaluating novel pseudoscientific phenomenon (i.e., phenomenon not directly debunked). It could be the case that student participants learned that the evidence was insufficient for each phenomenon highlighted within the course and adjusted their beliefs accordingly. The belief reduction evidenced does not necessarily indicate that participants learned the general skills necessary to critically evaluate all phenomena. Rather, reductions evidenced could be more parsimoniously explained by the explanation that direct debunking of specific paranormal phenomenon reduces belief in these specific phenomena. 
Within this review, Stark (2012) was the only study located that explicitly avoided the use of paranormal examples throughout the scientific reasoning intervention course. Stark (2012) did report a significant reduction in global paranormal beliefs at post-test, although no comparison group was utilized. Hence, Stark's (2012) study does provide some evidence for the learning and generalizability of evaluative skills taught in scientific reasoning interventions. Nonetheless, given the preponderance of direct debunking of specific paranormal phenomenon within these intervention courses, the generalizability of skills conveyed during the interventions is largely unknown, and additional research along these lines is warranted.

On a related issue, given the data available, synthesizing belief reductions within each domain of pseudoscience belief (paranormal and non-paranormal) was not possible. During the systematic literature review, it was found that paranormal and non-paranormal pseudoscience domain scores were rarely reported. It is possible that reductions in global belief scores are evidenced due to large reductions within only a select few domains. Future research should therefore assess the impact of scientific reasoning education between (i.e., domains) as well as across (i.e., global) paranormal domains. In doing so, similarities and differences among domains can be ascertained. It may be the case that different domains call for different interventions, and/or that some domains are more change resistant than others, as was the case with traditional religious beliefs in Kane, Core, and Hunt's (2010) study.

An additional, but related, avenue of research that may be worthwhile pertains to examining the extent to which scientific reasoning training generalizes to other nonparanormal pseudoscientific beliefs (i.e., homeopathy, conspiracy theories, etc.). A few 
of the studies presented in this systematic review used alternative measures of paranormal belief that did include evaluation of non-paranormal pseudoscientific beliefs such as alternative medicines, the Bermuda triangle, and biorhythms (e.g., Gray, 1985; Kane et al., 2010), or unsubstantiated psychological myths (Emme, 1940; Gilliland, 1929). These studies report significant reductions in global belief scores post intervention. Here again however, the phenomena assessed at post-test was the same as those directly debunked within the course. As such, it cannot be determined whether belief reductions were due to newly acquired scientific literacy skills or the direct debunking of these phenomena. Moreover, with the exception of a few domains (e.g., the Bermuda triangle), many of the domains assessed in these studies are not comparable with one another. Nor do they assess the broad spectrum of currently popular pseudoscientific beliefs (e.g., flat earth (Brait, 2016; Svarrior, 2013); anti-vaccination (Merlan, n.d.); "dietainment” (Keene, 2015); etc.). Thus, additional carefully controlled research is required to establish if the evaluative skills taught within these courses generalize to evaluating novel nonparanormal pseudoscience domains.

The current review revealed an additional, and disconcerting, issue within the literature. The majority of study participants in the intervention and comparison groups were in advanced years of their academic programs. That high levels of paranormal beliefs were reported amongst participants despite advanced education needs to be explored. As noted by Burke et al., (2014), it is typical to infuse scientific reasoning within the core psychology curriculum. If these indirect efforts were effective however, students in advanced years of their educational programs should have lower levels of belief in phenomena that are scientifically unsubstantiated. This was not the case across 
all of the studies reviewed. A trend that is emphasized when one contrasts intervention groups comprised of lower level students with comparison groups comprised

predominantly of upper level students (e.g., Burke et al., 2014, Manza et al., 2010, Morier \& Keeports, 1994). This finding is especially disconcerting when it is considered that both the American and Canadian Psychological Associations assert that critical thinking skills, including scientific reasoning and the ability to evaluate evidence, are a primary goal of psychology education (American Psychological Association, n.d.; Norcross et al., 2016; Service \& O’Neill, 2002). Longitudinal research is required to establish whether the current these primary goals of the undergraduate psychological education are being realized via this indirect or infused curriculum.

\subsection{CONCLUSION}

Despite the issues detected within the studies highlighted in the systematic review, the evidence does indicate a consistent reduction in paranormal beliefs postintervention. However, as the majority of interventions directly debunked specific paranormal and non-paranormal pseudoscientific phenomenon part of the reduction could be attributable to demand effects. Additionally, it is quite possible that while specific belief in the phenomena being debunked was reduced, it may not be due to a general increase in critical scientific reasoning skills. Parsing out the mechanisms behind belief reduction, while eliminating these alternate explanations is required in future research. Stark's (2012) study could serve as the model for future scientific reasoning intervention. By avoiding the discussion of phenomenon that the intervention is supposedly designed to reduce, it is possible to reduce demand effects and more strongly attribute any observed reduction in paranormal belief to a general improvement in critical thinking. 
In contrast, indirect efforts to impart scientific reasoning skills appear ineffective. Presumably, if these indirect efforts were effective, advanced students would forego pseudoscientific beliefs, yet the results of this review have shown this not to be the case. Longitudinal research is therefore necessary to assess whether the expected gains in reasoning ability are actually being realized via the current scientific reasoning infused psychology undergraduate programs. Some have suggested that scientific reasoning courses might be a necessary addition to the early psychology curriculum. Courses such as these may, provide basic understanding of scientific reasoning and critical evaluation that could then be built upon via the scientific reasoning infusions currently in place. Thus, in addition to the aforementioned longitudinal research, future research should undertake to evaluate the value added by the inclusion of early program direct scientific literacy education. 


\section{CHAPTER SIX. SUMMARY AND DISCUSSION}

This thesis focused on two types of fallacious beliefs: gambling specific fallacies and belief in the paranormal. In a series of four studies, the following research questions were addressed:

1. What errors constitute gambling fallacies and which assessment instruments best capture these fallacies?

2. What is the etiological relationship between gambling fallacies and problem gambling?

3. What individual differences characterize those who are susceptible to gambling fallacies and how are these individual differences similar or different from those that characterize people susceptible to paranormal beliefs?

4. How effective are interventions designed to reduce fallacious beliefs and what are the important elements of effective interventions?

The studies conducted to investigate these questions, and the results thereof, are discussed below.

Study One (Chapter Two)

Investigations of fallacious beliefs require first that the belief type be defined. While paranormal beliefs have long been studied and categorized as a unique type of fallacious belief, gambling fallacies have received much less attention. Indeed, prior to the current investigation, no study had been undertaken to identify the full scope of errors that should be categorized as gambling-specific fallacies. In addition, there was no consensus on how to best measure these fallacies. The first study of this thesis series 
undertook this challenge. A total of six distinct (but related) gambling fallacies were repeatedly identified in the literature: the 'hot hand fallacy', the 'Monte Carlo fallacy', the 'belief that luck is dispositional', the 'illusion of control', 'insensitivity to sample size', and 'base rate neglect'. The operationalization of gambling fallacies not only provides a foundation for future research, but also provides a lens through which past research can be objectively evaluated.

This first study also undertook a critical examination of the reliability and validity of all available instruments designed to measure susceptibility to these fallacies. A total of 18 instruments were identified. Most instruments were found to have good internal consistency as well as adequate convergent and external validity. Relatively few demonstrated test-retest reliability and/or discriminant validity. However, the main area of concern was content validity. Although instruments focusing on a particular fallacy tended to have adequate content validity, this was not true of the comprehensive instruments. In addition to insufficient coverage of the fallacies, most comprehensive instruments included questions pertaining to motivations for gambling, attitudes about gambling, and/or problem gambling symptomatology (e.g., chasing losses), which likely inflated their statistical association with problem gambling. Many of these comprehensive instruments also wrongly assumed that no skill is involved in any form of gambling. The inadequate content validity of most comprehensive gambling fallacy instruments drew into question the strong etiological relationship gambling fallacies were presumed to have with problem gambling (e.g., Delfabbro, 2004; Delfabbro \& Winefeld, 2000; Gaboury \& Ladouceur, 1989; Goodie \& Fortune, 2013; Jacobsen et al., 2007; Joukhador et al., 2003; MacKay \& Hodgins, 2012; Miller \& Currie, 2008; Myrseth et al., 
2010; Toneatto et al., 1997; Wohl et al., 2007; Xian et al., 2008). This concern was compounded by the fact that all research reporting this association had been crosssectional and correlational in nature.

Study Two (Chapter Three)

Thus, Study 2 (Chapter Three) involved a re-evaluation of the relationship between gambling specific erroneous cognitions and problem gambling in a large scale ( $n$ $=4,121$ ) five-year longitudinal study of gambling that used a psychometrically sound measure of gambling fallacies ('Gambling Fallacies Measure'). Therein it was found that gambling fallacies do appear to play an etiological role in the development of subsequent problem gambling, but that this relationship is relatively weak, in part due to the high prevalence of gambling fallacies among non-gamblers and recreational gamblers. Thus, it would appear that the 'robust' relationship with problem gambling touted throughout the gambling and addictions literature may have been inflated due to the specific instruments utilized to assess gambling fallacies as well as the cross-sectional nature of these investigations. In addition, it was found that the relationship between gambling fallacies and problem gambling is bidirectional, indicating that while gambling fallacies are related to subsequent increases in problematic gambling behaviours, engagement in gambling also appears to serve to subsequently increase gambling fallacy endorsement. The finding that problematic gambling engagement plays a role in the subsequent endorsement of gambling fallacies was novel, and has since been independently replicated in another longitudinal investigation of these variables (Nicholson, Graves, Ellery, \& Afifi, 2016). 
The main implication of the above findings is the need to re-examine the dominant focus that problem gambling prevention and treatment programs have in trying to correct gambling fallacies (e.g., Fortune \& Goodie, 2012; Ladouceur et al., 2001, 2002, 1998; Toneatto, 2002). It is instructive to note that while many of these prevention programs are known to reduce gambling fallacies, very few of them have demonstrated significant changes in actual gambling behaviour (Gaboury \& Ladouceur, 1993; Turner, Macdonald, Bartoshuk, \& Zangeneh, 2008; Williams, 2002; Williams, West, et al., 2012). Furthermore, those few programs that have reduced gambling and future problem gambling (e.g., Williams, Wood \& Currie, 2010) have been multifaceted in their nature, with gambling fallacies comprising a small part of the program. In a similar way, in the treatment of problem gambling, there is very little evidence that a) treatments focusing on gambling fallacies have achieved superior results compared to other treatments, and b) that the reduction in gambling that occurs (with any of these treatments) has enduring effects (Cowlishaw et al., 2012; Petry, Ginley, \& Rash, 2017). The point being made is that the weak empirical relationship between gambling fallacies and subsequent problem gambling found in the present results provides at least a partial explanation for this above pattern of results.

\section{Study Three (Chapter Four)}

Although there has been considerable attention paid to the relationship between gambling fallacies and problem gambling, there has been relatively little study of what predisposes individuals to develop gambling fallacies in the first place. Study 2 identified that gambling involvement is one of these contributors. However, beyond 
gambling involvement, there have been no other studies on this topic. This, then, was one of the purposes of Study 3 .

Study 3 drew from the literature regarding susceptibility to another type of fallacious belief with which gambling fallacies have been associated (Leonard, Williams, \& Vokey, 2015): belief in the paranormal. Thus, in addition to measures of gambling engagement, all individual difference variables that had previously been found to be associated with paranormal beliefs were assessed for their relationship with gambling fallacies in a sample of Lethbridge community members and university students $(n=$ 266). The results showed that the variables having the strongest cross-sectional relationship with gambling fallacies were: greater reliance on intuitive thought, a less rational cognitive style, and poorer probabilistic reasoning ability. In addition, adding support to previous studies (e.g., Leonard \& Williams, 2016; Yakovenko et al., 2016), gambling engagement was again found to predict gambling fallacy endorsement.

These findings complement previous work that has demonstrated that education in probability and statistical inference does reduce gambling fallacies (e.g., Williams \& Connolly, 2006). However, it is also clear from the present research that improved probabilistic reasoning may not be sufficient on its own. It remains an empirical question whether training to increase probabilistic reasoning ability also reduces reliance on intuition and increases rational cognitive style. Longitudinal research would also be required to assess if such training is sufficient to maintain resistance to these fallacies over time. It may be the case that the most effective interventions will comprehensively target each of the predisposing factors. 
Two additional points should be raised regarding Study 3. First, this was the first study to have investigated the factors, beyond gambling engagement, that lead to gambling fallacy susceptibility. Additional research is required to replicate, or refute, the findings of this study. Second, despite the broad spectrum of individual difference measures included in this study, much of the variance in gambling fallacy scores was not explained. Future research is necessary to identify other factors that contribute to fallacy susceptibility.

As noted, the literature on paranormal beliefs was used to inform the investigation of individual differences in this study. In addition to the previously evidenced association between these two types of fallacious beliefs, and beyond the fact that they are each endorsement of fallacious constructs, gambling fallacies and belief in the paranormal appeared to share other similar characteristics. For example, both types of beliefs are prevalent throughout the general population (Chapman University, 2017; Leonard \& Williams, 2016; Moore, 2005; Pechey \& Halligan, 2011; Tyson et al., 2011), and cognitive errors appear to play a role in susceptibility to both types of fallacious beliefs, including the misunderstanding of general statistical principles and a misunderstanding of randomness (Gambling Fallacies: Leonard, Williams, \& Vokey, 2015; Paranormal Beliefs: Blackmore \& Troscianko, 1985; Bressan, 2002; Brotherton \& French, 2014; Dagnall, Parker, \& Munley, 2007; Musch \& Ehrenberg, 2002; Pennycook, Cheyne, Koehler, \& Fugelsang, 2013; Rogers, Davis, \& Fisk, 2009; Rogers, Fisk, \& Wiltshire, 2011). Thus, it seemed reasonable to hypothesize that the factors for susceptibility to gambling fallacies might be similar to those associated with paranormal beliefs. 
So, in addition to identifying the factors associated with gambling fallacies, the second goal of Study 3 was to compare how similar or different the susceptibility factors for gambling fallacies were to those associated with paranormal beliefs. Consistent with our hypothesis, it was found that a very similar set of individual differences predict both gambling fallacy endorsement and belief in the paranormal, namely: greater reliance on intuitive thought, lower levels of analytical thought, and poorer probabilistic reasoning ability. Although these findings are novel in the gambling fallacy literature, they add support for the importance of these factors in the paranormal belief literature (e.g., Aarnio \& Lindeman, 2005; Blackmore \& Troscianko, 1985; Bressan, 2002; Brotherton \& French, 2014; Dagnall et al., 2007; Gervais, 2015; Gervais \& Norenzayan, 2012; Lindeman \& Aarnio, 2007; Musch \& Ehrenberg, 2002; Pennycook et al., 2013; Rogers et al., 2009; Rogers et al., 2011).

Based on the findings of the Study 3, it appears that the predisposition to erroneous beliefs is more generic, rather than belief-type specific. That being said, gambling fallacies and paranormal beliefs are not perfectly correlated. For example, gambling engagement contributed significantly to the explanation of variance in gambling fallacy scores above and beyond the predisposing individual difference factors, whereas gambling engagement was neither associated with, nor predictive of paranormal belief. This finding suggests that belief-type specific experience may be one factor that delineates belief type endorsement, a hypothesis consistent with some previous literature on paranormal belief (e.g., Orenstein, 2002; Thalbourne, 2009). Unfortunately, no paranormal belief variable analogous to gambling engagement was evaluated during this study (e.g., religious engagement). Thus, additional research should seek to evaluate 
whether experience with paranormal belief type activities a) reliably predicts paranormal belief, and b) distinguishes between gambling fallacy and paranormal believers.

Longitudinal research is also required to determine whether such experience engenders belief, or if belief instigates engagement. It remains a possibility that the relationship between paranormal belief and belief type specific experience/engagement is bidirectional as was the case with gambling engagement and gambling fallacy endorsement.

Of final note, it is worthwhile to recognize that the profile of believers, regardless of fallacious belief type, is comprised of factors that appear to be malleable. As noted previously, although there are studies that have reported effective gambling fallacy reduction interventions (Williams \& Connolly, 2006; Williams et al., 2010), the number of studies is relatively small. In the paranormal literature on the other hand, numerous intervention-based studies have been reported (e.g., statistics training: Fong, Nisbett, \& Krantz, 1993; Kosonen \& Winne, 1995, general psychology education: Lamal, 1979; McKeachie, 1960, general critical thinking education: Wesp \& Montgomery, 1998, psychology specific critical thinking education: Bensley, Crowe, Bernhardt, Buckner, \& Allman, 2010). That similar profiles were detected between gambling fallacy endorsers and paranormal believers, also suggests that intervention efforts designed to reduce one type of fallacious belief (i.e., paranormal beliefs) may be effective for reducing both types of fallacious beliefs (i.e., gambling specific and paranormal).

\section{Study Four (Chapter Five)}

Thus, Study 4 endeavored to synthesize the literature evaluating the efficacy of educational interventions designed to reduce belief in paranormal phenomena. A 
surprisingly small number of studies $(n=15)$ involved a pre-post design. There was a fair degree of uniformity between these 15 studies, with all 15 endeavoring, in a general way, to facilitate the development of 'scientific reasoning', typically by critically and directly examining the evidentiary basis of specific paranormal claims. In addition, the large majority of these studies were conducted with university students as part of a single semester course. The findings of these studies were all similarly uniform, with each of them demonstrating significant reductions in paranormal belief at post-test; with some preliminary evidence showing that the reductions may be enduring ( 6 months, Banziger, 1983; 12 months, Gray, 1985). Importantly, it was also observed that the same reductions are not achieved in more generic scientific literacy 'infused' courses (Burke et al., 2014; Kane et al., 2010; Manza et al., 2010; McLean \& Miller, 2010; Morier \& Keeports, 1994).

However, two study design issues temper confidence in these findings. To begin with, few of these interventions employed a comparison group (Burke et al., 2014; Kane et al., 2010; Manza et al., 2010; McLean \& Miller, 2010; Morier \& Keeports, 1994), without which the meaningful interpretation of any reduction effects is limited. A second issue concerns the fact that with the exception of one study (Stark, 2012), each intervention involved the direct 'debunking' of the phenomena the intervention had aimed to reduce. As a consequence, it is possible that some of the resultant paranormal belief reductions are due to demand effects rather than improved scientific reasoning ability that independently led to a decrease in paranormal belief. Thus, the generalizability of these interventions to phenomena other than those directly debunked (e.g., gambling fallacies), although plausible, remains uncertain. Reassuringly, Stark's 
(2012) study explicitly avoided the direct evaluation of paranormal phenomenon and still found statistically significant reductions in paranormal beliefs.

A final issue concerns the efficacy of indirect methods of imparting scientific reasoning skills. As noted by Burke, Sears, Kraus, and Roberts-Cady (2014), it is typical within core psychology courses to 'infuse' scientific reasoning within the course content. Presumably, if these indirect methods were achieving the goal of instilling critical scientific reasoning skills, advanced level students would forego belief in scientifically unfounded phenomenon. Yet, across all studies examined, advanced level student maintained high levels of paranormal beliefs. This trend becomes more clear when one notes the pre-test equivalency between lower level intervention groups and upper level comparison (e.g., Burke et al., 2014, Manza et al., 2010, Morier \& Keeports, 1994). At best, this trend could indicate that indirect methods used to impart scientific reasoning do not lead to independent and critical re-evaluation of personal beliefs. In the worst-case scenario however, this could indicate that these indirect efforts are generally ineffective. As critical thinking skills, including scientific literacy, are among the fundamental goals of many university programs (e.g., psychology, (American Psychological Association, n.d.; Norcross et al., 2016; Service \& O’Neill, 2002); nursing, (Papathanasiou, Kleisiaris, Fradelos, Kakou, \& Kourkouta, 2014); law, (Jacobson, 2009); etc.)), future research efforts should be devoted to evaluating whether scientific reasoning infusions are manifesting in legitimate and generalizable scientific reasoning gains. If not, introductory level scientific reasoning/critical thinking education may be a necessary addition university curriculum. 


\subsection{FUTURE DIRECTIONS}

The findings of the studies presented in this thesis highlight areas that future research should seek to address.

With respect to interventions designed to dispel gambling fallacies, having identified the confounded nature of most comprehensive gambling fallacy instruments, suggests that many of these interventions are likely in need of revision and re-evaluation (e.g., Fortune \& Goodie, 2012; Ladouceur et al., 2001, 2002, 1998; Toneatto, 2002). As mentioned previously, it would also be of interest, and a novel contribution to the literature, to ascertain the longevity of the reduction evidenced after effective comprehensive educational interventions (e.g., Williams \& Connolly, 2006; Williams et al., 2010). In a similar vein, examining whether these interventions could be used to inoculate individuals against the formation of gambling fallacies, rather than simply correcting them after they have developed, would be a worthwhile pursuit.

That gambling fallacies were found not to be central to the development of problem gambling suggests that the efficacy of problem gambling treatment and prevention programs, that focus predominantly on the correction of these fallacious beliefs, requires re-evaluation. Given the harms associated with problem gambling, the identification and implementation of effective problem gambling prevention and treatment programs should remain a research priority.

Additional research should also aim to investigate the possibility that these fallacious beliefs may play a mediating role in problem gambling. Gambling fallacies may be contributing to the continuation of gambling problems by impacting gambling related coping and/or motivation for example. It may be that gambling fallacies are a 
means by which cognitive dissonance is reduced, when dissonance is experienced from having lost time and money gambling ${ }^{19}$. Gambling fallacies may also be influencing motivation to gambling; thereby explaining continued gambling/financial risk taking. Believing that losses will be balanced out with gains could increase motivation to engage in financial risk taking (gambling or otherwise). These remain questions to be answered in future empirical investigations.

A profile of individual differences characterized by poor probabilistic reasoning ability, diminished tendency to engage in analytic thinking, and greater reliance on intuitive thought was found to be associated with fallacious belief susceptibility for both gambling fallacies and belief in the paranormal. Together however, these factors left much variance unexplained. Thus, future investigations should seek to identify other factors that contribute to erroneous beliefs susceptibility. The identified fallacious belief susceptible profile suggests that it may be productive to evaluate the role additional cognitive factors such as need for cognition and intolerance to uncertainty as these factors may influence desire to engage in analytic thinking or even reinforce reliance on intuitive thought. Given the variance accounted for by belief type specific engagement (i.e., gambling engagement in gambling fallacy susceptibility), future research exploring belief type specific engagement would also be justifiable. Along these lines, the impact of social/environmental learning may be informative. Considering for example, belief systems passed on directly through generations including religious convictions or learning derived from culturally pervasive belief systems such as the Asian cultural focus on luck and superstition.

\footnotetext{
${ }^{19}$ Cognitive dissonance is mental discomfort experienced when behaviours contradict attitudes or beliefs, and it can be reduced by changing belief to account for behaviour (Festinger, 1957).
} 
The apparently malleable nature of the susceptibility factors identified in Study Three, allows for the optimistic expectation of correcting fallacious beliefs, provided appropriate interventions are implemented. The most effective interventions for fallacious beliefs however, have not yet been established. The review and synthesis of the existing literature in Study Four determined that there is only preliminary evidence supporting direct efforts to impart scientific reasoning as a useful means to reduce fallacious beliefs (i.e., Stark, 2012). Additional, and well controlled, study is required before firm conclusions can be drawn regarding the efficacy of scientific reasoning interventions for reducing paranormal and other fallacious beliefs (e.g., gambling fallacies, nonparanormal pseudoscientific beliefs, conspiracy theories, etc.). The results of this review were nonetheless informative for directing future examinations.

Future examinations of scientific reasoning interventions would be well served by using Stark's (2012) intervention as a template, and avoid the direct discrediting/debunking of dependent variable phenomena. Only in doing so, will it be possible to reduce or eliminate alternate explanations for post-intervention fallacious belief reductions (e.g., demand effects, specified learning, etc.). That being said, Stark's (2012) methodology did not make use of a comparison group, which is not advisable for future studies. As previously discussed, only in contrast with a comparison group, are belief reduction effects clearly understood. At the very least, future examinations of scientific reasoning interventions should 1) use a pre- post-test design, 2) make use of a comparison group, 3 ) intentionally and explicitly avoid the examination of dependent variable phenomena within the intervention (e.g., paranormal beliefs, gambling fallacies, etc.). Optimally, future studies would also 1) employ comparison groups that are 
comparable to the intervention group in years of education (see discussion of comparison groups employed in Study Four), 2) use sample sizes (in both intervention and comparison groups) sufficient for statistical power, 3) further reduce the potential for demand effects by including filler tasks assessments, and 4) include sufficient follow-up examinations to determine whether reduction effects are enduring.

A final direction for future research revealed in Study Four pertains to the efficacy of the indirect efforts to teach critical scientific thinking that are typical across many university programs. It is currently common practice to 'infuse' scientific reasoning within core course content rather than teach scientific reasoning skills directly. Nonsignificant differences in fallacious beliefs between lower level intervention students and upper level comparison groups, indicate that these indirect efforts, that are expected to produce science based critical thinkers, may not be effective. Cross-sequential program evaluations, evaluating whether scientific reasoning skills are in fact being realized via a scientific reasoning 'infused' university education, would therefore be prudent. It may be the case that direct, and early year (i.e., ${ }^{\text {st }}$ year), scientific literacy courses are a necessary addition to university programs, as these courses would provide a platform on which later 'infusions' could build. This too, is a question to be addressed in future research. 


\section{References}

Aarnio, K., \& Lindeman, M. (2005). Paranormal beliefs, education, and thinking styles. Personality and Individual Differences, 39(7), 1227-1236.

https://doi.org/10.1016/j.paid.2005.04.009

Abdollahnejad, R., Delfabbro, P., \& Denson, L. (2015). Personality disorders and erroneous beliefs in pathological gambling. International Journal of Mental Health and Addiction, 13(3), 376-390. https://doi.org/10.1007/s11469-014-95359

American Psychological Association. (n.d.). APA guidelines for the undergraduate psychology major: Version 2.0. Washington, D.C. Retrieved from http://www.apa.org/ed/precollege/undergrad/index.aspx

Andre, N. (2006). Good fortune, luck, opportunity and their lack: How do agents perceive them? Personality and Individual Differences, 40, 1461-1472.

Arcan, K., \& Karanci, A. N. (2015). Adaptation study of the Turkish Version of the Gambling-Related Cognitions Scale (GRCS-T). Journal of Gambling Studies, 31(1), 211-224. https://doi.org/10.1007/s10899-013-9414-5

Ayton, P., \& Fischer, I. (2004). The hot hand fallacy and the gambler's fallacy: Two faces of subjective randomness? Memory \& Cognition, 32(8), 1369-1378. https://doi.org/10.3758/BF03206327

Banziger, G. (1983). Normalizing the paranormal: Short-term and long-term change in belief in the paranormal among older learners during a short course. Teaching of Psychology, 10(4), 212-215.

Bar-Hillel, M. (1980). The base-rate fallacy in probability judgments. Acta Psychologica, 44(3), 211-233.

Baron, J. (2000). Thinking and Deciding (4th ed.). Edinburgh: Cambridge University Press.

Beck, A. T., Ward, C. H., Mendelson, M., Mock, J., \& Erbaugh, J. (1961). An inventory for measuring depression. Archives of General Psychiatry, 40, 561-571.

Billi, R., Stone, C. A., Marden, P., \& Yeung, K. (2014). Victorian Gambling Study: A Longitudinal Study of Gambling and Health in Victoria, 2008-2011. Victoria, Australia: Victorian Responsible Gambling Foundation.

Blackmore, S. J., \& Troscianko, T. (1985). Belief in the paranormal: Probability judgements, illusory control, and the "chance baseline shift." British Journal of Psychology, 76, 459-468. 
Blagrove, M., French, C. C., \& Jones, G. (2006). Probabilistic reasoning, affirmative bias and belief in precognitive dreams. Applied Cognitive Psychology, 20(1), 65-83. https://doi.org/10.1002/acp.1165

Blaszczynski, A., \& Nower, L. (2002). A pathways model of problem and pathological gambling. Addiction, 97(5), 487-499. https://doi.org/10.1046/j.13600443.2002.00015.x

Borgo, A. (2018). Why Pseudoscience Should Be Taught in College. Skeptical Inquirer, $42(1), 9-10$.

Brait, E. (2016, January 26). “I didn”t wanna believe it either': Rapper BoB insists the Earth is flat. The Guardian. Retrieved from http://www.theguardian.com/music/2016/jan/25/bob-rapper-flat-earth-twitter

Breen, R. B., \& Zuckerman, M. (1999). 'Chasing' in gambling behavior: Personality and cognitive determinants. Personality and Individual Differences, 27(6), 10971111. https://doi.org/10.1016/S0191-8869(99)00052-5

Bressan, P. (2002). The connection between random sequences, everyday coincidences, and belief in the paranormal. Applied Cognitive Psychology, 16(1), 17-34. https://doi.org/10.1002/acp.754

Brotherton, R., \& French, C. (2014). Belief in conspiracy theories and susceptibility to the conjunction fallacy. Applied Cognitive Psychology, 28, 238-248.

Burke, B., Sears, S., Kraus, S., \& Roberts-Cady, S. (2014). Critical Analysis: A Comparison of Critical Thinking Changes in Psychology and Philosophy Classes. Teaching of Psychology, 41(1), 28-36. https://doi.org/10.1177/0098628313514175

Calvin, S. (2009). Crazy ideas 101: How to teach skeptical thinking in the classroom. Skeptic, 15(1), 14-17.

Cantinotti, M., Ladouceur, R., \& Jacques, C. (2004). Sports betting: Can gamblers beat randomness? Psychology of Addictive Behaviors, 18(2), 143-147. https://doi.org/10.1037/0893-164X.18.2.143

Capitanucci, D., Smaniotto, R., \& Biganzoli, A. (2010). La prevenzione del gioco d'azzardo problematico negli adolescenti attraverso l'adattamento del video Lucky. Quaderni Italiani di Psichiatria, 29(1), 30-39. https://doi.org/10.1016/j.quip.2010.04.002

Chapman University. (2017, October 11). Paranormal America 2017: Chapman University Survey of American Fears 2017. Retrieved from https://blogs.chapman.edu/wilkinson/2017/10/11/paranormal-america-2017/ 
Chiu, J., \& Storm, L. (2010). Personality, perceived luck and gambling attitudes as predictors of gambling involvement. Journal of Gambling Studies, 26, 205-227.

Cohen, P., Cohen, J., Aiken, L. S., \& West, S. G. (1999). The Problem of Units and the Circumstance for POMP. Multivariate Behavioral Research, 34(3), 315-346. https://doi.org/10.1207/S15327906MBR3403_2

Cohen, S., \& Williamson, G. (1988). Perceived stress in a probability sample of the United States. In S. Spacapan \& S. Oskamp (Eds.), The social psychology of health (pp. 31-67). Thousand Oaks, CA, US: Sage Publications, Inc.

Cosenza, M., Baldassarre, I., Matarazzo, O., \& Nigro, G. (2014). Youth at stake: Alexithymia, cognitive distortions, and problem gambling in late adolescents. Cognitive Computation, 6(4), 652-660. https://doi.org/10.1007/s12559-014-9274$\mathrm{Z}$

Cosmides, L., \& Tooby, J. (1997). Evolutionary psychology: A primer.

Costa, P. T., \& McCrae, R. R. (1992). Revised NEO Personality Inventory (NEO PI-R) and NEO Five-Factor Inventory (NEO-FFI) professional manual. Odessa, FL: Psychological Assessment Resources.

Cote, D., Caron, A., Aubert, J., Desrochers, V., \& Ladouceur, R. (2003). Near wins prolong gambling on a Video Lottery Terminal. Journal of Gambling Studies, 19(4), 433-438.

Cowlishaw, S., Merkouris, S., Dowling, N., Anderson, C., Jackson, A., \& Thomas, S. (2012). Psychological therapies for pathological and problem gambling. Cochrane Database of Systematic Reviews. https://doi.org/10.1002/14651858.CD008937.pub2

Croson, R., \& Sundali, J. (2005). The gambler's fallacy and the hot hand: Empirical data from c asinos. Journal of Risk and Uncertainty, 30(3), 195-209. https://doi.org/10.1007/s11166-005-1153-2

Dagnall, N., Parker, A., \& Munley, G. (2007). Paranormal belief and reasoning. Personality and Individual Differences, 43(6), 1406-1415. https://doi.org/10.1016/j.paid.2007.04.017

Darke, P. R., \& Freedman, J. L. (1997). The Belief in Good Luck scale. Journal of Research in Personality, 31, 486-511.

Delfabbro, P. (2004). The stubborn logic of regular gamblers: Obstacles and dilemmas in cognitive gambling research. Journal of Gambling Studies, 20(1), 1-21. https://doi.org/10.1023/B:JOGS.0000016701.17146.d0 
Delfabbro, P. H., \& Winefeld, A. H. (2000). Predictors of irrational thinking in regular slot machine gamblers. The Journal of Psychology, 134(2), 117-128. https://doi.org/10.1080/00223980009600854

Diaz-Vilela, L., \& Alvarez-Gonzalez, C. J. (2004). Differences in paranormal beliefs across fields of study from a Spanish adaptation of Tobacyk's RPBS. The Journal of Parapsychology, 68, 405-421.

Dixon, M. R. (2012). Manipulating the illusion of control: Variations in gambling as a function of perceived ontrol over chance outcomes. The Psychological Record, $50(4), 6$.

Donati, M. A., Primi, C., \& Chiesi, F. (2014). Prevention of problematic gambling behavior among adolescents: Testing the efficacy of an integrative intervention. Journal of Gambling Studies, 30(4), 803-818. https://doi.org/10.1007/s10899013-9398-1

Dougherty, M. J. (2004). Educating believers: Research demonstrates that courses in skepticism can effectively decrease belief in the paranormal. Skeptic, 10(4), 3135 .

Dunn, T. J., Baguley, T., \& Brunsden, V. (2014). From alpha to omega: A practical solution to the pervasive problem of internal consistency estimation. British Journal of Psychology, 105(3), 399-412. https://doi.org/10.1111/bjop.12046

Eckblad, M., \& Chapman, L. J. (1983). Magical ideation as an indicator of Schizotypy. Journal of Consulting and Clinical Psychology, 51(2), 215-225.

Ejova, A., Delfabbro, P. H., \& Navarro, D. J. (2015). Erroneous gambling-related beliefs as illlusions of primary and secondary control: A confirmatory factor analysis. Journal of Gambling Studies, 31(1), 133-160. https://doi.org/10.1007/s10899013-9402-9

el-Guebaly, N., Casey, D. M., Currie, S., Hodgins, D. C., Schopflocher, D., Smith, G. J., \& Williams, R. J. (2015). The Leisure, Lifestyle, \& Lifecycle Project (LLLP): A longitudinal study of gambling in Alberta (No. Final Report for the Alberta Gambling Research Institute).

Ellis, B., \& Hicken, M. (2016, May 10). Scam with more victims than Madoof shut down in the U.S. Cable News Network. Retrieved from http://money.cnn.com/2016/05/09/news/maria-duval-fraud-settlement/

Emme, E. E. (1940). Modification and origin of certain beliefs in superstition among 96 college students. Journal of Psychology, 10, 279-291.

Epstein, R. A. (2012). The theory of gambling and statistical logic. Academic Press. 
Ferland, F., Ladouceur, R., \& Vitaro, F. (2002). Prevention of problem gambling: Modifying misconceptions and increasing knowledge. Journal of Gambling Studies, 18(1), 19-29.

Festinger, L. (1957). A Theory of Cognitive Dissonance. California: Stanford University Press.

Fichten, C. S., \& Sunerton, B. (1983). Popular horoscopes and the "Barnum Effect." Journal of Psychology, 114, 123-134.

Fortune, E. E., \& Goodie, A. S. (2012). Cognitive distortions as a component and treatment focus of pathological gambling: A review. Psychology of Addictive Behaviors, 26(2), 298-310. https://doi.org/10.1037/a0026422

Frederick, S. (2005). Cognitive reflection and decision making. Journal of Economic Perspectives, 19(4), 25-42. https://doi.org/10.1257/089533005775196732

Gaboury, A., \& Ladouceur, R. (1989). Erroneous perceptions and gambling. Journal of Social Behavior \& Personality, 4(4), 411-420.

Gaboury, A., \& Ladouceur, R. (1993). Evaluation of a prevention program for pathological gambling among adolescents. The Journal of Primary Prevention, 14(1), 21-28. https://doi.org/10.1007/BF01324653

Gerstein, D., Hoffman, J., Larison, C., Engelman, L., Murphy, S., Palmer, A., ... Hill, M. A. (1999). Gambling Impact and Behavior Study: Report to the National Gambling Impact Study Commission. Chicago, Illinois: National Opinion Research Center at the University of Chicago.

Gervais, W. M. (2015). Override the controversy: Analytic thinking predicts endorsement of evolution. Cognition, 142, 312-321. https://doi.org/10.1016/j.cognition.2015.05.011

Gervais, W. M., \& Norenzayan, A. (2012). Analytic thinking promotes religious disbelief. Science, 336(6080), 493-496. https://doi.org/10.1126/science.1215647

Gilinsky, A. S., \& Judd, B. B. (1994). Working memory and bias in reasoning across the life-span. Psychology of Aging, 9, 356-371.

Gilliland, A. R. (1929). A study of the superstitions of college students. Journal of Abnormal and Social Psychology, 24(4), 472-479.

Gilovich, T., Vallone, R., \& Tversky, A. (1985). The Hot Hand in Basketball: On the misperception of random sequences. Cognitive Psychology, 17, 295-314. 
Goodie, A. S., \& Fortune, E. E. (2005). The role of perceived control and overconfidence in pathological gambling. Journal of Gambling Studies, 21(4), 481-502.

Goodie, A. S., \& Fortune, E. E. (2013). Measuring cognitive distortions in pathological gambling: Review and meta-analyses. Psychology of Addictive Behaviors: Journal of the Society of Psychologists in Addictive Behaviors, 27(3), 730-743. https://doi.org/10.1037/a0031892

Gray, T. (1985). Changing unsubstantiated belief: Testing the ignorance hypothesis. Canadian Journal of Behavioural Science, 17(3), 263-270. https://doi.org/10.1037/h0080144

Guttentag, D. A., \& Havitz, M. E. (2010). Superstition as a personal moderator in the development of commitment and loyalty to and within casinos. Leisure, 34(1), 125.

Hall, H. (2014). Faith healing: Relgious freedom vs. child protection. Skeptical Inquirer, 38(4). Retrieved from http://www.csicop.org/si/show/faith_healing_religious_freedom_vs._child_protec tion

Hate Pseudoscience. (2016, July 12). Logical Fallacies vs Cognitive Biases. Retrieved from https://hatepseudoscience.com/2016/07/12/logical-fallacies-vs-cognitivebiases/

Hemphill, J. F. (2003). Interpreting the magnitudes of correlation coefficients. American Psychologist, 58(1), 78-79. https://doi.org/10.1037/0003-066X.58.1.78

Hogarth, R. M. (1987). Judgement and choice: The psychology of decision. John Wiley \& Sons.

Holtgraves, T., \& Skeel, J. (1992). Cognitive biases in playing the lottery: Estimating the odds and choosing the numbers. Journal of Applied Social Psychology, 22(12), 934-952. https://doi.org/10.1111/j.1559-1816.1992.tb00935.x

Holyoak, K. J. (1995). Problem Solving. In D. Osherson \& E. E. Smith (Eds.), Invitation to cognitive science (2nd ed., Vol. 3: Thinking, pp. 267-296). Cambridge, MA: MIT Press.

Iliceto, P., Fino, E., Cammarota, C., Giovani, E., Petrucci, F., Desimoni, M., ... Oei, T. P. (2015). Factor structure and psychometric properties of the Italian version of the Gambling Related Cognitions Scale (GRCS-I). Journal of Gambling Studies, 31(1), 225-242. https://doi.org/10.1007/s10899-013-9405-6

Irwin, H. (2001). Age and sex differences in paranormal beliefs after controlling for differential item functioning. European Journal of Parapsychology, 16, 102-106. 
Irwin, H. J. (1990). Parapsychology courses and students' belief in the paranormal. Journal of the Society for Psychical Research, 56(821), 265-271.

Irwin, H. J. (1993). Belief in the paranormal: A review of the empirical literature. Journal of the American Society for Psychical Research, 87(1), 1-39.

Jacobsen, L. H., Knudsen, A. K., Krogh, E., Pallesen, S., \& Molde, H. (2007). An overview of cognitive mechanisms in pathological gambling. Nordic Psychology, 59(4), 347-361. https://doi.org/10.1027/1901-2276.59.4.347

Jacobson, M. H. S. (2009). Legal analysis \& communication (2009 ed). Bloomington, IN: AuthorHouse.

Jefferson, S., Doiron, J., Nicki, R., \& MacLean, A. (2004). Further psychometric development of the Informational Biases Scale: an instrument designed to assess gambling cognitive distortions in video lottery terminal players. Gambling Research: Journal of the National Association for Gambling Studies (Australia), $16(2), 28$.

Jefferson, S., \& Nicki, R. (2003). A new instrument to measure cognitive distortions in video lottery terminal users: The Informational Biases Scale (IBS). Journal of Gambling Studies / Co-Sponsored by the National Council on Problem Gambling and Institute for the Study of Gambling and Commercial Gaming, 19(4), 387-403.

Jones, R. A. (1969). A factored measure of Ellis' irrational belief system with personality and maladjustment correlates. Dissertation Abstracts International, 29, 43794380 .

Jones, W. H., Russell, D. W., \& Nickel, T. W. (1977). Belief in the Paranormal Scale: An objective instrument to measure belief in magical phenomena and causes. American Psychological Association, Journal Supplement Abstract Service, Catalog of Selected Documents in Psychology, 7(100), MS 1577.

Jones, W. H., \& Zusne, L. (1981). Teaching anomalistic psychology. Teaching of Psychology, 8(2), 78-82. https://doi.org/10.1207/s15328023top0802_3

Joukhador, J., Blaszczynski, A., \& Maccallum, F. (2004). Superstitious beliefs in gambling among problem and non-problem gamblers: Preliminary data. Journal of Gambling Studies / Co-Sponsored by the National Council on Problem Gambling and Institute for the Study of Gambling and Commercial Gaming, 20(2), 171-180. https://doi.org/10.1023/B:JOGS.0000022308.27774.2b

Joukhador, J., Maccallum, F., \& Blaszczynski, A. (2003). Differences in cognitive distortions between problem and social gamblers. Psychological Reports, 92, 1203-1214. 
Kahneman, D. (2013). Thinking, fast and slow.

Kahneman, D., \& Tversky, A. (1972). Subjective probability: A judgment of representativeness. Cognitive Psychology, 3(3), 430-454. https://doi.org/10.1016/0010-0285(72)90016-3

Kahneman, D., \& Tversky, A. (1982). The psychology of preferences. Scientific American, 246(1), 160-173.

Kane, M. J., Core, T. J., \& Hunt, R. R. (2010). Bias versus bias: Harnessing hindsight to reveal paranormal belief change beyond demand characteristics. Psychonomic Bulletin \& Review, 17(2), 206-212. https://doi.org/10.3758/PBR.17.2.206

Keene, S. (2015, July 31). "Dietainment": Powerful ad exposes everything wrong with the diet industry in 31 seconds. Collective Evolution, Online. Retrieved from http://www.collective-evolution.com/2015/07/31/dietainment-powerful-adexposes-everything-wrong-with-the-diet-industry-in-31-seconds/

Koehler, J. J., \& Conley, C. (2003). The "Hot Hand" myth in professional basketball. Journal of Sport \& Exercise Psychology, 25, 253-259.

Kumpfer, K. L., Trunnell, E. P., \& Whiteside, H. O. (1990). Controversies in the Addiction Field. In R. C. Engs (Ed.), The biopsychosocial model: Application to the addictions field (pp. 55-67). Dubuque, Iowa: Kendal-Hunt.

Kyung Kim, E. (2016, April 19). Denied medical care because of religion, she now wants her parents prosecuted [.com]. Retrieved from http://www.today.com/health/denied-medical-care-because-religion-she-nowwants-her-parents-t87141

Ladouceur, R. (2004). Gambling: The hidden addiction. The Canadian Journal of Psychiatry, 49(8), 501-503.

Ladouceur, R., Mayrand, M., Dussault, R., Letarte, A., \& Tremblay, J. (1984). Illusion of control: Effects of participation and involvement. Journal of Psychology, 117, $47-52$.

Ladouceur, R., \& Sévigny, S. (2005). Structural characteristics of Video Lotteries: Effects of a stopping device on Illusion of Control and gambling persistence. Journal of Gambling Studies, 21(2), 117-131. https://doi.org/10.1007/s10899005-3028-5

Ladouceur, R., Sylvain, C., Boutin, C., \& Doucet, C. (2002). Understanding and treating pathological gamblers. London: Wiley. 
Ladouceur, R., Sylvain, C., Boutin, C., Lachance, S., Doucet, C., Leblond, J., \& Jacques, C. (2001). Cognitive treatment of pathological gambling. The Journal of Nervous and Mental Disease, 189(11), 774-780.

Ladouceur, R., Sylvain, C., Letarte, H., Giroux, I., \& Jacques, C. (1998). Cognitive treatment of pathological gamblers. Behaviour Research and Therapy, 36(12), 1111-1119. https://doi.org/10.1016/S0005-7967(98)00086-2

Lambos, C., \& Delfabbro, P. (2007). Numerical reasoning ability and irrational beliefs in problem gambling. International Gambling Studies, 7(2), 157-171. https://doi.org/10.1080/14459790701387428

Lange, R., Irwin, H. J., \& Houran, J. (2000). Top-down purification of Tobacyk's Revised Paranormal Belief Scale. Personality and Individual Differences, 29(1), 131-156. https://doi.org/10.1016/S0191-8869(99)00183-X

Lange, R., \& Thalbourne., M. (2002). Rasch scaling paranormal belief and experience structure and semantics of Thalbourne's Australian sheep-goat scale. Psychological Reports, 91, 1065-1073.

Langer, E. J. (1975). The illusion of control. Journal of Personality and Social Psychology, 32(2), 311-328. https://doi.org/10.1037/0022-3514.32.2.311

Lawrence, T. R., \& De Cicco, P. (1997). The factor structure of the paranormal belief scale: More evidence in support of the oblique five. Journal of Parapsychology, $61,243-251$.

Lawrence, T. R., Roe, C. A., \& Williams, C. (1997). Confirming the factor structure of the paranormal belief scale: Big orthogonal seven or oblique five? Journal of Parapsychology, 61, 13-31.

Ledgerwood, D. M., \& Petry, N. M. (2006). Psychological experience of gambling and subtypes of pathological gamblers. Psychiatry Research, 144(1), 17-27. https://doi.org/10.1016/j.psychres.2005.08.017

Leonard, C. A., Staples, J., \& Williams, R. J. (2015). Development and Validation of the Poker Skills Measure (PSM). Journal of Gambling Studies, 31(3), 849-866. https://doi.org/10.1007/s10899-014-9475-0

Leonard, C. A., \& Williams, R. J. (2016). The relationship between gambling fallacies and problem gambling. Psychology of Addictive Behaviors, 30(6), 694-704. https://doi.org/10.1037/adb0000189

Leonard, C. A., \& Williams, R. J. (2017). Characteristics of paranormal believers. Unpublished Manuscript. 
Leonard, C. A., Williams, R. J., \& Vokey, J. (2015). Gambling fallacies: What are they and how are they best measured? Journal of Addiction Research \& Therapy, 6(4). https://doi.org/10.4172/2155-6105.1000256

Lesieur, H. R., \& Blume, S. B. (1987). The South Oaks Gambling Screen (SOGS): A new instrument for the identification of pathological gamblers. The American Journal of Psychiatry, 144(9), 1184-1188.

Lindeman, M., \& Aarnio, K. (2007). Superstitious, magical, and paranormal beliefs: An integrative model. Journal of Research in Personality, 41(4), 731-744. https://doi.org/10.1016/j.jrp.2006.06.009

MacKay, T., \& Hodgins, D. C. (2012). Cognitive distortions as a problem gambling risk factor in Internet gambling. International Gambling Studies, 12(2), 163-175. https://doi.org/10.1080/14459795.2011.648652

Malouff, J. M., \& Schutte, N. S. (1986). Development and validation of a measure of irrational belief. Journal of Consulting and Clinical Psychology, 54(6), 860-862. https://doi.org/10.1037/0022-006X.54.6.860

Maltby, J., Day, L., Gill, P., Colley, A., \& Wood, A. M. (2008). Beliefs around luck: Confirming the empirical conceptualization of beliefs around luck and the development of the Darke and Freedman beliefs around luck scale. Personality and Individual Differences, 45, 655-660.

Manza, L., Hilperts, K., Hindley, L., Marco, C., Santana, A., \& Hawk, M. (2010). Exposure to science is not enough: The influence of classroom experiences on belief in paranormal phenomena. Teaching of Psychology, 37(3), 165-171. https://doi.org/10.1080/00986283.2010.488554

Markovits, H., Doyon, C., \& Simoneau, M. (2002). Individual differences in working memory and conditional reasoning with concrete and abstract content. Thinking \& Reasoning, 8(2), 97-107. https://doi.org/10.1080/13546780143000143

Marlatt, G. A., Baer, J. S., Donovan, D. M., \& Kivlahan, D. R. (1988). Addictive behaviours: Etiology and treatment. Annual Review of Psychology, 39, 223-252.

Marmurek, H. H. C., Switzer, J., \& D’Alvise, J. (2014). A comparison of university student and community gamblers: Motivations, impulsivity, and gambling cognitions. Journal of Behavioral Addictions, 3(1), 54-64. https://doi.org/10.1556/JBA.3.2014.007

Marmurek, H. H. C., Switzer, J., \& D’Alvise, J. (2015). Impulsivity, gambling cognitions, and the gambler's fallacy in university students. Journal of Gambling Studies, 31(1), 197-210. https://doi.org/10.1007/s10899-013-9421-6 
McBurney, D. (2002). How to think like a psychologist: critical thinking in psychology (2nd ed). Upper Saddle River, N.J: Prentice Hall.

McBurney, D. H. (1976). ESP in the Psychology Curriculum. Teaching of Psychology, $3(2), 66$.

McInnes, A., Hodgins, D. C., \& Holub, A. (2014). The Gambling Cognitions Inventory: Scale development and psychometric validation with problem and pathological gamblers. International Gambling Studies, 14(3), 410-431. https://doi.org/10.1080/14459795.2014.923483

McLean, C., \& Miller, N. (2010). Changes in critical thinking skills following a course on science and pseudoscience: A quasi-experimental study. Teaching of Psychology, 37(2), 85-90. https://doi.org/10.1080/00986281003626714

Merlan, A. (n.d.). Here's a fairly comprehensive list of anti-vaccination celebrities. Retrieved from http://jezebel.com/heres-a-fairly-comprehensive-list-of-antivaccination-c-1714760128

Messer, W. S., \& Griggs, R. A. (1989). Student belief and involvement in the paranormal and performance in introductory psychology. Teaching of Psychology, 16(4), 187-191. https://doi.org/10.1207/s15328023top1604_4

Miller, N. V., \& Currie, S. R. (2008). A Canadian population level analysis of the roles of irrational gambling cognitions and risky gambling practices as correlates of gambling intensity and pathological gambling. Journal of Gambling Studies / CoSponsored by the National Council on Problem Gambling and Institute for the Study of Gambling and Commercial Gaming, 24(3), 257-274. https://doi.org/10.1007/s10899-008-9089-5

Moodie, C. (2007). An exploratory investigation into the erroneous cognitions of pathological and social fruit machine gamblers. Journal of Gambling Issues, 19, 31-49.

Moodie, C. (2008). Student gambling, erroneous cognitions, and awareness of treatment in Scotland. Journal of Gambling Issues, 21, 30-56.

Moore, D. W. (2005, June 16). Three in four Americans believe in paranormal: Little change from similar results in 2001 [.com]. Retrieved from http://www.gallup.com/poll/16915/three-four-americans-believe-paranormal.aspx

Moore, S. M., \& Ohtsuka, K. (1999). Beliefs about control over gambling among young people, and their relation to problem gambling. Psychology of Addictive Behaviors, 13(4), 339-347. 
Morier, D., \& Keeports, D. (1994). Normal science and the paranormal: The effect of a scientific method course on students' beliefs. Research in Higher Education, 35(4), 443-453.

Musch, J., \& Ehrenberg, K. (2002). Probability misjudgment, cognitive ability, and belief in the paranormal. British Journal of Psychology, 93, 169-177.

Myrseth, H., Brunborg, G. S., \& Eidem, M. (2010). Differences in cognitive distortions between pathological and non-pathological gamblers with preferences for chance or skill games. Journal of Gambling Studies, 26(4), 561-569.

https://doi.org/10.1007/s10899-010-9180-6

National Center For Education Statistics. (1993). 120 Years of American Education: A Statistical Portrait. (T. D. Snyder, Ed.). U.S. Department of Education.

Neighbors, C., Lostutter, T. W., Cronce, J. M., \& Larimer, M. E. (2002). Exploring college student gambling motivation. Journal of Gambling Studies, 18(4), 361370 .

Nicholson, R., Graves, C., Ellery, M., \& Afifi, T. O. (2016). The temporal relationship between faulty gambling cognitions and gambling severity in young adults. Journal of Gambling Studies, 32(4), 1215-1229. https://doi.org/10.1007/s10899016-9605-y

Nisbett, R. E. (2015). Mindware: Tools for smart thinking (First edition). New York: Farrar, Straus and Giroux.

Nisbett, R. E., \& Ross, L. (1980). Human inference: Strategies and shortcomings of social judgment. Prentice-Hall.

Nixon, H. K. (1925). Popular answers to some psychological questions. American Journal of Psychology, 36, 418-423.

Norcross, J. C., Hailstorks, R., Aiken, L. S., Pfund, R. A., Stamm, K. E., \& Christidis, P. (2016). Undergraduate study in psychology: Curriculum and assessment. American Psychologist, 71(2), 89-101. https://doi.org/10.1037/a0040095

Novella, S. (2016, May 3). Pulling Back Canadian Censorship of Science [.com]. Retrieved May 3, 2016, from http://theness.com/neurologicablog/index.php/pulling-back-canadian-censorshipof-science/

Nower, L., \& Blaszczynski, A. (2010). Gambling motivations, money-limiting strategies, and precommitment preferences of problem versus non-problem gamblers. Journal of Gambling Studies, 26(3), 361-372. https://doi.org/10.1007/s10899009-9170-8 
Oei, T. P. S., Lin, J., \& Raylu, N. (2007). Validation of the Chinese version of the Gambling Related Cognitions Scale (GRCS-C). Journal of Gambling Studies, 23(3), 309-322. https://doi.org/10.1007/s10899-006-9040-6

Office of Public Affairs. (2016, June 6). Justice Department Permanently Shuts Down International "Psychic" Mail Fraud Scheme. Justice News. Retrieved from https://www.justice.gov/opa/pr/justice-department-permanently-shuts-downinternational-psychic-mail-fraud-scheme

O’Leary, U. M., Rusch, K. M., \& Guastello, S. J. (1991). Estimating age-stratified WAIS-R IQS from scores on the Raven's Standard Progressive Matrices. Journal of Clinical Psychology, 47(2), 277-284.

Oskarsson, A. T., Van Boven, L., McClelland, G. H., \& Hastie, R. (2009). What's next? Judging sequences of binary events. Psychological Bulletin, 135(2), 262-285. https://doi.org/10.1037/a0014821

Otis, L. P., \& Alcock, J. E. (1982). Factors affecting extraordinary belief. The Journal of Social Psychology, 118(1), 77-85. https://doi.org/10.1080/00224545.1982.9924420

Pacini, R., \& Epstein, S. (1999). The relation of rational and experiential information processing styles to personality, basic beliefs, and the ratio-bias phenomenon. Journal of Personality and Social Psychology, 76(6), 972-987. https://doi.org/10.1037/0022-3514.76.6.972

Papathanasiou, I., Kleisiaris, C., Fradelos, E., Kakou, K., \& Kourkouta, L. (2014). Critical Thinking: The Development of an Essential Skill for Nursing Students. Acta Informatica Medica, 22(4), 283-286. https://doi.org/10.5455/aim.2014.22.283-286

Pechey, R., \& Halligan, P. (2011). The prevalence of delusion-like beliefs relative to sociocultural beliefs in the general population. Psychopathology, 44(2), 106-115. https://doi.org/10.1159/000319788

Pelletier, M. F., \& Ladouceur, R. (2007). The effect of knowledge of mathematics on gambling behaviours and erroneous perceptions. International Journal of Psychology, 42(2), 134-140. https://doi.org/10.1080/00207590600788047

Pennycook, G., Cheyne, J. A., Seli, P., Koehler, D. J., \& Fugelsang, J. A. (2012). Analytic cognitive style predicts religious and paranormal belief. Cognition, 123(3), 335-346. https://doi.org/10.1016/j.cognition.2012.03.003

Pennycook, G., Cheyne, J., Koehler, D., \& Fugelsang, J. (2013). Belief bias during reasoning among religious believers and skeptics. Psychonomic Bulletin \& Review, 20(4), 806-811. https://doi.org/10.3758/s13423-013-0394-3 
Petry, N. M., Ginley, M. K., \& Rash, C. J. (2017). A systematic review of treatments for problem gambling. Psychology of Addictive Behaviors, 31(8), 951-961. https://doi.org/10.1037/adb0000290

Pinker, S. (1999). How the mind works. Annals of the New York Academy of Sciences, 882(1), 119-127. https://doi.org/10.1111/j.1749-6632.1999.tb08538.x

Pohl, R. (2004). Cognitive illusions: A handbook on fallacies and biases in thinking, judgement and memory. New York, NY: Psychology Press.

Prendergast, G. P., \& Thompson, E. R. (2008). Sale promotion strategies and belief in luck. Psychology \& Marketing, 25, 1043-1062.

Rattet, S., \& Bursik, K. (2000). Investigating the personality correlates of paranormal belief and precognitive experience. Personality and Individual Differences, 31, 433-444.

Raven, J., Raven, J. C., \& Court, H. H. (2000). Raven manual: Section 3. Standard Progressive Matrices. Oxford ; New York: Oxford Psychological Press Ltd.

Raylu, N., \& Oei, T. P. S. (2004). The Gambling Related Cognitions Scale (GRCS): development, confirmatory factor validation and psychometric properties. Addiction, 99(6), 757-769. https://doi.org/10.1111/j.1360-0443.2004.00753.x

Rogers, P. (1998). The cognitive psychology of lottery gambling: A theoretical review. Journal of Gambling Studies, 14(2), 111-134. https://doi.org/10.1023/A:1023042708217

Rogers, P., Davis, T., \& Fisk, J. (2009). Paranormal belief and susceptibility to the conjunction fallacy. Applied Cognitive Psychology, 23(4), 524-542. https://doi.org/10.1002/acp.1472

Rogers, P., Fisk, J. E., \& Wiltshire, D. (2011). Paranormal belief and the conjunction fallacy: Controlling for temporal relatedness and potential surprise differentials in component events. Applied Cognitive Psychology, 25(5), 692-702. https://doi.org/10.1002/acp.1732

Rogers, P., Qualter, P., \& Wood, D. (2016). The impact of event vividness, event severity, and prior paranormal belief on attributions towards a depicted remarkable coincidence experience: Two studies examining the misattribution hypothesis. British Journal of Psychology, 107(4), 710-751. https://doi.org/10.1111/bjop.12173

Romild, U., Volberg, R., \& Abbott, M. (2014). The Swedish Longitudinal Gambling Study (Swelogs): Design and methods of the epidemiological (EP-) track. 
International Journal of Methods in Psychiatric Research, 23(3), 372-386. https://doi.org/10.1002/mpr.1449

Salthouse, T. A. (1996). The processing-speed theory of adult age differences in cognition. Psychological Review, 103(3), 403-428. https://doi.org/10.1037/0033295X.103.3.403

Service, J., \& O'Neill, P. (2002). Productivity, culture and society: The essential contribution of psychology as a social science. Ottawa, ON: Scientific Affairs Committee of the Canadian Psychological Association. Retrieved from http://www.cpa.ca/cpasite/UserFiles/Documents/advocacy/Productivity_Culture_ Society.pdf

Shermer, M. (2002). Why people believe weird things: Pseudoscience, superstition, and other confusions of our time (Rev. and expanded). New York: A.W.H. Freeman/Owl Book.

Smith, C. L., Johnson, J. L., \& Hathaway, W. (2009). Personality contributes to belief in paranormal phenomena. Individual Differences Research, 7(2), 85-96.

Smith, D. P., Battersby, M. W., Pols, R. G., Harvey, P. W., Oakes, J. E., \& Baigent, M. F. (2015). Predictors of relapse in problem gambling: A prospective cohort study. Journal of Gambling Studies, 31(1), 299-313. https://doi.org/10.1007/s10899013-9408-3

Smith, J. C. (2010). Pseudoscience and extraordinary claims of the paranormal: A critical thinker's toolkit. Malden, MA: Wiley-Blackwell.

Smith, M. D., Foster, C. L., \& Stovin, G. (1998). Intelligence and paranormal belief: Examining the role of context. Journal of Parapsychology, 62, 65-77.

Sparks, G. G., Nelson, C. L., \& Campbell, R. G. (1997). The relationship between exposure to televised messages about paranormal phenomena and paranormal beliefs. Journal of Broadcasting \& Electronic Media, 41(3), 345-359. https://doi.org/10.1080/08838159709364412

Standing, L. G., \& Huber, H. (2003). Do psychology courses reduce belief in psychological myths. Social Behavior and Personality, 31(6), 585-592.

Stanovich, K. E., \& West, R. F. (1997). Reasoning independentyly of prior belief and individual differences in actively open-minded thinking. Journal of Educational Psychology, 89, 342-357.

Stanovich, K. E., \& West, R. F. (2000). Individual differences in reasoning: Implications for the rationality debate. Behavioral and Brain Sciences, 23(5), 645-665. 
Stark, E. (2012). Enhancing and assessing critical thinking in a psychological research methods course. Teaching of Psychology, 39(2), 107-112. https://doi.org/10.1177/0098628312437725

Steenbergh, T. A., Meyers, A. W., May, R. K., \& Whelan, J. P. (2002). Development and validation of the Gamblers' Beliefs Questionnaire. Psychology of Addictive Behaviors, 16(2), 143-149. https://doi.org/10.1037//0893-164X.16.2.143

Strong, D. R., Breen, R. B., \& Lejuez, C. W. (2004). Using item response theory to examine gambling attitudes and beliefs. Personality and Individual Differences, 36(7), 1515-1529. https://doi.org/10.1016/j.paid.2003.06.001

Svarrior, P. (2013). The Flat Earth Society [.org]. Retrieved from www.tfes.org

Svedholm, A. M., \& Lindeman, M. (2013). The separate roles of the reflective mind and involuntary inhibitory control in gatekeeping paranormal beliefs and the underlying intuitive confusions. British Journal of Psychology, 104(3), 303-319. https://doi.org/10.1111/j.2044-8295.2012.02118.x

Swami, V., Chamorro-Premuzic, T., \& Shafi, M. (2010). Psychology in outerspace: personality, individual difference, and demographic predictors of beliefs about extraterrestrial life. European Psychologist, 15(3), 220-228. https://doi.org/10.1027/1016-9040/a000023

Swords, M. D. (1990). Using the study of anomalies to enhance critical thinking in the classroom. Journal of Scientific Exploration, 4(2), 123-136.

Terrell, D. (1994). A test of the gambler's fallacy: Evidence from pari-mutuel games. Journal of Risk and Uncertainty, 8(3), 309-317.

Thalbourne, M. A. (1981). Extraversion and the sheep-goat variable: A conceptual replication. Journal of the American Society for Psychical Research, 75, 105-119.

Thalbourne, M. A., Dunbar, K. A., \& Delin, P. S. (1995). An investigation into correlates of belief in the paranormal. Journal of American Society for Psychical Research, $89,215-231$.

Thalbourne, M. A., \& Haraldsson, E. (1980). Personality characteristics of sheep and goats. Personality and Individual Differences, 1, 180-185.

The Parapsychological Association. (2017a). Harvey J. Irwin Profile. Retrieved from http://www.parapsych.org/users/hirwin/profile.aspx

The Parapsychological Association. (2017b). What is the Parapsychological Association? Retrieved from http://www.parapsych.org/articles/1/1/what_is_the_parapsychological.aspx 
Thompson, E. R., \& Prendergast, G. P. (2013). Belief in luck and luckiness: Conceptual clarification and new measure validation. Personality and Individual Differences, 54(4), 501-506.

Tobacyk, J. J. (1983). Reduction in paranormal belief among participants in a college course. Skeptical Inquirer, 8, 57-61.

Tobacyk, J. J. (2004). A revised Paranormal Belief Scale. The International Journal of Transpersonal Studies, 23, 94-98.

Tobacyk, J., \& Milford, G. (1983). Belief in paranormal phenomena: Assessment instrument development and implications for personality functioning. Journal of Personality and Social Psychology, 44(5), 1029-1037. https://doi.org/10.1037/0022-3514.44.5.1029

Tochkov, K. (2009). The effects of anticipated regret on risk preferences of social and problem gamblers. Judgment and Decision Making, 4(3), 227-234.

Toneatto, T. (1999). Cognitive psychopathology of problem gambling. Substance Use \& Misuse, 34(11), 1593-1604.

Toneatto, T. (2002). Cognitive therapy for problem gambling. Cognitive and Behavioral Practice, 9(3), 191-199. https://doi.org/10.1016/S1077-7229(02)80049-9

Toneatto, T., Blitz-Miller, T., Calderwood, K., Dragonetti, R., \& Tsanos, A. (1997). Cognitive distortions in heavy gambling. Journal of Gambling Studies, 13(3), 253-266.

Toplak, M. E., West, R. F., \& Stanovich, K. E. (2011). The Cognitive Reflection Test as a predictor of performance on heuristics-and-biases tasks. Memory \& Cognition, 39(7), 1275-1289. https://doi.org/10.3758/s13421-011-0104-1

Turner, N., Macdonald, J., Bartoshuk, M., \& Zangeneh, M. (2008). The evaluation of a 1$\mathrm{h}$ prevention program for problem gambling. International Journal of Mental Health and Addiction, 6(2), 238-243. https://doi.org/10.1007/s11469-007-9121-5

Tversky, A., \& Kahneman, D. (1971). Belief in the law of small numbers. Psychological Bulletin, 76(2), 105-110. https://doi.org/10.1037/h0031322

Tversky, A., \& Kahneman, D. (1973). Availability: A heuristic for juding frequency and probability. Cognitive Psychology, 5, 207-232.

Tversky, A., \& Kahneman, D. (1974). Judgment under uncertainty: Heuristics and biases. Science, 185(4157), 1124-1131. 
Tyson, P. J., Jones, D., \& Elcock, J. (2011). Psychology in Social Context: Issues and Debates. Oxford, UK: John Wiley \& Sons.

Volberg, R. A., \& Williams, R. J. (2013). Epidemiology: An international perspective. In D. C. S. Richard, A. Blaszczynski, \& L. Nower (Eds.), The Wiley-Blackwell handbook of disordered gambling (pp. 26-48). Retrieved from http://public.eblib.com/choice/publicfullrecord.aspx?p=1469185

Wagenaar, W. A. (1988). Paradoxes of gambling behaviour. London: Erlbaum.

Wagenaar, W. A., \& Keren, G. B. (1988). Chance and luck are not the same. Journal of Behavioral Decision Making, 1, 65-75.

Walker, M. B. (1992a). Irrational thinking among slot machine players. Journal of Gambling Studies, 8(3), 245-261.

Walker, M. B. (1992b). The psychology of gambling. Oxford, UK: Pergamon Press.

Wallace, J. (1993). Modern disease models of alcoholism and other chemical dependencies: The new biopsychosocial models. Drugs \& Society, 8(1), 69-87. https://doi.org/10.1300/J023v08n01_03

Wesp, R., \& Montgomery, K. (1998). Developing critical thinking through the study of paranormal phenomena. Teaching of Psychology, 25(4), 275-278.

West, R. F., \& Stanovich, K. E. (2003). Is probability matching smart? Associations between probabilistic choices and cognitive ability. Memory \& Cognition, 31(2), 243-251. https://doi.org/10.3758/BF03194383

West, R. F., Toplak, M. E., \& Stanovich, K. E. (2008). Heuristics and biases as measures of critical thinking: Associations with cognitive ability and thinking dispositions. Journal of Educational Psychology, 100(4), 930-941. https://doi.org/10.1037/a0012842

Williams, R., \& Connolly, D. (2006). Does learning about the mathamatics of gambling change gambling behavior. Psychology of Addictive Behaviors, 20(1), 62-68.

Williams, R. J. (2002). Prevention of problem gambling: A school-based intervention: Final report (Technical Report). Alberta Gaming Research Institute. Retrieved from http://www.uleth.ca/dspace/handle/10133/370

Williams, R. J. (2003). Reliability and validity of four scales to assess gambling attitudes, gambling knowledge, gambling fallacies and ability to calculate gambling odds. (Unpublished technical report). Lethbridge, Alberta: Available from author. 
Williams, R. J., Connolly, D., Wood, R. T., \& Nowatzki, N. (2006). Gambling and problem gambling in a sample of university students. Journal of Gambling Issues, 16. https://doi.org/10.4309/jgi.2006.16.19

Williams, R. J., Hann, R., Schopflocher, D., West, B., McLaughlin, P., White, N., ... Flexhaug, T. (2015). Quinte longitudinal study of gambling and problem gambling (Technical Report). Ontario Problem Gambling Research Centre. Retrieved from http://www.uleth.ca/dspace/handle/10133/3641

Williams, R. J., Lee, C., \& Back, K. J. (2013). The prevalence and nature of gambling and problem gambling in South Korea. Social Psychiatry and Psychiatric Epidemiology, 48(5), 821-834. https://doi.org/10.1007/s00127-012-0580-z

Williams, R. J., \& Volberg, R. A. (2010). Best practices in the populations assessment of problem gambling. (pp. 1-97). Ontario Problem Gambling Research Center.

Williams, R. J., \& Volberg, R. A. (2014). Classification accuracy of four problem gambling assessment instruments in population research. International Gambling Studies, (14), 15-28. https://doi.org/10.1080/14459795.2013.839731

Williams, R. J., Volberg, R. A., \& Stevens, R. (2012). The population prevalence of problem gambling: Methodological influences, standardized, rates, jurisdictional differences, and worldwide trends. Report Prepared for the Ontario Problem Gambling Research Centre and the Ontario Ministry of Health and Long Term Care.

Williams, R. J., West, B. L., \& Simpson, R. I. (2012). Prevention of Problem Gambling: A comprehensive review of the evidence, and identified best practices. Report Prepared for the Ontario Problem Gambling Research Centre and the Ontario Ministry of Health and Long Term Care.

Williams, R. J., Wood, R. T., \& Currie, S. R. (2010). Stacked Deck: An effective, schoolbased program for the prevention of problem gambling. The Journal of Primary Prevention, 31(3), 109-125. https://doi.org/10.1007/s10935-010-0212-x

Wilson, M. (2015, June 5). Man Who Gave Psychics \$718,000 “Just Got Sucked In." New York Times. Retrieved from http://www.nytimes.com/2015/11/16/nyregion/lured-in-by-two-manhattanpsychics-to-the-tune-of-718000.html?_r=0

Windholz, G., \& Diamant, L. (1974). Some personality traits of believers in extraordinary phenomena. Bulletin of the Psychonomic Society, 3(2), 125-126.

Windross, A. J. (2003). The luck of the draw: Superstition in gambling. Gambling Research, 15(1), 63. 
Wohl, M. J. A., \& Enzle, M. E. (2002). The Deployment of Personal Luck: Sympathetic Magic and Illusory Control in Games of Pure Chance. Personality and Social Psychology Bulletin, 28(10), 1388-1397. https://doi.org/10.1177/014616702236870

Wohl, M. J. A., \& Enzle, M. E. (2003). The effects of near wins and near losses on selfperceived personal luck and subsequent gambling behavior. Journal of Experimental Social Psychology, 39(2), 184-191. https://doi.org/10.1016/S00221031(02)00525-5

Wohl, M. J. A., Stewart, M. J., \& Young, M. M. (2011). Personal Luck Usage Scale (PLUS): psychometric validation of a measure of gambling-related belief in luck as a personal possession. International Gambling Studies, 11(1), 7-21. https://doi.org/10.1080/14459795.2010.541270

Wohl, M. J. A., Young, M. M., \& Hart, K. E. (2005). Untreated young gamblers with game-specific problems: Self-concept involving luck, gambling ecology and delay in seeking professional treatment. Addiction Research \& Theory, 13(5), 445-459. https://doi.org/10.1080/16066350500168444

Wohl, M. J. A., Young, M. M., \& Hart, K. E. (2007). Self-Perceptions of dispositional luck: Relationship to DSM gambling symptoms, subjective enjoyment of gambling and treatment readiness. Substance Use \& Misuse, 42(1), 43-63. https://doi.org/10.1080/10826080601094223

Wolfgang, A. K., Zenker, S. I., \& Viscusi, T. (1984). Control motivation and the illusion of control in betting on dice. Journal of Psychology, 116(1), 67-72.

Wood, R. T. A., \& Griffiths, M. D. (2007). A qualitative investigation of problem gambling as an escape-based coping strategy. Psychology and Psychotherapy: Theory, Research and Practice, 80(1), 107-125. https://doi.org/10.1348/147608306X107881

Wood, R. T., \& Williams, R. J. (2009). Internet gambling: Prevalence, patterns, problems, and policy options (Final Report prepared for the Ontario Problem Gambling Research Center) (pp. 1-152). Guelph, Ontario: Ontario Problem Gambling Research Center. Retrieved from http://hdl.handle.net/10133/693

Wood, W. S., \& Clapham, M. M. (2005). Development of the Drake Beliefs about Chance Inventory. Journal of Gambling Studies (Online), 21(4), 411-430. https://doi.org/http://0-dx.doi.org.darius.uleth.ca/10.1007/s10899-005-5556-4

Xian, H., Shah, K. R., Phillips, S. M., Scherrer, J. F., Volberg, R., \& Eisen, S. A. (2008). The association of cognitive distortions with problem and pathological gambling in adult male twins. Psychiatry Research, 160(3), 300-307. https://doi.org/10.1016/j.psychres.2007.08.007 
Yakovenko, I., Hodgins, D. C., el-Guebaly, N., Casey, D. M., Currie, S. R., Smith, G. J., ... Schopflocher, D. (2016). Cognitive distortions predict future gambling involvement. International Gambling Studies.

https://doi.org/10.1080/14459795.2016.1147592 
APPENDIX A: GAMBLING FALLACIES MEASURE (WILLIAMS, 2003)

1) Which of the following set of Lottery numbers has the greatest probability of being selected as the winning combination?
a. $1,2,3,4,5,6$
b. $8,18,3,55,32,28$
c. each of the above have an equal probability of being selected

2) Which gives you the best chance of winning the jackpot on a slot machine?

a. Playing a slot machine that has not had a jackpot in over a month.

b. Playing a slot machine that had a jackpot an hour ago.

c. Your chances of winning the jackpot are the same on both machines.

3) How lucky are you? If 10 people's names were put into a hat and one name drawn for a prize, how likely is it that your name would be chosen?
a. About the same likelihood as everyone else
b. Less likely than other people
c. More likely than other people

4) If you were to buy a lottery ticket, which would be the best place to buy it from?
a. a place that has sold many previous winning tickets
b. a place that has sold few previous winning tickets
c. one place is as good as another

5) A positive attitude or doing good deeds increases your likelihood of winning money when gambling.
a. Disagree
b. Agree

6) A gambler goes to the casino and wins $75 \%$ of the time. How many times has he or she likely gone to the casino?
a. 4 times
b. 100 times
c. It is just as likely that he has gone either 4 or 100 times

7) You go to a casino with $\$ 100$ hoping to double your money. Which strategy gives you the best chance of doing this?
a. Betting all your money on a single bet
b. Betting small amounts of money on several different bets
c. Either strategy gives you an equal chance of doubling your money.

8) Which game can you consistently win money at if you use the right strategy?
a. Slot machines
b. Roulette
c. Bingo (Baccarat for Asian populations)
d. None of the above

9) Your chances of winning a lottery are better if you are able to choose your own numbers.
a. disagree
b. agree

10) You have flipped a coin and correctly guessed 'heads' 5 times in a row. What are the odds that heads will come up on the next flip. Would you say...
a. $\mathbf{5 0 \%}$
b. more than $50 \%$
c. or less than $50 \%$ 


\section{APPENDIX B: PROBLEM AND PATHOLOGICAL GAMBLING MEASURE}

(PPGM)

1a. Has your involvement in gambling caused you either to borrow a significant ${ }^{20}$ amount of money or sell some of your possessions in the past 12 months? (Yes/No).

1b. Has your involvement in gambling caused significant financial concerns for you or someone close to you in the past 12 months? (Yes/No). (Note: do not score 1 for $1 \mathrm{~b}$ if 1 has already been scored for $1 \mathrm{a})$.

2. Has your involvement in gambling caused significant mental stress in the form of guilt, anxiety, or depression for you or someone close to you in the past 12 months? (Yes/No).

3a. Has your involvement in gambling caused serious problems ${ }^{21}$ in your relationship with your spouse/partner, or important friends or family in the past 12 months? (Note: Family is whomever the person themselves defines as "family")(Yes/No).

3b. Has your involvement in gambling caused you to repeatedly neglect your children or family in the past 12 months? (Yes/No). (Note: do not score 1 for $3 \mathrm{~b}$ if 1 has already been scored for 3a).

4. Has your involvement in gambling resulted in significant health problems or injury for you or someone close to you in the past 12 months? (Yes/No).

5a. Has your involvement in gambling caused significant work or school problems for you or someone close to you in the past 12 months? (Yes/No).

$5 \mathrm{~b}$. Has your involvement in gambling caused you to miss a significant amount of time off work or school in the past 12 months? (Yes/No). (Note: do not score 1 for $5 b$ if 1 has already been scored for $5 \mathrm{a}$ ).

6. Has your involvement in gambling caused you or someone close to you to write bad cheques, take money that didn't belong to you or commit other illegal acts to support your gambling in the past 12 months? (Yes/No).

7. Is there anyone else who would say that your involvement in gambling in the past 12 months has caused any significant problems regardless of whether you agree with them or not? (Yes/No).

\footnotetext{
${ }^{20}$ If people ask what 'significant'means, say 'significant means something that either you or someone else would say is considerable, important, or major', either because of its frequency or seriousness.

${ }^{21}$ If people ask what 'problem'means say 'a difficulty that needs to be fixed'.
} 
8. In the past 12 months, have you often gambled longer, with more money or more frequently than you intended to? (Yes/No).

9. In the past 12 months, have you often gone back to try and win back the money you lost? (Yes/No).

10a. In the past 12 months, have you made any attempts to either cut down, control or stop your gambling? (Yes/No). (go to 11 if 'no') (this item not scored)

10b. Were you successful in these attempts? (Yes/No). (score' 1 ' for no and ' 0 ' for yes)

11. In the past 12 months, is there anyone else who would say that you have had difficulty controlling your gambling, regardless of whether you agreed with them or not? (Yes/No).

\section{IMPAIRED CONTROL SCORE}

12. In the past 12 months, would you say you have been preoccupied with gambling? (Yes/No).

13. In the past 12 months, when you were not gambling did you often experience irritability, restlessness or strong cravings for it? (Yes/No).

14. In the past 12 months, did you find you needed to gamble with larger and larger amounts of money to achieve the same level of excitement? (Yes/No).

15. (Optional question; not included in scoring): In the past 12 months, have you often lied to people about your gambling or often concealed the extent of your gambling from other people? (Yes/No).

16. (Optional question; not included in scoring): In the past 12 months, have you often gambled to escape bad moods or other troubles? (Yes/No).

17. (Optional question; not included in scoring): Do you believe you had have a problem with gambling in the past 12 months? (Yes/No). 


\section{PPGM Scoring and Classification}

Pathological Gambler (4)

1. Problems Score of 1 or higher, plus

2. Impaired Control Score of 1 or higher, plus

3. Total Score of 5 or higher, plus

4. Reported gambling frequency of at least once a month on some form of gambling.

\section{Problem Gambler (3)}

1. Problems Score of 1 or higher, plus

2. Impaired Control Score of 1 or higher, plus

3. Total Score of 2 to 4 , plus

4. Reported gambling frequency of at least once a month on some form of OR gambling.

1. Total Score of 3 or higher, plus

2. Frequency of gambling ${ }^{22}$ AND average reported gambling $\operatorname{loss}^{23} \geq$ median for unambiguously identified Problem and Pathological Gamblers in the population (i.e., as established by the most recent population prevalence survey).

At Risk Gambler (2) (this category also includes people who may be problem gamblers in denial)

1. Does not meet criteria for Problem or Pathological gambling, plus

2. Total Score of 1 or higher

3. Reported gambling frequency of at least once a month on some form of gambling.

\section{OR}

1. Frequency of gambling ${ }^{9}$ AND average reported gambling loss ${ }^{10} \geq$ median for unambiguously identified Problem and Pathological Gamblers in the population (i.e., as established by the most recent population prevalence survey).

Recreational Gambler (1)

- Gambler who does not meet criteria for Pathological, Problem or At-Risk gambler.

${ }^{22}$ Highest frequency of gambling reported for any individual form in the past year.

${ }^{23}$ Note also that the scorer may chose not to apply the gambling loss criteria so as to designate someone as an 'At Risk Gambler' or 'Problem Gambler' in situations where the person's income and/or net worth is very high relative to the general population. 
Non-Gambler (0)

- No reported gambling on any form in past year 